OPEN ACCESS

Edited by:

Wee-Jun Ong

Xiamen University, Malaysia

Reviewed by:

Herma Dina Setiabudi,

Universiti Malaysia Pahang, Malaysia

Shanhui Zhu,

Institute of Coal Chemistry (CAS),

China

Guangbo Chen, Dresden University of

Technology, Germany

*Correspondence:

Leilei Xu

leileixu88@gmail.com

Mindong Chen

chenmdnuist@163.com

Xun $\mathrm{Hu}$

xun.hu@outlook.com

${ }^{\dagger}$ These authors have contributed equally to this work

Specialty section: This article was submitted to Catalysis and Photocatalysis,

a section of the journal

Frontiers in Chemistry

Received: 30 December 2019 Accepted: 19 March 2020

Published: 28 April 2020

Citation:

Lv C, Xu L, Chen M, Cui Y, Wen X, Li Y, Wu C-e, Yang B, Miao Z, Hu X and Shou Q (2020) Recent Progresses in Constructing the Highly Efficient Ni Based Catalysts With Advanced Low-Temperature Activity Toward $\mathrm{CO}_{2}$ Methanation. Front. Chem. 8:269. doi: 10.3389/fchem.2020.00269

\title{
Recent Progresses in Constructing the Highly Efficient Ni Based Catalysts With Advanced Low-Temperature Activity Toward $\mathrm{CO}_{2}$ Methanation
}

\begin{abstract}
Chufei $\mathrm{Lv}^{1 \dagger}$, Leilei Xu ${ }^{1 * \dagger}$, Mindong Chen ${ }^{1 *}$, Yan Cui ${ }^{1}$, Xueying Wen ${ }^{1}$, Yaping $\mathrm{Li}^{1}$, Cai-e $\mathrm{Wu}^{2}$, Bo Yang ${ }^{1}$, Zhichao Miao ${ }^{3}$, Xun $\mathrm{Hu}^{4 *}$ and Qinghui Shou ${ }^{5}$

${ }^{1}$ Jiangsu Key Laboratory of Atmospheric Environment Monitoring and Pollution Control, Collaborative Innovation Center of the Atmospheric Environment and Equipment Technology, School of Environmental Science and Engineering, Nanjing University of Information Science \& Technology, Nanjing, China, ${ }^{2}$ College of Light Industry and Food Engineering, Nanjing Forestry University, Nanjing, China, ${ }^{3}$ School of Chemistry and Chemical Engineering, Shandong University of Technology, Zibo, China, ${ }^{4}$ School of Material Science and Engineering, University of Jinan, Jinan, China, ${ }^{5}$ CAS Key Laboratory of Bio-Based Materials, Qingdao Institute of Bioenergy and Bioprocess Technology (QIBEBT), Chinese Academy of Sciences (CAS), Qingdao, China
\end{abstract}

With the development and prosperity of the global economy, the emission of carbon dioxide $\left(\mathrm{CO}_{2}\right)$ has become an increasing concern. Its greenhouse effect will cause serious environmental problems, such as the global warming and climate change. Therefore, the worldwide scientists have devoted great efforts to control $\mathrm{CO}_{2}$ emissions through various strategies, such as capture, resource utilization, sequestration, etc. Among these, the catalytic conversion of $\mathrm{CO}_{2}$ to methane is considered as one of the most efficient routes for resource utilization of $\mathrm{CO}_{2}$ owing to the mild reaction conditions and simple reaction device. Pioneer thermodynamic studies have revealed that low reaction temperature is beneficial to the high catalytic activity and $\mathrm{CH}_{4}$ selectivity. However, the low temperature will be adverse to the enhancement of the reaction rate due to kinetic barrier for the activation of $\mathrm{CO}_{2}$. Therefore, the invention of highly efficient catalysts with promising low temperature activities toward $\mathrm{CO}_{2}$ methanation reaction is the key solution. The $\mathrm{Ni}$ based catalysts have been widely investigated as the catalysts toward $\mathrm{CO}_{2}$ methanation due to their low cost and excellent catalytic performances. However, the $\mathrm{Ni}$ based catalysts usually perform poor low-temperature activities and stabilities. Therefore, the development of highly efficient Ni based catalysts with excellent low-temperature catalytic performances has become the research focus as well as challenge in this field. Therefore, we summarized the recent research progresses of constructing highly efficient Ni based catalysts toward $\mathrm{CO}_{2}$ methanation in this review. Specifically, the strategies on how to enhance the catalytic performances of the $\mathrm{Ni}$ based catalysts have been carefully reviewed, which include various influencing factors, such as catalytic supports, catalytic 
auxiliaries and dopants, the fabrication methods, reaction conditions, etc. Finally, the future development trend of the $\mathrm{Ni}$ based catalysts is also prospected, which will be helpful to the design and fabrication of the Ni catalysts with high efficiency toward $\mathrm{CO}_{2}$ methanation process.

Keywords: carbon dioxide, methanation, $\mathrm{Ni}$-based catalyst, low-temperature catalytic activity, recent progresses

\section{INTRODUCTION}

In the context of the rapid development of global economy, the energy crisis, and environmental pollution has been becoming more and more serious. The consumption of a large number of fossil fuels has led to a sharp rise in $\mathrm{CO}_{2}$ emissions. In 2017, the total $\mathrm{CO}_{2}$ emissions reached 41 billion tons, attracting the increasing worldwide attention. Therefore, how to control and reduce the amount of $\mathrm{CO}_{2}$ in the atmosphere has become an urgent issue (Gac et al., 2018; Zhang G. et al., 2018; Li W. et al., 2019). The strategies for $\mathrm{CO}_{2}$ emission reduction mainly cover capture-storage as well as capture-conversion. However, gas leakage is a crucial problem with capture and storage technologies, and it is also difficult to choose suitable storage sites. Chemical conversion is considered as the most convenient and effective method (Bian et al., 2018). In 1902, Sabatier proposed the process of methanation of $\mathrm{CO}_{2}$ (Zhang G. et al., 2018). The process is a reaction which could convert the sustainable hydrogen energy from solar energy and biomass into methane with high $\mathrm{CO}_{2}$ conversion rate and high $\mathrm{CH}_{4}$ selectivity. The results of thermodynamic calculation show that higher pressure and lower temperature are more suitable for methanation process (Su et al., 2016; Champon et al., 2019). Compared to reactions with $\mathrm{C}_{2}$ hydrocarbons as the products, $\mathrm{CO}_{2}$ methanation has relatively lower requirements on reaction temperature and pressure and has much broader application prospects, such as replacing natural gas production with syngas. The $\mathrm{CO}_{2}$ methanation reaction achieves the goal of reducing environmental pollution by converting $\mathrm{CO}_{2}$ into value-added $\mathrm{CH}_{4}$, which is also a kind of clean energy with high calorific value and can alleviate the problem of energy shortage. Therefore, the $\mathrm{CO}_{2}$ methanation process can be considered as the one of the most effective routes toward $\mathrm{CO}_{2}$ emission control at present (Solis-Garcia et al., 2017; Gnanakumar et al., 2019).

As regarding the $\mathrm{CO}_{2}$ methanation reaction, the most concerning factors are the reaction rate and chemical equilibrium. From the perspective of thermodynamics, the $\mathrm{CO}_{2}$ methanation reaction will generate a large amount of heat release $(-165 \mathrm{~kJ} / \mathrm{mol})$ due to the exothermic feature of this process. Therefore, when the reaction temperature is higher than $627^{\circ} \mathrm{C}$, it is supposed to obtain lower $\mathrm{CO}_{2}$ conversion and $\mathrm{CH}_{4}$ selectivity. However, the change in Gibbs free energy will be $>0$ according to thermodynamic calculation and the reverse reaction will take place, namely, $\mathrm{CH}_{4}$ reacts with $\mathrm{H}_{2} \mathrm{O}$ to form $\mathrm{CO}_{2}$ (Hu et al., 2019). From the perspective of dynamics, $\mathrm{CO}_{2}$ methanation is an eight-electron involved process with obvious kinetic barrier. This process demands high temperature to overcome the kinetic barrier to reduce the stable $\mathrm{CO}_{2}(+4)$ with strong $\mathrm{C}=\mathrm{O}$ bond into $\mathrm{CH}_{4}(-4)$. Low temperature will reduce the reaction rate based on the dynamic theory (Alarcón et al., 2019). In order to obtain high theoretical $\mathrm{CO}_{2}$ conversion and $\mathrm{CH}_{4}$ selectivity, the whole reaction process is desirable to carry out at low temperature (Jiang et al., 2019; Ou et al., 2019). Therefore, it is of great necessity to employ highly efficient catalyst to achieve advanced low-temperature catalytic activity.

As well-known, the catalyst are mainly composed of active center, catalytic support, and catalytic dopant, among which the active center is considered as the key component of the catalyst. It was reported that most of the VIII group metals, such as $\mathrm{Ru}$, $\mathrm{Rh}, \mathrm{Pd}, \mathrm{Ni}, \mathrm{Co}$, and Fe, could act as the active centers toward $\mathrm{CO}_{2}$ methanation process. Among these metals, $\mathrm{Pd}, \mathrm{Rh}$, and $\mathrm{Ru}$ are all precious metals. Compared with other non-precious metal catalysts, the precious metal based catalysts have better lowtemperature catalytic activities, and higher methane selectivity. However, they are not suitable for large-scale promotion and application due to the limitations of high price and rare resources (Panagiotopoulou, 2017; Chai et al., 2019). Although Co-based catalysts have excellent low-temperature activity and stability, yet they usually have low methane selectivity (Li et al., 2018a; Liu H. et al., 2018). As for the Fe-based catalysts, they may tend to accumulate carbon over the catalyst surface, easily form liquid hydrocarbons, and are not suitable for low reaction temperatures (Kirchner et al., 2018). Consequently, Ni-based catalysts are widely investigated as the catalysts toward $\mathrm{CO}_{2}$ methanation due to their excellent catalytic performances and low price, though their low-temperature activities and anti-sintering properties are not excellent enough. Therefore, the development of $\mathrm{Ni}$ based catalysts with outstanding low-temperature activity and endurable stability has been considered as an important Research Topic in this field. For the Ni-based catalysts, their catalytic activities are not as high as those of noble metal catalysts. Besides, the heat release and low reaction temperature will also lead to the formation of carbonyl nickel, and then $\mathrm{Ni}$ sintering and deactivation will occur (Veselovskaya et al., 2018). In order to address these drawbacks, the researchers have devoted great efforts to study the influence of different supports and auxiliaries on Ni-based catalysts. Bacariza et al. (2018a) reported that SBA-15 and MCM-41 could prevent the sintering process due to their large pore sizes and interesting textural properties. Valinejad Moghaddam et al. (2018) found that all the investigated additives except $\mathrm{Cu}$ could promote the $\mathrm{CO}_{2}$ conversion of the catalysts modified by Fe, $\mathrm{Co}, \mathrm{Zr}, \mathrm{La}$, and $\mathrm{Cu}$. $\mathrm{Ni}-\mathrm{Fe} / \mathrm{Al}_{2} \mathrm{O}_{3}$ catalyst showed the best catalytic performance because the addition of Fe changed the physical properties of the catalyst and increased the number of surface exposed active centers. In addition, some researchers have devoted themselves to exploring the effect of 


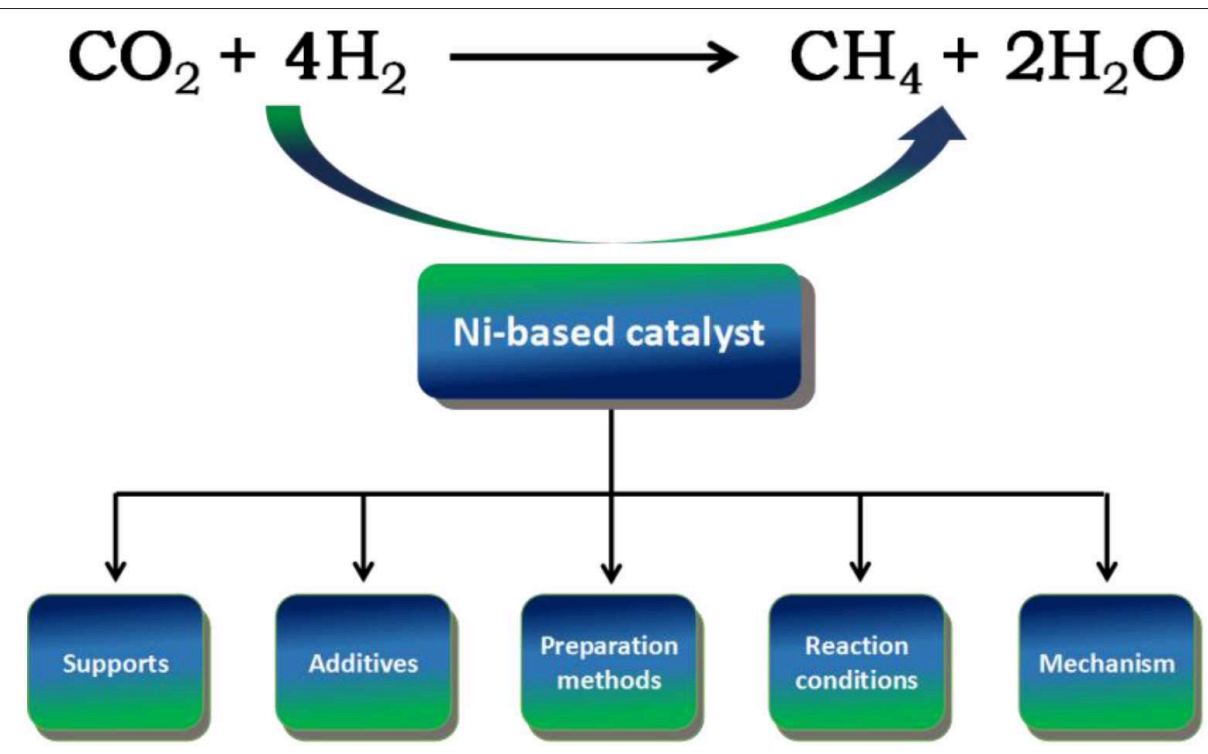

FIGURE 1 | The main outline of this review.

preparation conditions on Ni-based catalysts. It was reported that the calcination temperature could affect the structure and activity of the catalyst (Haynes et al., 2019). In general, the catalytic activity of Ni-based catalysts can be improved by tuning various influencing factors of the catalyst.

In recent years, many scholars have summarized the development of catalysts from different aspects. For example, Stangeland et al. (2017a) studied the $\mathrm{CO}_{2}$ methanation from the perspective of the reaction conditions of catalysts. Aziz and Jalil (2015) discussed recent developments in heterogeneous catalysts with emphases on their physicochemical properties, catalytic activities, and reaction mechanism. Ni-based catalysts are commonly used in $\mathrm{CO}_{2}$ methanation due to its low cost and high activity. However, the review on this topic is somewhat incomplete and the perspective of the relevant literature summary of recent research progress is not sufficient. Therefore, it is of great significance to summarize the recent development of $\mathrm{Ni}$-based catalysts with excellent low-temperature activity. The main outline of this review is displayed in Figure 1. Specifically, the subject of this review is focused on the influencing parameters of the catalyst design on the low-temperature catalytic performance of Ni-based catalysts. Furthermore, the reaction mechanism of $\mathrm{CO}_{2}$ methanation over different Ni-based catalysts is also summarized. Finally, the future development trend of Ni-based catalysts is also prospected in this review.

\section{TYPES OF NI-BASED CATALYSTS}

Structural property, nickel dispersion, and strong metal-support interaction are important index factors of Ni-based catalysts, which affect the low-temperature catalytic activity and sinteringresistant performance of Ni-based catalysts. Therefore, it is important to design and develop novel catalysts with suitable porosity, high nickel dispersion, and strong metal-support interaction (Gac et al., 2018). High nickel dispersion is usually achieved by employing microporous or mesoporous supports with excellent structural property and doping various modifiers, such as Co, Zr, Sm, etc. (Li et al., 2020). Besides, the support can also inhibit or even avoid the serious sintering of metal nanoparticles by enhancing the strong metal-support interaction and affect the activity of $\mathrm{CO}_{2}$ methanation by promoting the dissociation and adsorption of $\mathrm{CO}_{2}$ (Ye et al., 2019). The catalytic performances of the representative catalysts are summarized in Table 1 based on overall discussion of Ni-based catalysts.

\section{Ni-Based Catalysts With Different Supports}

As the skeleton of catalyst, the supports with large specific surface areas and large pore volumes can accommodate the $\mathrm{Ni}$ active centers in highly dispersed state (Bacariza et al., 2018a). The promotion of the redox property of electron transfer between the support and the metal active center will promise the increase of electron density in the metal. These electrons can enhance the coupling between nickel and carbon, thereby facilitating the $\mathrm{C}=\mathrm{O}$ bond-breaking and the formation of $\mathrm{CH}_{4}$ (Liu W. et al., 2018). Besides, the physicochemical properties of different supports will affect the crystal size and surface properties of $\mathrm{Ni}$ as well as the reducibility and catalytic properties of catalysts. The hierarchical pore structure of the support could also promote the mass transfer of the feed stock on the catalyst surface (Pizzolitto et al., 2019). Meanwhile, the dispersion of the Ni species over the catalyst surface is also greatly affected by the structure of the support (Bian and Kawi, 2017). Furthermore, the chemisorption and activation of the $\mathrm{CO}_{2}$ over the support with strong alkalinity could be intensified and the activated $\mathrm{CO}_{2}$ will react quickly due to low kinetic barrier, which in turn makes the catalyst equipped with anti-coke deposition performance. Therefore, the catalytic 
TABLE 1 | The summaries of the structural properties and catalytic performances of the $\mathrm{Ni}$-based catalysts toward $\mathrm{CO}_{2}$ methanation.

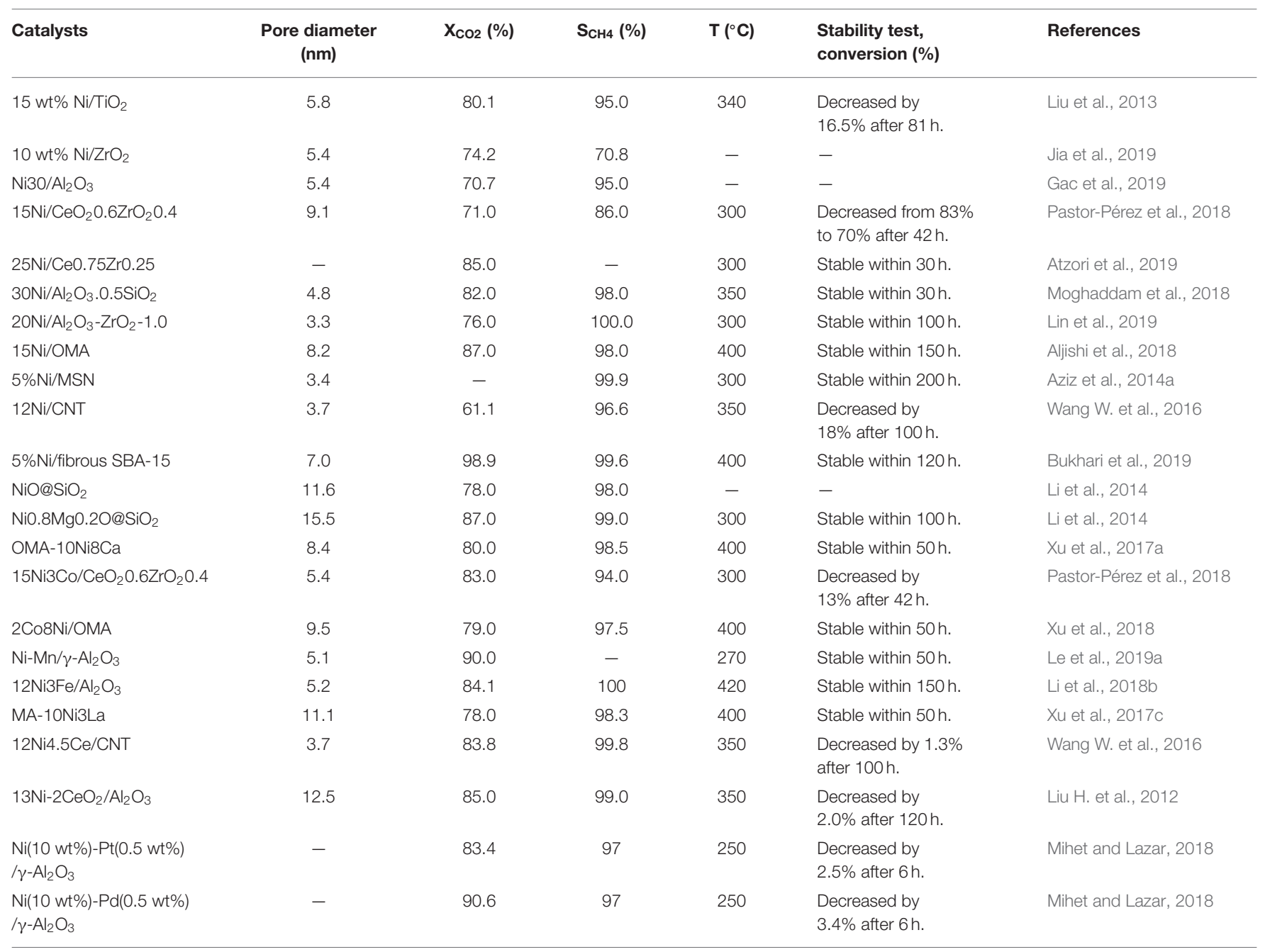

support is closely related to the catalytic performance of the catalyst (Rönsch et al., 2016).

\section{Single Type Catalytic Support}

The single type catalytic supports with different morphologies are usually used as the supports for $\mathrm{Ni}$ based catalysts toward $\mathrm{CO}_{2}$ methanation, such as $\mathrm{Al}_{2} \mathrm{O}_{3}, \mathrm{TiO}_{2}, \mathrm{SiO}_{2}, \mathrm{ZrO}_{2}$, etc. (Ferreira and Branco, 2019). For example, $\mathrm{TiO}_{2}$, well-known as an $\mathrm{N}$ type semiconductor with good thermal stability, can easily form the strong metal-support interaction with the active component $\mathrm{Ni}$, so that $\mathrm{CO}_{2}$ can easily adsorb on the catalyst surface (Liu et al., 2013; Zhou R. et al., 2016). It was reported that the $\mathrm{CO}_{2}$ conversion over $\mathrm{Ni} / \mathrm{TiO}_{2}$ catalyst was $96 \%$ at the low temperature $\left(260^{\circ} \mathrm{C}\right.$ ) (Liu et al., 2013). $\mathrm{ZrO}_{2}$ is an amphoteric compound with good stability, abundant oxygen vacancies, and it can remain active under high temperature conditions (Jia et al., 2019; Tan et al., 2019). Besides, $\mathrm{ZrO}_{2}$ usually has three types of monoclinic $\left(\mathrm{m}-\mathrm{ZrO}_{2}\right)$, tetragonal $\left(\mathrm{t}-\mathrm{ZrO}_{2}\right)$, and cubic structure (Guilera et al., 2019). In terms of reaction mechanism, the catalytic activity of the catalyst is mainly related to the relative content of $\mathrm{m}$ $\mathrm{ZrO}_{2}$ because $\mathrm{m}-\mathrm{ZrO}_{2}$ usually has more oxygen vacancies, which are beneficial to the adsorption of oxygen-containing substances (Zhao et al., 2016a; Zhang X. et al., 2019). According to the report by Romero-Sáez et al. (2018), $\mathrm{ZrO}_{2}$ could not activate and decompose $\mathrm{H}_{2}$, but also could activate $\mathrm{CO}_{2}$ molecules to generate $\mathrm{CO}$. Therefore, $\mathrm{H}_{2}$ molecule was dissociated on the surface of $\mathrm{Ni}$ and the $\mathrm{CO}_{2}$ molecule was activated on the surface of $\mathrm{ZrO}_{2}$ (Ocampo et al., 2011). Therefore, the interaction between hydrogen atoms and activated $\mathrm{CO}_{2}$ molecules could be promoted, and the selectivity of $\mathrm{CH}_{4}$ and reaction rate could be improved by increasing the range of the $\mathrm{Ni}-\mathrm{ZrO}_{2}$ interface (Garbarino et al., 2019). $\mathrm{CeO}_{2}$ has good stability, strong $\mathrm{CO}_{2}$ adsorption performance and outstanding oxygen storage capacity, which promise the high low-temperature activity over its supported Ni based catalysts (Tada et al., 2012; Löfberg et al., 2017; Ratchahat et al., 2018; Yan et al., 2019). Specifically, the redox cycle between $\mathrm{Ce}^{3+} / \mathrm{Ce}^{4+}$ ion pairs on the surface of $\mathrm{CeO}_{2}$ can form the oxygen vacancy, which can promote the adsorption and activation of $\mathrm{CO}_{2}$ to generate $\mathrm{CO}$ during the reaction (Tada 


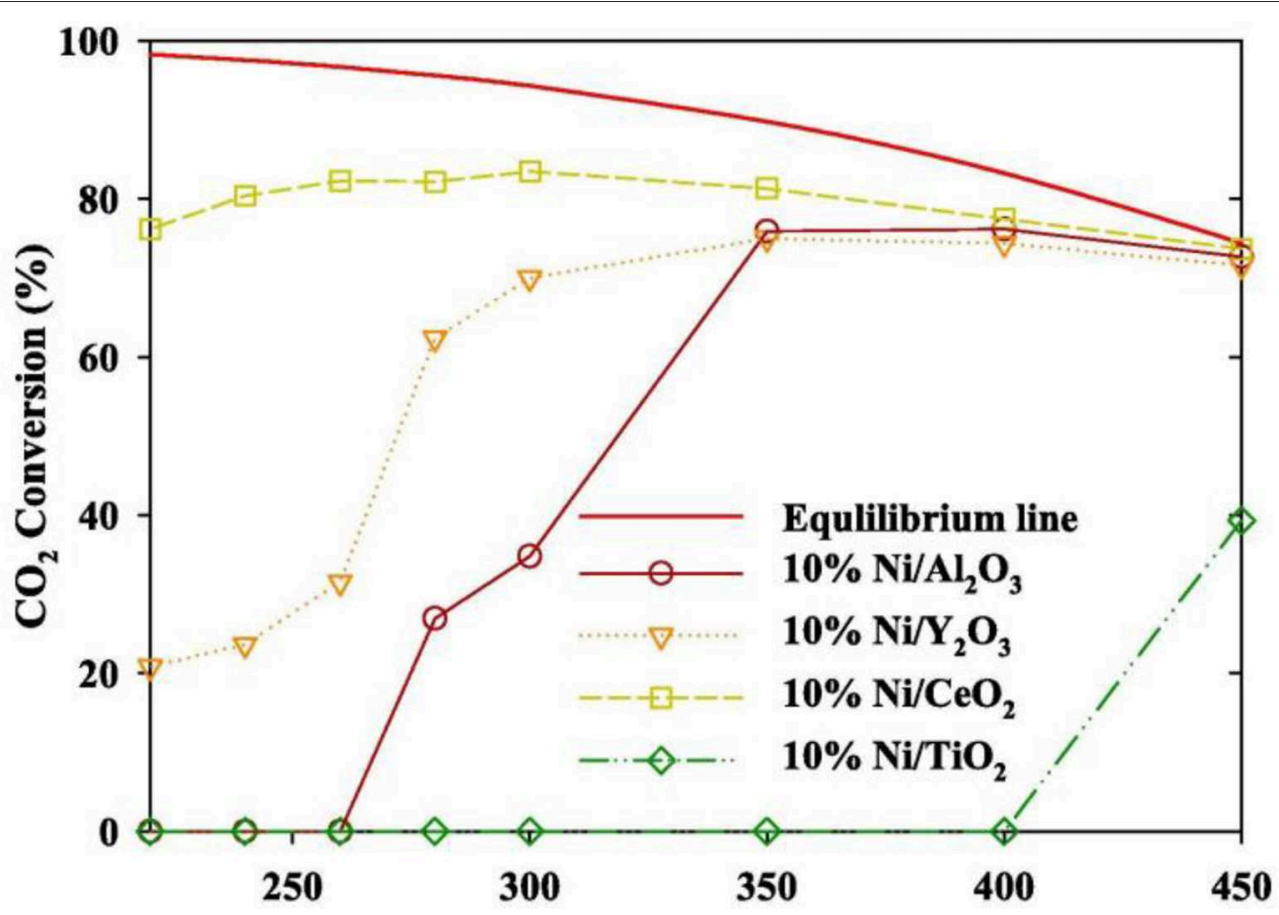

FIGURE 2 | Evaluation of the $\mathrm{CO}_{2}$ methanation of a Ni catalyst containing different supports (inlet gas $\mathrm{CO}_{2}: \mathrm{N}_{2}: \mathrm{H}_{2}=1: 1: 4, \mathrm{SV} 14,400 \mathrm{~h}^{-1}$, catalyst loading $0.5 \mathrm{~g}$ ). Reproduced from Ahn et al. (2019) with permission from Elsevier and Copyright Clearance Center.

et al., 2012; Löfberg et al., 2017; Ratchahat et al., 2018; Yan et al., 2019). $\mathrm{Al}_{2} \mathrm{O}_{3}$ is a porous support with low cost and large specific surface area, promising the homogenous dispersion of $\mathrm{Ni}$ over the catalyst surface (Akbari et al., 2018; Ray et al., 2018). Besides, $\mathrm{Al}_{2} \mathrm{O}_{3}$ and $\mathrm{Ni}$ could form the $\mathrm{NiAl}_{2} \mathrm{O}_{4}$ structure with strong $\mathrm{Ni}-\mathrm{O}$ chemical bond that hinders the reduction of $\mathrm{Ni}^{2+}$. Thus, the metallic Ni particles over the catalyst surface are small in crystalline size, which can inhibit the carbon deposition (Ahn et al., 2019).

In order to realize the high-efficient conversion of $\mathrm{CO}_{2}$ to $\mathrm{CH}_{4}$ at low temperature, the influences of different supports on catalysts are also discussed. Martínez et al. (2018) compared the effects of Ni-based catalysts supported over $\mathrm{ZrO}_{2}, \mathrm{SiO}_{2}$, and $\mathrm{MgAl}_{2} \mathrm{O}_{4}$ on the hydrogenation of $\mathrm{CO}_{2}$ to $\mathrm{CH}_{4}$. The $\mathrm{CO}_{2}$ conversion of all $\mathrm{Ni}$-based catalysts was positively correlated with the reaction temperature. $20 \% \mathrm{Ni} / \mathrm{ZrO}_{2}$ catalyst exhibited the best catalytic activity and long-term stability. Specifically, the majority presence of tetragonal zirconia as well as the strong $\mathrm{Ni}-\mathrm{ZrO}_{2}$ interaction were responsible for the high catalytic performance of the $\mathrm{Ni} / \mathrm{ZrO}_{2}$ catalysts ( $\mathrm{Li}$ et al., 2018b). Ahn et al. (2019) found that $\mathrm{Ni} / \mathrm{CeO}_{2}$ catalysts exhibited the best stability and highest selectivity in Ni-based catalysts supported by $\mathrm{TiO}_{2}, \mathrm{Al}_{2} \mathrm{O}_{3}, \mathrm{Y}_{2} \mathrm{O}_{3}$, and $\mathrm{CeO}_{2}$, respectively. Figure 2 showed the $\mathrm{CO}_{2}$ conversion of Ni-based catalysts based on different supports and $\mathrm{Ni} / \mathrm{CeO}_{2}$ had the highest $\mathrm{CO}_{2}$ conversion. Besides, it was found that high activation temperature was required for alumina supported catalysts because aluminasupported nickel catalysts were less reductive than $\mathrm{CeO}_{2}$ and $\mathrm{ZrO}_{2}$ (Gac et al., 2019). Therefore, $\mathrm{CeO}_{2}$ and $\mathrm{ZrO}_{2}$ are more suitable for carbon dioxide methanation under low temperature conditions.

\section{Composite Catalytic Support}

The composite catalytic supports for the $\mathrm{Ni}$ based catalysts for $\mathrm{CO}_{2}$ methanation mainly include $\mathrm{CeO}_{2}-\mathrm{ZrO}_{2}, \mathrm{ZrO}_{2}$ $\mathrm{Al}_{2} \mathrm{O}_{3}, \mathrm{Al}_{2} \mathrm{O}_{3}-\mathrm{SiO}_{2}$, etc. They can combine the characteristics of different supports together to better exert the catalytic performance of the catalyst than single support. In addition, the synergy between the composite supports would further affect the catalytic performance of $\mathrm{CO}_{2}$ methanation (Wang Y. et al., 2018; Champon et al., 2019).

For the $\mathrm{CeO}_{2}-\mathrm{ZrO}_{2}$ support, the crystalline lattices of $\mathrm{CeO}_{2}$ and $\mathrm{ZrO}_{2}$ could infiltrate into each other in atomic level and form the solid solution. The incorporation of $\mathrm{ZrO}_{2}$ in the $\mathrm{CeO}_{2}$ causes defects in the structure, which can promote the activation of $\mathrm{CO}_{2}$ during the process of methanation (Rezaei and Alavi, 2019). It was reported that the catalytic performance of the $\mathrm{Ni} / \mathrm{CeO}_{2}-\mathrm{ZrO}_{2}$ (CZ) catalyst was affected by the composition of the $\mathrm{Ce} / \mathrm{Zr}$ ratio (Ocampo et al., 2011). As shown in Figure 3, the $\mathrm{CO}_{2}$ conversion over $5 \mathrm{Ni} / \mathrm{CZ}(60-40)$ catalyst was higher than other catalysts. Specifically, the addition of $\mathrm{ZrO}_{2}$ increased the oxygen mobility in the lattice of cerium oxide and promoted the formation of vacancies, which in turn affected the consumption of $\mathrm{H}_{2}$ and the activation of $\mathrm{CO}_{2}$ rapidly (Bacani et al., 2017; Pastor-Pérez et al., 2018; Atzori et al., 2019). Iglesias et al. (2019) also found that $\mathrm{Ni} / \mathrm{CeO}_{2}-\mathrm{ZrO}_{2}$ catalyst had higher oxygen vacancy rate and higher $\mathrm{Ni}$ utilization rate than $\mathrm{Ni} / \mathrm{CeO}_{2}$. Therefore, the improvement of catalyst performance was mainly attributed to 


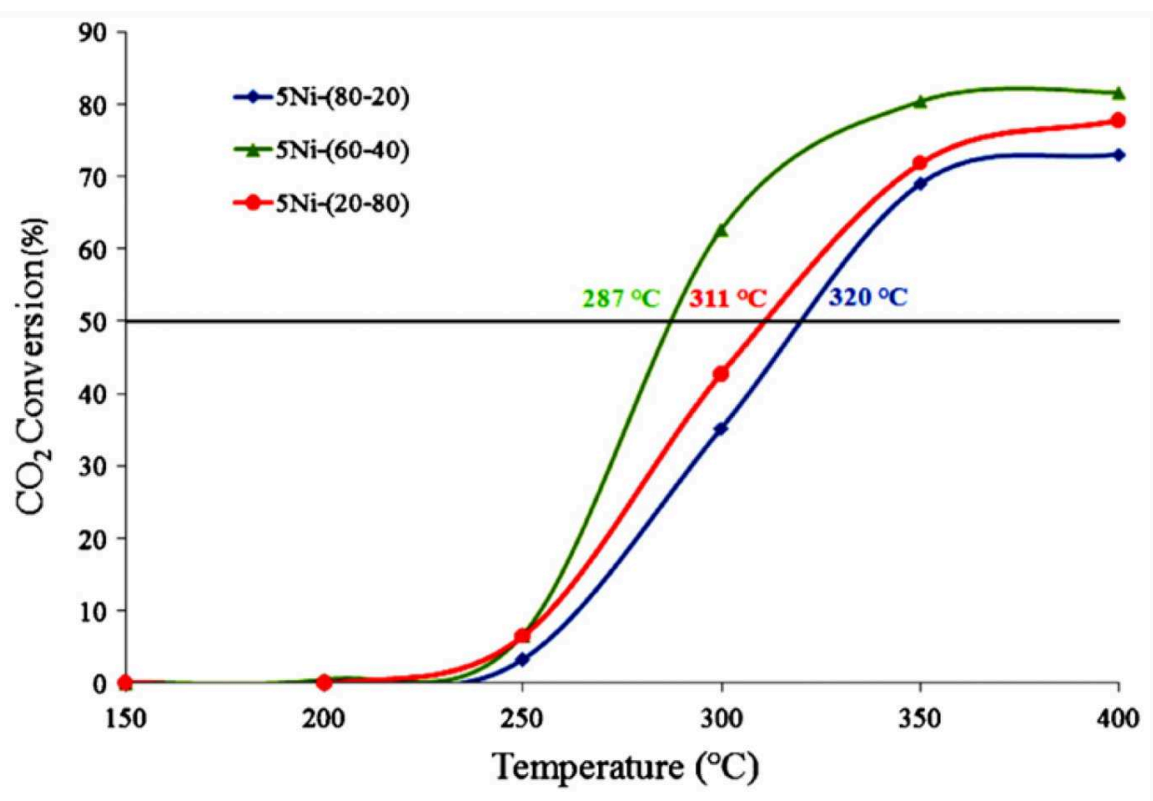

FIGURE 3 | $\mathrm{CO}_{2}$ conversion vs. temperature over 5Ni-CZ catalytic systems. Reproduced from Ocampo et al. (2011) with permission from Elsevier and Copyright Clearance Center.

their high oxygen storage capacity, excellent oxygen vacancy, and high Ni dispersion.

As regard to the $\mathrm{Al}_{2} \mathrm{O}_{3}-\mathrm{SiO}_{2}$ support, its large specific surface area can expose much more accessible $\mathrm{Ni}$ active centers to the gaseous feedstock than the single counterparts. Besides, the interaction between $\mathrm{Al}_{2} \mathrm{O}_{3}$ and $\mathrm{NiO}$ is enhanced by the formation of strong chemical bonds, which can effectively hinder the accumulation of $\mathrm{Ni}$ on the catalyst surface. However, $\mathrm{Al}_{2} \mathrm{O}_{3}$ will react with $\mathrm{NiO}$ species to form $\mathrm{NiAl}_{2} \mathrm{O}_{4}$ when calcined at high temperature, which makes the reduction of the $\mathrm{Ni}$ species very difficult ( $\mathrm{Xu}$ Y. et al., 2019). The presence of $\mathrm{SiO}_{2}$ can weaken the interaction between $\mathrm{Ni}$ and $\mathrm{Al}_{2} \mathrm{O}_{3}$ by inhibiting the phase transformation of $\mathrm{Al}_{2} \mathrm{O}_{3}$ from $\mathrm{r}$ to $\alpha$ and hinder the serous accumulation of $\mathrm{Ni}$ species via obtaining the optimal codissociation energy. As a result, its catalytic performance under low temperature conditions can be greatly improved (Cai et al., 2014; Charisiou et al., 2019). Moghaddam et al. (2018) studied the catalytic performance of $\mathrm{Ni}$-based catalysts supported by $\mathrm{Al}_{2} \mathrm{O}_{3}$ $\mathrm{SiO}_{2}$. Compared with the single support, the dispersion of the $\mathrm{Ni}$ active center over the $\mathrm{Ni} / \mathrm{Al}_{2} \mathrm{O}_{3}-\mathrm{SiO}_{2}$ catalyst was better due to the larger surface area and bigger pore volume of the composite support, which made the hydrogenation of $\mathrm{CO}_{2}$ to methane more easier. Thus, this catalyst performed the best performance (82.38\% $\mathrm{CO}_{2}$ conversion and $98.19 \% \mathrm{CH}_{4}$ selectivity at $350^{\circ} \mathrm{C}$ ) among all the catalysts.

$\mathrm{ZrO}_{2}-\mathrm{Al}_{2} \mathrm{O}_{3}$ has excellently sintering-resistant and thermally stable properties (Cai et al., 2011). As well-known, $\mathrm{Al}_{2} \mathrm{O}_{3}$ suffers the disadvantage of poor thermal stability in the $\mathrm{CO}_{2}$ methanation reaction while $\mathrm{ZrO}_{2}$ can easily form stable interaction with $\mathrm{NiO}$, which is beneficial to the improvement of stability toward $\mathrm{CO}_{2}$ methanation (Peymani et al., 2017; Jia et al., 2019). Therefore, the application of mesoporous $\mathrm{ZrO}_{2}$ $\mathrm{Al}_{2} \mathrm{O}_{3}$ composite support with unique structural properties and chemical properties is a novel strategy to prepare high efficient catalyst (Guo et al., 2014). As shown in Figure 4, the $\beta$-type peak of $20 \mathrm{Ni} / 20 \mathrm{ZrO}_{2}-\mathrm{Al}_{2} \mathrm{O}_{3}(\mathrm{ZA})$ was obviously higher than that of $20 \mathrm{Ni} / \mathrm{Al}_{2} \mathrm{O}_{3}$. When the $\mathrm{ZrO}_{2}$ content of the support was $<40 \%$, the weakening effect of $\mathrm{ZrO}_{2}$ on the $\mathrm{NiO}-\mathrm{Al}_{2} \mathrm{O}_{3}$ interaction was more obvious, and the reduction was easier to proceed with the increase of $\mathrm{ZrO}_{2}$ content (Guo et al., 2014; Liu et al., 2014). This phenomenon could be owing to the interaction between $\mathrm{NiO}$ and $\mathrm{Al}_{2} \mathrm{O}_{3}$ weakened by the presence of $\mathrm{ZrO}_{2}$ in $\mathrm{ZrO}_{2}-\mathrm{Al}_{2} \mathrm{O}_{3}$ support. As a result, the formation of $\mathrm{NiAl}_{2} \mathrm{O}_{4}$ was effectively inhibited and the $\mathrm{Ni}$ particles with smaller particle size were thus obtained. Therefore, the catalyst had excellent catalytic effect in $\mathrm{CO}_{2}$ methanation. In addition, more active metallic $\mathrm{Ni}^{0}$ active centers could be obtained under milder reduction conditions due to the lower content of the $\mathrm{NiAl}_{2} \mathrm{O}_{4}$. Therefore, the catalytic activity of the $\mathrm{Ni} / \mathrm{ZrO}_{2}-\mathrm{Al}_{2} \mathrm{O}_{3}$ catalyst was higher than that of $\mathrm{Ni} / \mathrm{Al}_{2} \mathrm{O}_{3}$ (Abate et al., 2016; Zhan et al., 2018). Cai et al. (2011) also found that the $\mathrm{CO}_{2}$ conversion over $\mathrm{Ni} / \mathrm{ZrO}_{2}$ catalyst was much lower than that of $\mathrm{Ni} / \mathrm{ZrO}_{2}-\mathrm{Al}_{2} \mathrm{O}_{3}$ as shown in Figure 5. The $\mathrm{CO}_{2}$ chemisorption and conversion had been intensified owing to the presence of the oxygen vacancies over the $\mathrm{ZrO}_{2}-\mathrm{Al}_{2} \mathrm{O}_{3}$ composite support, which was in favor of the hinderance of the carbon deposition and the improvement of the catalytic stability. Besides, the number of the oxygen vacancies and metallic $\mathrm{Ni}$ active centers over the catalyst surface gradually increased with the increase of the $\mathrm{Zr}$ loading, which could significantly improve the low-temperature catalytic activity and $\mathrm{CH}_{4}$ selectivity of the catalyst according to Lin et al. (2019). 


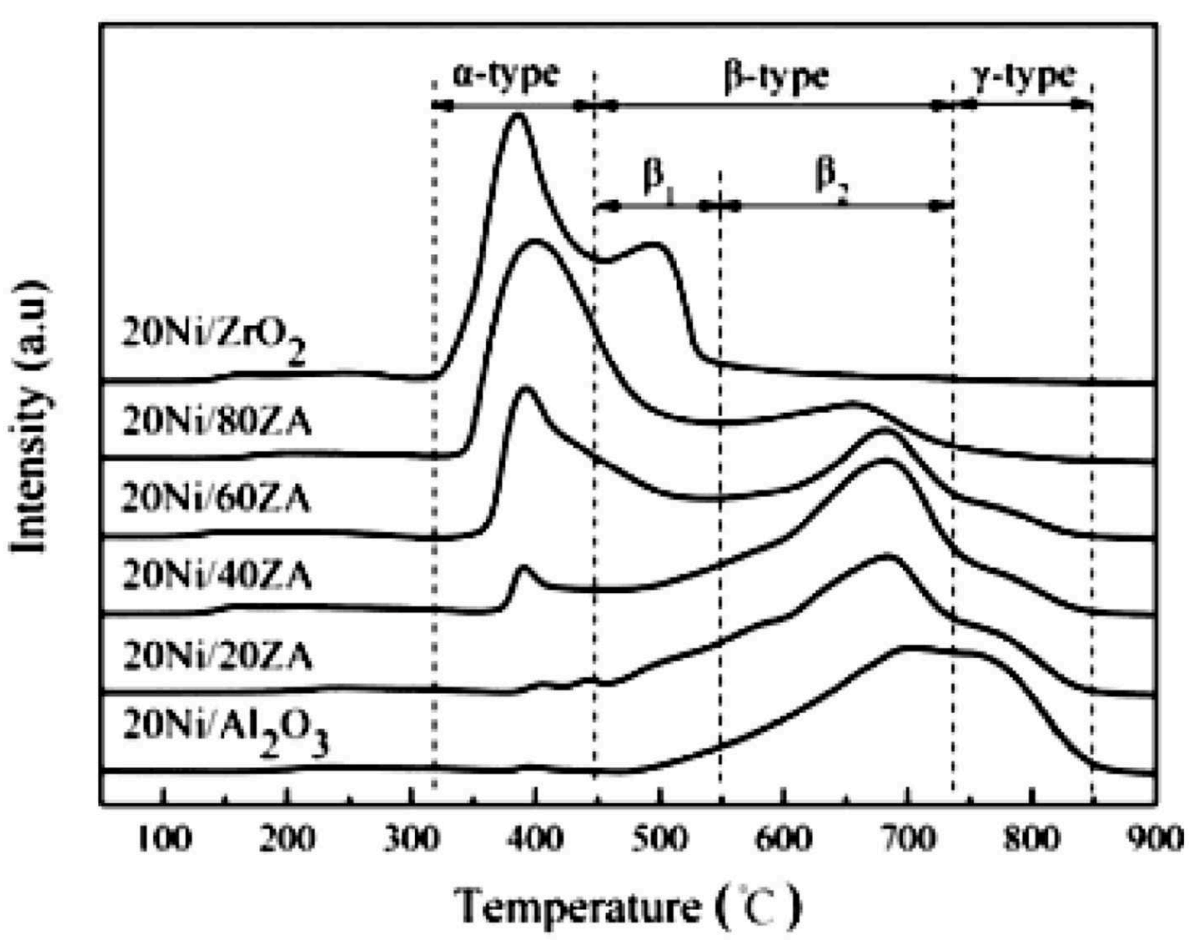

FIGURE 4 I TPR profiles of catalysts with different $\mathrm{ZrO}_{2}$ contents. Reproduced from Guo et al. (2014) with permission from Elsevier and Copyright Clearance Center.
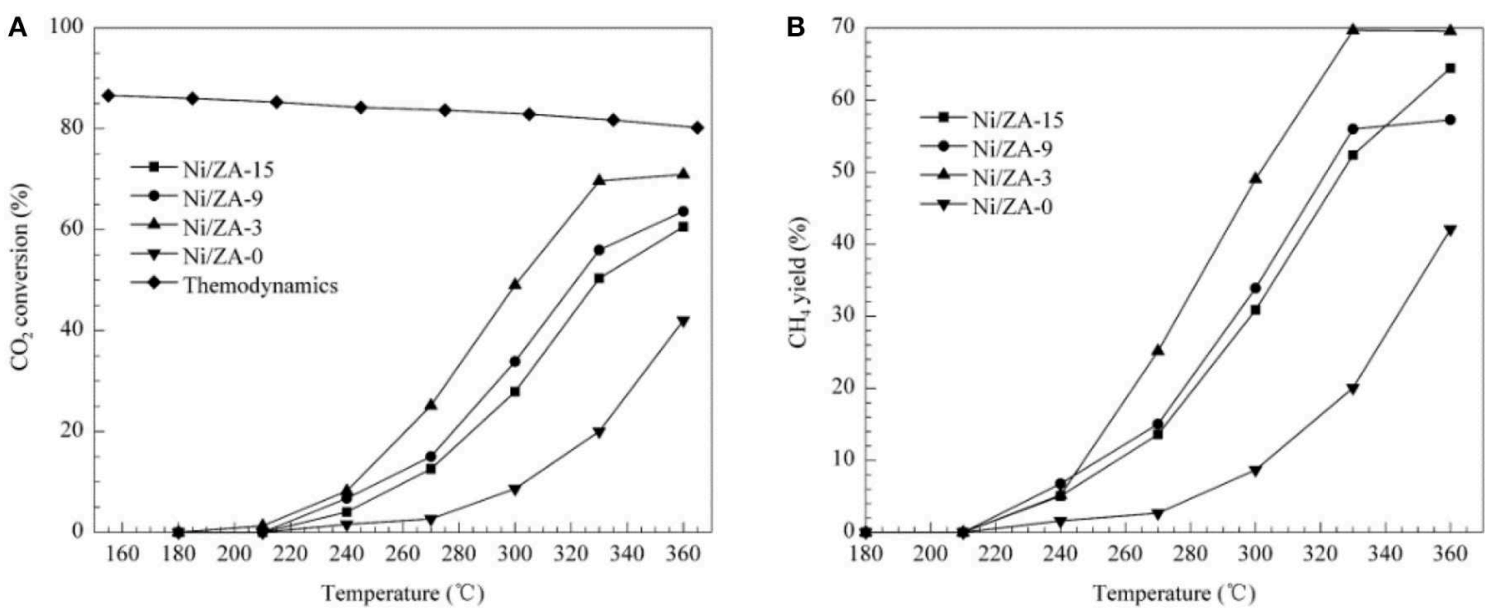

FIGURE 5 | (A) $\mathrm{CO}_{2}$ conversion and (B) $\mathrm{CH}_{4}$ selectivity vs. temperature for the $\mathrm{Ni} / \mathrm{ZA}-\mathrm{x}(\mathrm{x}=0,3,9,15)$ catalysts. Reaction conditions: $101.3 \mathrm{kPa}$, GHSV = 8,100 $\mathrm{mL} /\left(\mathrm{h} \cdot \mathrm{g}_{\mathrm{cat}}\right), \mathrm{H}_{2} / \mathrm{CO}_{2}$ molar ratio = 3.5. Reproduced from Cai et al. (2011) with permission from Elsevier and Copyright Clearance Center.

\section{Novel Support}

The novel supports, such as mesoporous materials (Zhang G. et al., 2019), molecular sieves (Quindimil et al., 2018), nanotubes (László et al., 2016), grapheme (Hu et al., 2019), MOFs (Ghanbari et al., 2019), and ZIFs (Zhao et al., 2019), are commonly used. Compared with the traditional support, the novel supports mainly possess the following two aspects of advantages. Firstly, the novel supports usually possesses excellent textural structures, such as specific surface area, pore volume, pore diameter, etc.
Take the zeolite as an example, it is a kind of microporous materials with high thermal stability, large surface area, and strong chemisorption for $\mathrm{CO}_{2}$, which are conducive to the improvement of catalytic activity and stability by providing more accessible active centers (Luengnaruemitchai and Kaengsilalai, 2008; Quindimil et al., 2018). Secondly, the novel support can endow the metallic active center in high dispersion state. For example, the graphene oxide can modify the electronic structure of $\mathrm{Ni}$ on the catalyst surface and reduce the dissociation 

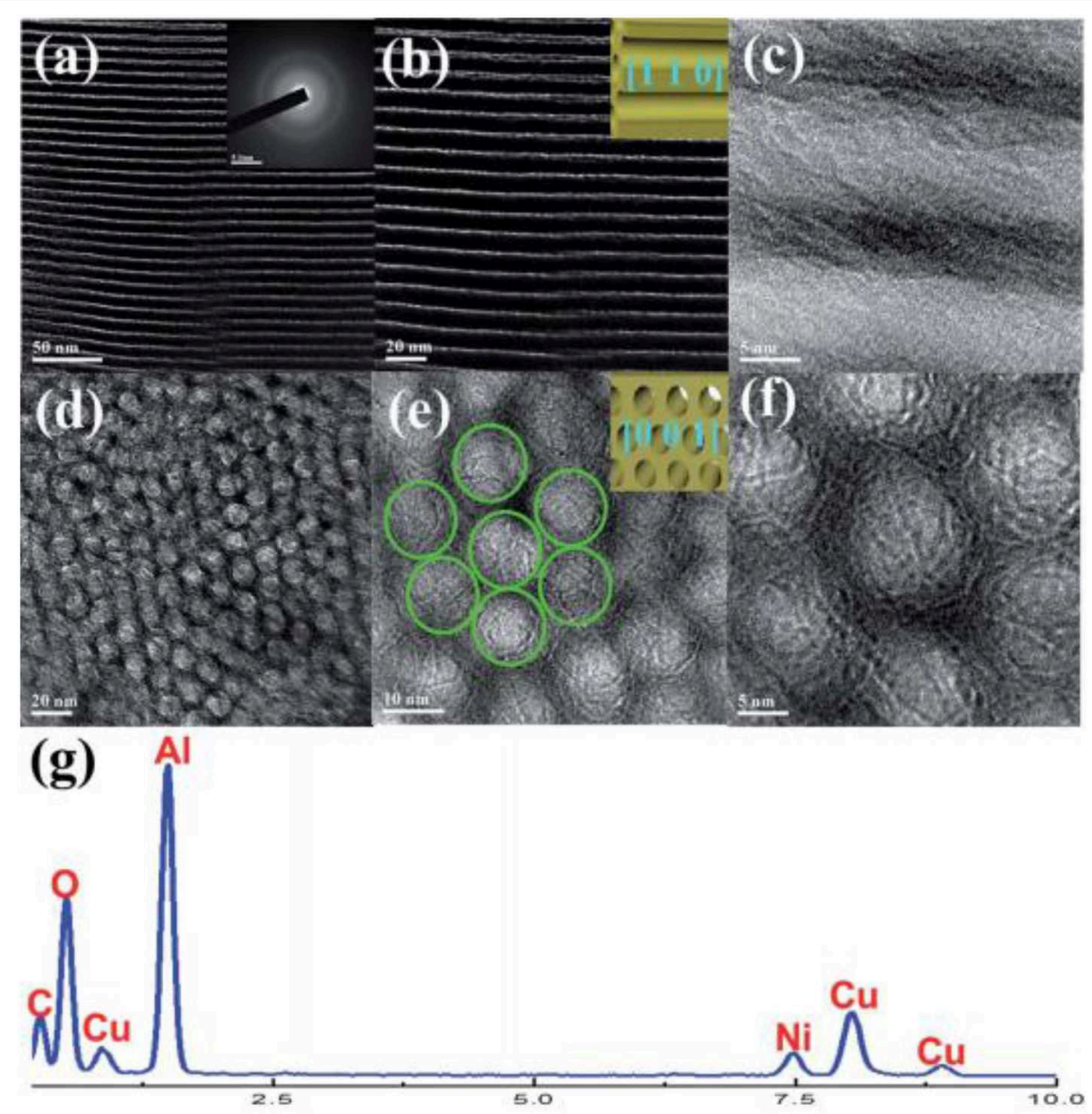

FIGURE 6 | TEM (a-e), SAED (f), and EDS (g) measurements of the OMA-10Ni catalyst. Reproduced from Xu et al. (2016) with permission from Royal Society of Chemistry.

energy of $\mathrm{H}_{2}$ and $\mathrm{CO}_{2}$ (He et al., 2016). Ma et al. (2019) prepared $\mathrm{Ni}-\mathrm{SiO}_{2} / \mathrm{GO}-\mathrm{Ni}$-foam catalyst by intercalation method. Compared with the $\mathrm{Ni}-\mathrm{SiO}_{2} / \mathrm{Ni}$-foam catalyst, $\mathrm{Ni}-\mathrm{SiO}_{2} / \mathrm{GO}-\mathrm{Ni}$ foam with larger surface area had stronger $\mathrm{CO}_{2}$ adsorption capacity and good anti-sintering ability. Besides, graphene oxide could enhance the interaction between $\mathrm{Ni}$ and $\mathrm{SiO}_{2}$ and the $\mathrm{Ni}-\mathrm{SiO}_{2} / \mathrm{GO}-\mathrm{Ni}$-foam catalyst could form a large amount of $\mathrm{Ni}$ silicate, promising high dispersion of $\mathrm{Ni}$.

Mesoporous materials are considered as the ideal catalytic supports with novel structure. The mesoporous structure could not only confine the metal $\mathrm{Ni}$ to a fixed space, but also provide a large surface area for the high dispersion of the metallic active centers. Thereby, the stability of the catalyst could be greatly improved (Liu Q. et al., 2015). Recently, mesoporous alumina and mesoporous silica materials have been widely investigated as the catalytic supports toward different catalytic reactions. Shen et al. (2011) reported that mesoporous materials were excellent supports for preventing metal particle from sintering. $\mathrm{Xu}$ et al. (2016) found that ordered mesoporous $\mathrm{NiO}-\mathrm{Al}_{2} \mathrm{O}_{3}$ (MA) exhibited higher catalytic activity and better stability than non-mesoporous materials(NPA) and $\mathrm{Ni} / \mathrm{x}-\mathrm{Al}_{2} \mathrm{O}_{3}$ due to its outstanding structural property as shown in Figure 6. Specifically, the ordered mesoporous catalyst with uniform pore size could promise the facile access to the exposed $\mathrm{Ni}$ active sites for the gaseous feedstock, which would be beneficial to the diffusion of the reactant gases and accelerating the reaction speed. Besides, Xu et al. (2017a) synthesized Co/Ca modified ordered mesoporous Ni based catalysts by the evaporation-induced selfassembly (EISA) strategy to further improve the low-temperature catalytic activity of the catalyst. The alkaline earth and rare earth dopants are used to intensify the chemisorption and activation of $\mathrm{CO}_{2}$ (Li B. et al., 2019). Xu et al. (2018) found that the ordered mesoporous $\mathrm{Al}_{2} \mathrm{O}_{3}$ prepared by this method had uniform porous structure and outstanding thermal stability. The framework of MA could stabilize the particle size of $\mathrm{Ni}$ particles via the confinement effect of the mesoporous channel and strong metalsupport interaction, which could effectively hinder the sintering of the Ni particle at high reaction temperatures (Xu L. et al., 2012). In addition, MA's unique structure was conducive to the mass transfer of both the gaseous reactants and products 
owing to outstanding structural properties (Liu Q. et al., 2016). Aljishi et al. (2018) found that the physical properties of ordered mesoporous nickel alumina catalyst (Ni/OMA) were in favor of the uniform dispersion and the formation of more accessible $\mathrm{Ni}$ reaction centers, thus promoting the $\mathrm{CO}_{2}$ methanation reaction. It was reported that the $\mathrm{CO}_{2}$ conversion and $\mathrm{CH}_{4}$ selectivity of the catalyst Ni/OMA was higher than those of traditional catalysts in the range of $300-500^{\circ} \mathrm{C}$ (Liu et al., 2018a). Meanwhile, the hydrothermal stability of Ni/OMA was good and the fiber structure of the catalyst was successfully retained after the catalytic reaction. As for mesoporous silica, it has a high surface area, on which the high dispersion of $\mathrm{Ni}$ active centers could be achieved (Li et al., 2018c). Besides, it was reported that the high activity of $\mathrm{Ni} / \mathrm{MSN}$ may be due to the existence of both interparticle porosity and the high basicity of the catalysts (Aziz et al., 2014a). Specifically, the basic sites could promote the chemisorption of $\mathrm{CO}_{2}$ on the catalyst surface, thus increasing the reaction rate. The interparticle pores could facilitate the mass transport of the reactants and product molecules during the catalytic reaction and thus allowing higher $\mathrm{CO}_{2}$ conversion to be obtained (Wang et al., 2006). In addition, Aziz et al. (2015) found that the $\mathrm{CO}_{2}$ conversion rate over Ni/MSN catalyst did not decrease significantly during the stability test in Figure 7, showing excellent coke resistance and good stability within $200 \mathrm{~h}$ time on stream. The phenomenon may be ascribed to the strong metal-support interaction between the MSN and Ni metal, which could endow the catalyst with high carbon deposition resistance (Xiang et al., 2016).

In recent years, carbon nanotubes have been widely used as the support of the catalysts due to their excellent properties (Andersen et al., 2015). It has a unique structure and can enhance the dispersion of metallic Ni. Meanwhile, the carbon nanotubes can improve the reduction performance and catalytic activity of the catalyst because the binding effect of the CNTs has a

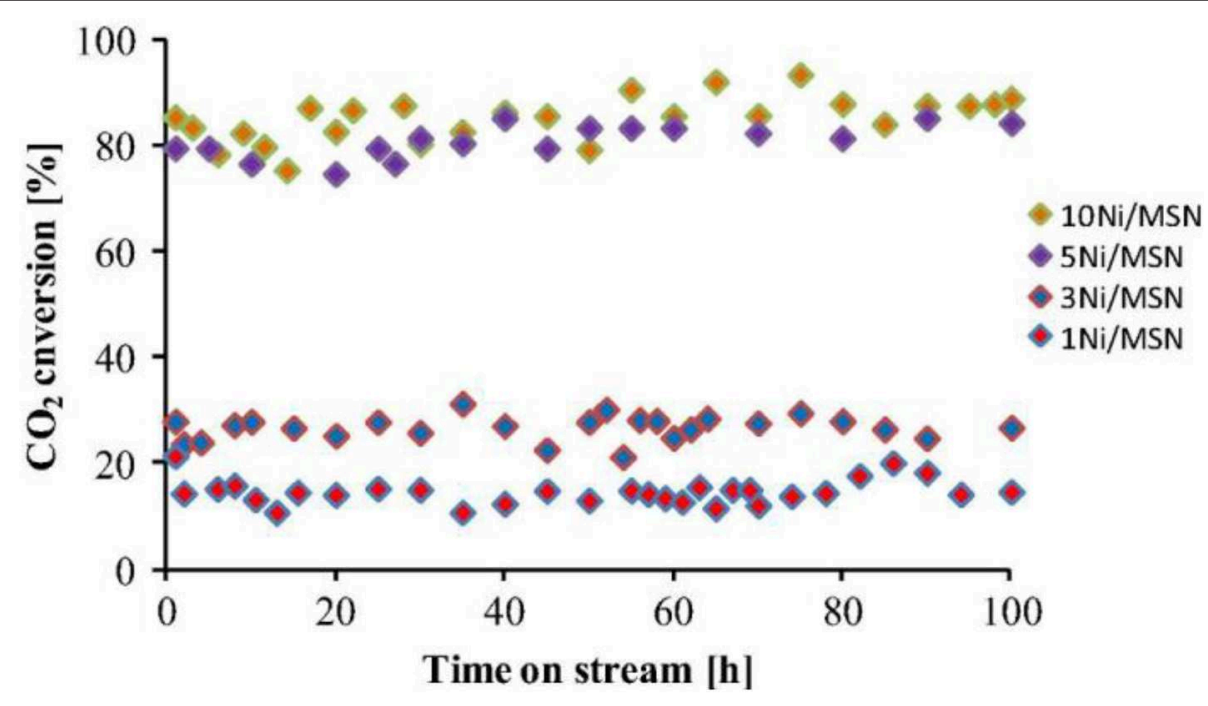

FIGURE 7 | Stability test of all catalysts. Reaction temperature $=623 \mathrm{~K}, \mathrm{H}_{2} / \mathrm{CO}_{2}=4 / 1, \mathrm{GHSV}=50,000 \mathrm{~mL} \mathrm{~g}_{\text {cat }}^{-1} \mathrm{~h}^{-1}$. Reproduced from Aziz et al. (2015) with permission from Elsevier and Copyright Clearance Center.
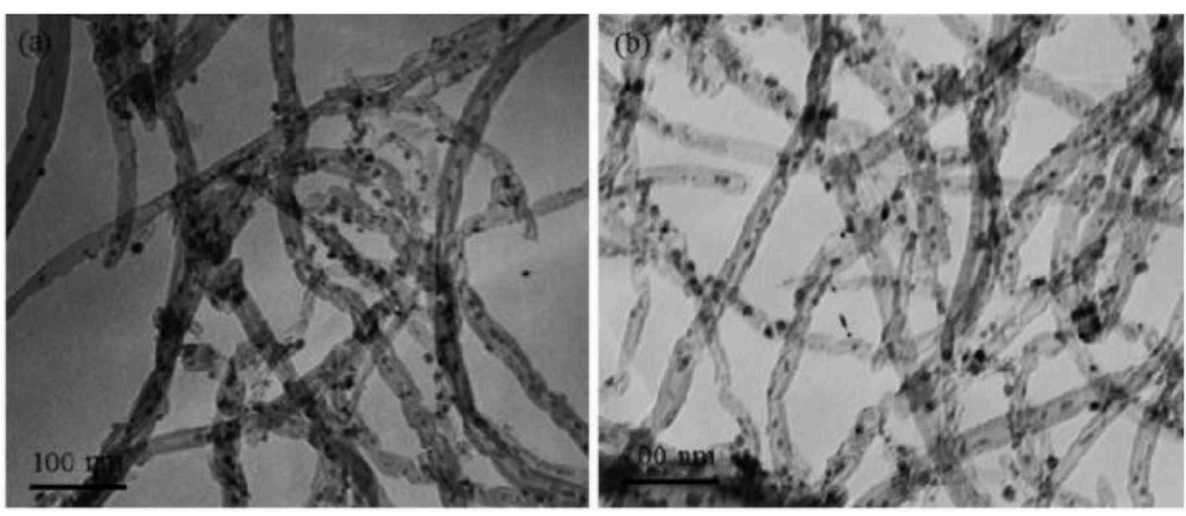

FIGURE 8 | TEM images of 12Ni4.5Ce/CNT catalyst before (a) and after (b) stability test. Reproduced from Wang W. et al. (2016) with permission from Elsevier and Copyright Clearance Center. 
confinement effect on the particle size of the Ni particles, which can hinder the migration and sintering of the active component $\mathrm{Ni}$ (Xiong et al., 2013). In addition, active centers with strong adsorption and conductivity exist in the interior and surface of carbon nanotubes, which can promote the electron transfer of active substances (Li J. et al., 2018). Wang W. et al. (2016) compared Ce-doped Ni-based catalysts with $\mathrm{Al}_{2} \mathrm{O}_{3}$ and carbon nanotubes as supports. Compared with the catalyst with $\mathrm{Al}_{2} \mathrm{O}_{3}$ as the support, the carbon nanotube-supported catalyst had a larger specific surface area. Therefore, as shown in Figure 8, the average particle size of the metallic Ni particles was about 3-5 nm before the $\mathrm{CO}_{2}$ methanation reaction. The particle size of metallic $\mathrm{Ni}$ was also not substantially changed after the stability test. This indicated that the CNT support can effectively limit the Ni particle size in the tubular structure below the nanometer scale.

$\mathrm{SiO}_{2}$ is widely considered as a common support for $\mathrm{Ni}$ based catalysts. However, $\mathrm{Ni} / \mathrm{SiO}_{2}$ catalysts are prone to generate carbon deposits during the reaction and thus cause inactivation (Wang F. et al., 2018). Therefore, many scholars have studied the structure of $\mathrm{SiO}_{2}$ in order to solve this problem. Zhang L.

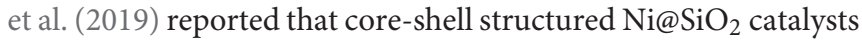
fabricated by microemulsion method could achieve strong metal-support interaction, which was beneficial to preserve the small size of Ni nanoparticles during the reaction. Therefore, $\mathrm{Ni@SiO} 2$ catalysts had excellent catalytic performance. In addition, Bukhari et al. (2019) synthesized the Ni-based catalyst supported on fibrous SBA-15 (F-SBA-15) by impregnation method. As shown in Figure 9, 5\%Ni/F-SBA-15 exhibited 98.9\% $\mathrm{CO}_{2}$ conversion and $99.6 \% \mathrm{CH}_{4}$ selectivity at $673 \mathrm{~K}$ for $6 \mathrm{~h}$ timeon-stream because the fibrous morphology and dendrimeric structure of F-SBA-15 were in favor of Ni dispersion.

\section{Nickel-Based Catalyst Doped With Different Additives}

Ni-based catalysts always have some inherent drawbacks, such as poor low-temperature activity and serious thermal sintering at high temperature. The incorporation of catalytic dopants has been considered as an effective strategies to improve these drawbacks (Alrafei et al., 2019). It was reported that the modified catalyst with adequate additive usually had a higher $\mathrm{CO}_{2}$ conversion than the corresponding reference catalyst (Li Y. et al., 2019). Although the catalytic additive itself has no evidently catalytic activity, it can significantly promote the catalytic performances by regulating the dispersion of the metallic active center and surface properties. Specifically, the dispersion of the active component can be improved by changing the structure of the catalyst and the electronic property and/or alkalinity of the catalyst surface could be modified due to the incorporation of the catalytic additives. As a result, the reaction barrier in terms of the apparent activation energy can be greatly lowered and as a result, the low-temperature catalytic activity could be greatly promoted (Wang Y. et al., 2018). For the bimetal and/or multifetal based catalyst, the synergistic effect between $\mathrm{Ni}$ with the incorporated metal also improves the dissociation and desorption capacity of the catalyst for $\mathrm{H}_{2}$ and $\mathrm{CO}_{2}$, thereby enhancing the methanation reactivity (Liu X. et al., 2012). For an instance, Wang X. et al.

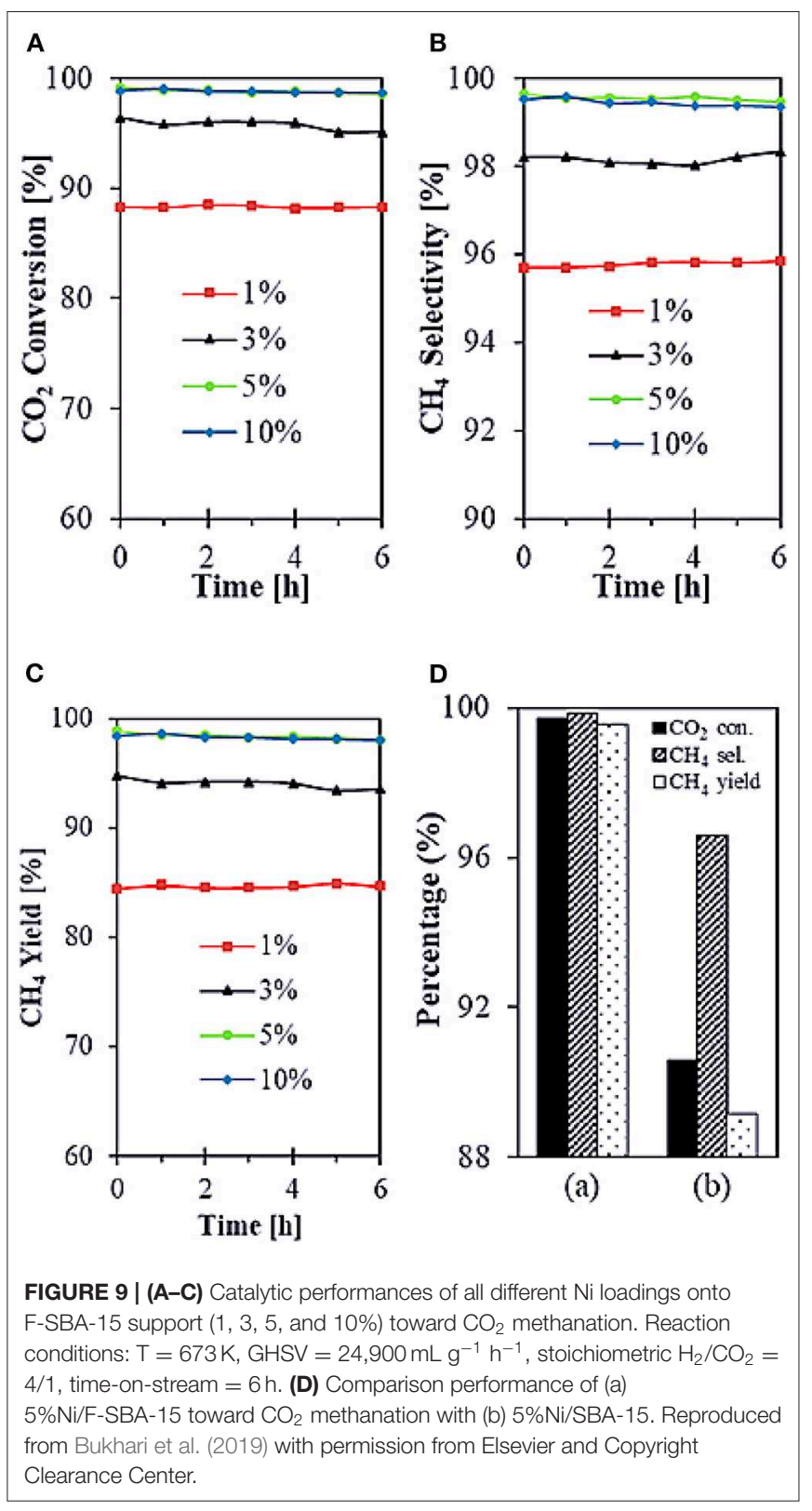

(2018) found that Ce-doped catalysts not only had good catalytic stability, but also had outstanding adaptability to different reaction conditions because the synergy between the metals $\mathrm{Ce}$ and $\mathrm{Ni}$ promoted the activation of $\mathrm{CO}_{2}$ at lower temperatures. In addition, the incorporated dopants, such as $\mathrm{Zr}$, Co, $\mathrm{La}, \mathrm{Mg}$, can change the reaction pathways of $\mathrm{CO}_{2}$ methanation and reaction intermediates. As a result, the production of $\mathrm{CO}$ can be effectively avoided owing to the effective hinderance of the side reaction. Liang et al. (2019a)found that all the Cr, Mn, Fe, $\mathrm{Co}, \mathrm{La}$, and Ce modified catalysts were provided with multiple oxygen vacancies, promising higher catalytic activities than $\mathrm{Ni}$ $\mathrm{Al}_{2} \mathrm{O}_{3}$ catalysts by the enhancement of the chemisorption and activation of $\mathrm{CO}_{2}$ adsorption. The reason for promoted catalytic performance was that these modified catalysts experienced the 
formate-type intermediates, which could be converted to $\mathrm{CH}_{4}$ more rapidly.

\section{Single Additive}

The type of single additives for Ni based catalysts can be mainly classified into alkaline earth metal oxides, transition metals, rare earth metal oxides, and noble metals. They can improve catalytic performance by adjusting the structural parameters of the catalyst, such as specific surface area and pore size, the electronic effect, and surface basicity, which would influence the interaction between the catalyst and the $\mathrm{CO}_{2}$ molecule (Su et al., 2016).

\section{Alkaline earth metal oxides}

The addition of alkaline earth metal oxides, such as $\mathrm{MgO}$, $\mathrm{CaO}, \mathrm{SrO}$, and $\mathrm{BaO}$, have been widely considered as a series of structural additives, which can obviously increase the surface basicity of the catalyst. Besides, Sr-modified catalysts can also

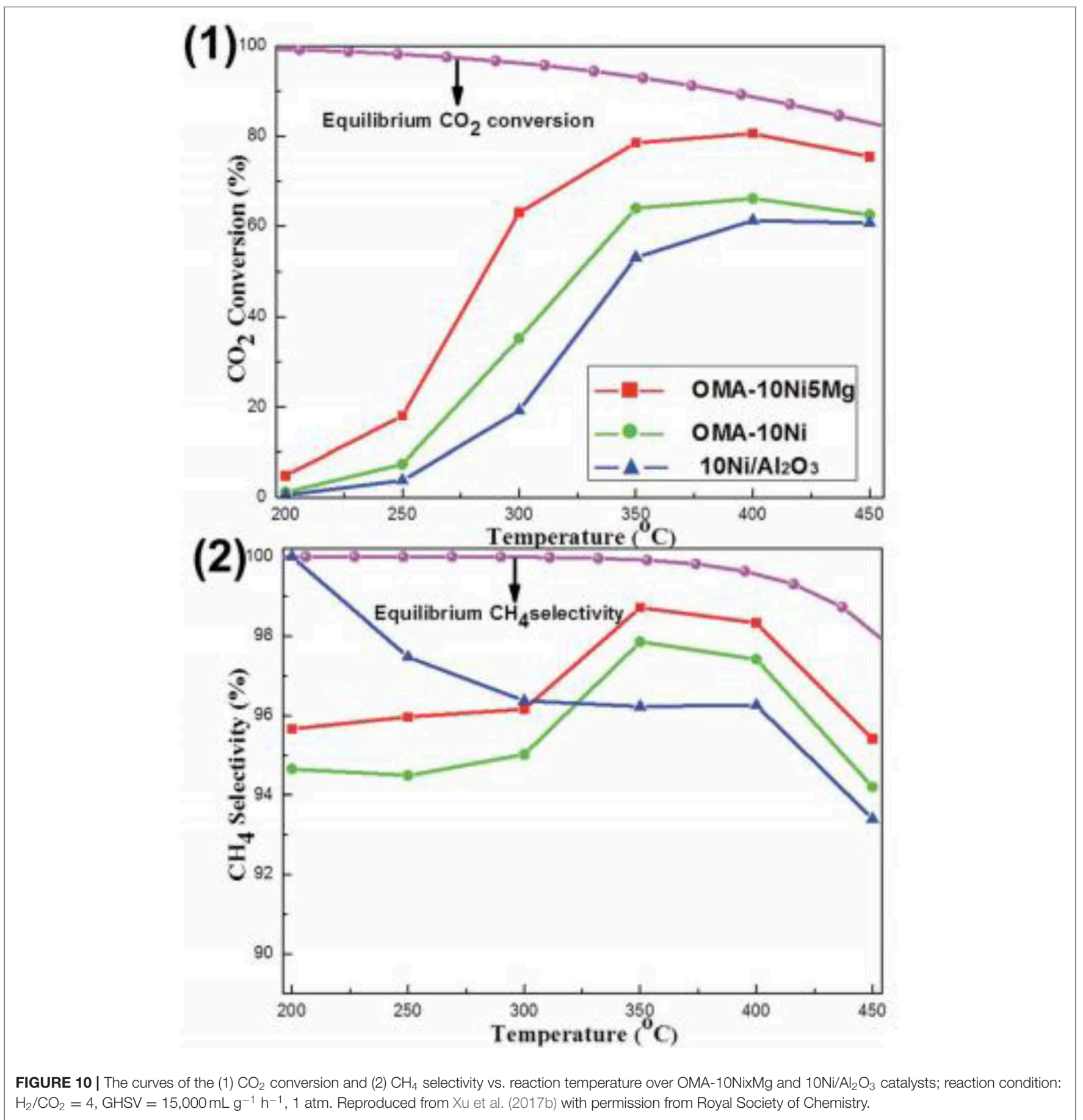


generate the oxygen vacancies and prevent electron pairing. $\mathrm{Ba}$ can inhibit $\mathrm{CO}$ formation by inhibiting the reverse water-gas shift reaction (Liang et al., 2019b).

As for the $\mathrm{MgO}$, it has been extensively investigated as the basic modifier as the $\mathrm{Ni}$ based catalysts toward the $\mathrm{CO}_{2}$ methanation reaction (Ye et al., 2019). The catalytic activity of the catalyst can be enhanced by adding a low concentration of $\mathrm{Mg}$ because the chemisorption and dissociation of $\mathrm{CO}_{2}$ is promoted (Tan et al., 2019). Meanwhile, the addition of $\mathrm{MgO}$ can also improve the dispensability and improving the oxidizing environment around the Ni particles in the catalyst. Thereby, the serious agglomeration of metallic $\mathrm{Ni}$ active centers and carbon deposition over the catalyst surface can be effectively prevented (Al-Fatesh et al., 2017; Feng et al., 2018; Vidal Vázquez et al., 2018). In order to further investigate the role of $\mathrm{Mg}$ in depth, the researchers have extensively studied the catalytic activity of different catalysts doped with MgO. Li X. et al. (2019) found that $\mathrm{MgNiO}_{2}$ could be formed by co-impregnation in $\mathrm{Ni}-\mathrm{Mg} /$ coconut shell carbon (CSC), which could enhance the metal-support interaction and improve the high temperature stability of Ni. Furthermore, Xu et al. (2017b) found that the addition of $\mathrm{MgO}$ could evidently increase the surface alkalinity of the catalyst by forming various types of basic centers with different intensities. As shown in Figure 10, the $\mathrm{CO}_{2}$ conversion of $\mathrm{Ni}-\mathrm{Mg}$ /ordered mesoporous alumina matrix (OMA) was obviously higher than that of Ni/OMA. In addition, Guo and $\mathrm{Lu}$ (2014) reported that the introduction of $\mathrm{MgO}$ would greatly affect the structure of the catalyst and fully expose the $\mathrm{Ni}$ active center with coordination unsaturation to promote the transformation of reactants $\left(\mathrm{H}_{2}\right.$ and $\mathrm{CO}_{2}$ ). However, excessive $\mathrm{Mg}$ doping can also cause blockage of the active center of the catalyst, resulting in the decrease of the catalytic activity (Li et al., 2014; Xu et al., 2017b).

$\mathrm{CaO}$ can intensify the chemisorption of the $\mathrm{CO}_{2}$ and then decrease the activation energy of $\mathrm{CO}_{2}$ as the basic modifier (Pan et al., 2014). Besides, it was reported that $\mathrm{CaO}$ increased the number and intensity of the basic sites over $15 \mathrm{Ni} /$ activated carbon (AC) catalyst (Feng et al., 2016). Therefore, the catalytic performance at low reaction temperature could be promoted. Furthermore, Xu et al. (2017a) found that Ca could increase the wall thickness of mesoporous channels of the catalyst, which could improve the thermal stability of these materials. Meanwhile, although Ca modifier had no effect on the chemical coordination environment of the $\mathrm{Ni}^{2+}$ cation, it could promote the reduction of $\mathrm{Ni}$ species by inhibiting the formation of $\mathrm{NiAl}_{2} \mathrm{O}_{4}$ spinel as shown in Figure 11.

\section{Transition metals}

Transition metals, such as $\mathrm{Ti}, \mathrm{V}, \mathrm{Mn}, \mathrm{Fe}, \mathrm{Co}$, and $\mathrm{Cu}$, have unique acid-base and redox properties and widely investigated as the modifier of $\mathrm{Ni}$ based catalysts toward $\mathrm{CO}_{2}$ methanation. For example, Yuan et al. (2018) further found that transition metal Re could significantly reduce the activation barrier of $\mathrm{C}$ $\mathrm{O}$ bond cleavage, which was usually considered as the ratedetermining step of methanation reaction. Therefore, Re dopant could accelerate the $\mathrm{CO}_{2}$ methanation process and thus improve low-temperature catalytic performance. Besides, it has been reported that the addition of the transition metal to $\mathrm{Ni} / \mathrm{Al}_{2} \mathrm{O}_{3}$ can significantly change the electronic structure of the catalyst and affect the chemical properties of the Ni clusters of the catalyst (Shadravan et al., 2018; Long et al., 2019).

In terms of $\mathrm{Co}$, it has good $\mathrm{CO}_{2}$ activation ability at low temperature and can promote the uniform dispersion of active metal on catalyst (Xu L. et al., 2019). Xu et al. (2018) found that Co could improve the catalytic effect of Ni-based catalysts at low temperature. As shown in Figure 12, Ni-based catalyst doped with cobalt displayed much higher $\mathrm{CO}_{2}$ conversion than $\mathrm{Ni}$, Co monometallic counterparts. This phenomenon may be ascribed to the synergistic effect between $\mathrm{Co}$ and $\mathrm{Ni}$, which could make the catalyst resistant to thermal agglomeration (Siang et al., 2018). Liu et al. (2018b) found that $\mathrm{Ni}-\mathrm{Co} / \mathrm{Al}_{2} \mathrm{O}_{3}$ reduced the activation energy of the reaction and increased the catalytic activity compared with $\mathrm{Ni} / \mathrm{Al}_{2} \mathrm{O}_{3}$. Furthermore, it was reported that the addition of Co could increase the reducibility of $\mathrm{Ni}$ based catalyst at low temperature and improve $\mathrm{Ni}$ dispersion over the support, which had a positive impact on the catalytic activity (Alrafei et al., 2019).

In recent years, $\mathrm{Mn}$ has been considered as an effective promoter in the $\mathrm{CO}_{2}$ methanation reaction. They have strong resistance to thermal sintering because the surface oxygen intermediates produced by manganese can react with the surface carbon deposition, inhibiting the formation of $\mathrm{Ni}$ carbide (Rahmani et al., 2014). Besides, the interaction between Mn and the oxide phase as well as the increased $\mathrm{CO}_{2}$ adsorption capacity can improve the catalytic activity of the catalyst (Le et al., 2019a). Zhao et al. (2016b) also found that the addition of $\mathrm{Mn}$ increased the alkaline site of the catalyst, which improved the $\mathrm{CO}_{2}$ chemisorption capacity and low-temperature catalytic activity of the catalyst. Besides, the oxygen vacancy of catalyst can promote the chemisorption and dissociation of $\mathrm{CO}_{2}$ during the process of methanation. Therefore, the doping of $\mathrm{Mn}$ can promote the activation of $\mathrm{CO}_{2}$ by generating more oxygen vacancies (Burger et al., 2018).

The low-temperature catalytic activity of Ni-Fe alloy catalyst is usually higher than those of the single-metal Ni reference counterparts, especially at higher pressure due to the optimal $\mathrm{CO}_{2}$ dissociation energy (Mutz et al., 2018). Simultaneously, with the addition of $\mathrm{Fe}$, the stability of the catalyst, the conversion of $\mathrm{CO}_{2}$ and the selectivity of $\mathrm{CH}_{4}$ are all improved, indicating that $\mathrm{Ni}$ and Fe have synergistic effects (Mutz et al., 2017). In the view of the reaction mechanism, the addition of Fe could facilitate the formation of hydrocarbon, enhance $\mathrm{CO}_{2}$ adsorption capacity, and accelerate the reaction rate (Li et al., 2018d). It was reported that the promoting effect of the $\mathrm{Ni} / \mathrm{Fe}$ ratio on the reducibility of the catalyst became obvious and the reducibility of the catalyst gradually became better with the increase of the Fe loading (Burger et al., 2018). Ren et al. (2015) also reported that both the appropriate electronic environment and the enhanced reductive properties of Fe were key factors in the enhancement of lowtemperature catalytic performance toward $\mathrm{CO}_{2}$ methanation.

\section{Rare earth metal oxides}

The rare earth metal mainly includes lanthanide and actinide elements, such as Y, La, Ce, Pr, Nd, Sm, and so on. Compared with alkaline earth elements, rare earth elements with a unique 

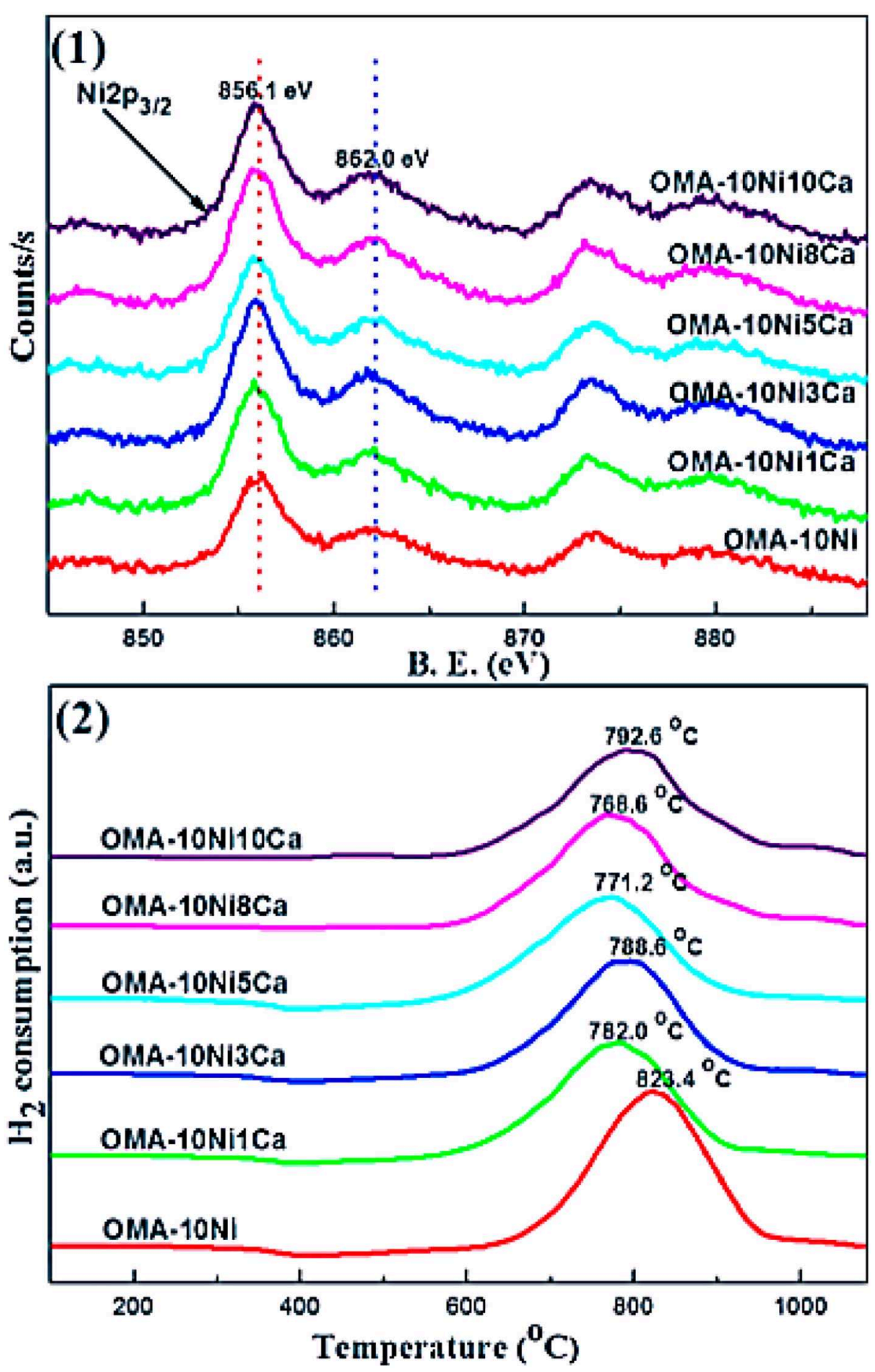

FIGURE 11 | (1) Ni 2p XPS and (2) $\mathrm{H}_{2}$-TPR profiles of the as-prepared OMA-10NixCa catalysts. Reproduced from Xu et al. (2017a) with permission from Elsevier and Copyright Clearance Center

electronic structure can regulate the electronic properties of active centers (Xu et al., 2017c; Fang et al., 2018). Fang et al. (2018) also found that the presence of rare earth metal could promote the reducibility of the $\mathrm{Ni}^{2+}$ species and greatly increase the number of surface basic sites. Furthermore, they are also commonly used as the lattice defect additives, which can make the arrangement of the Ni active center become irregular. As a result, the active crystallites exhibit more lattice defects, thereby 

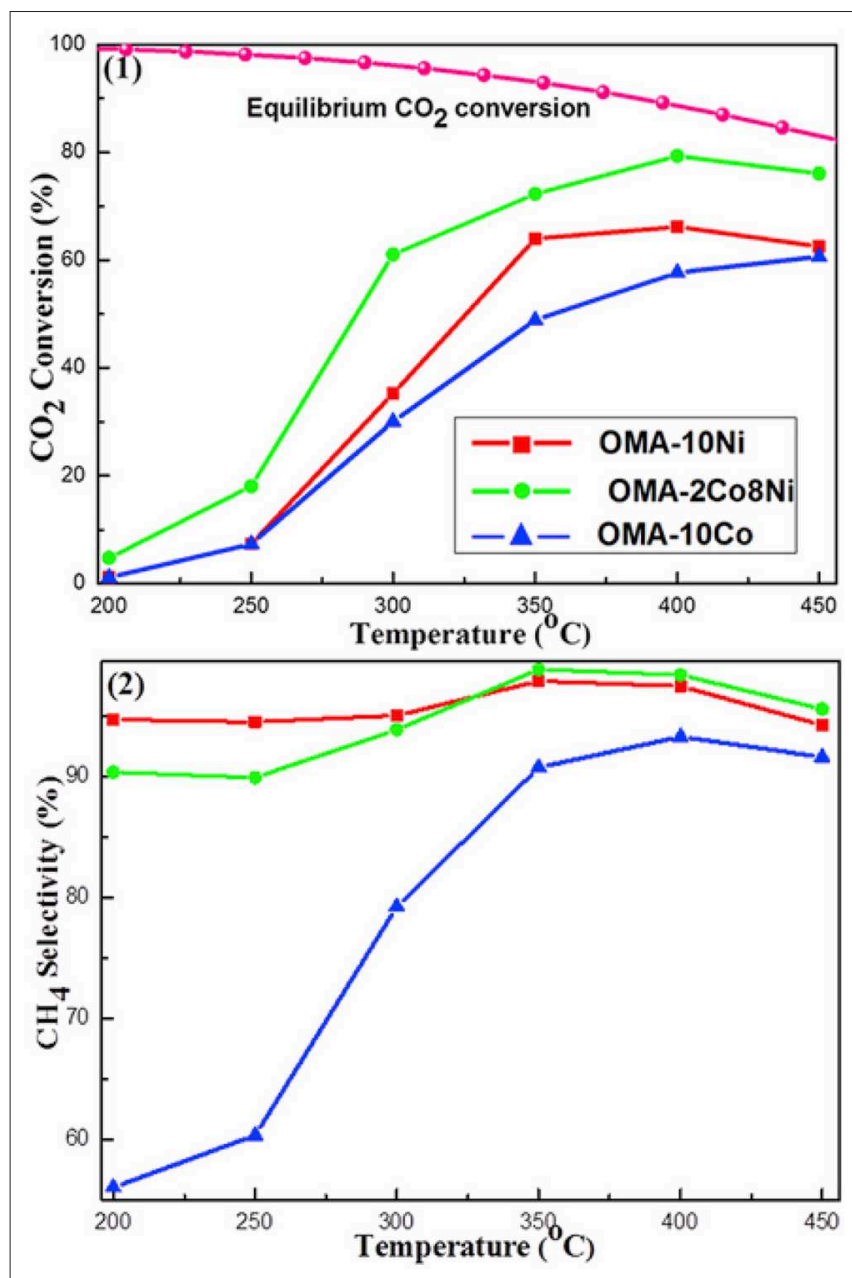

FIGURE 12 | The curves of the (1) $\mathrm{CO}_{2}$ conversion and (2) $\mathrm{CH}_{4}$ selectivity vs. reaction temperature over OMA-10Ni, OMA-2Co8Ni, and (3) OMA-10Co catalysts; reaction condition: $\mathrm{H}_{2} / \mathrm{CO}_{2}=4$, GHSV $=15,000 \mathrm{~mL} \mathrm{~g}^{-1} \mathrm{~h}^{-1}, 1$ atm. Reproduced from Xu et al. (2018) with permission from Elsevier and Copyright Clearance Center.

finally making the catalyst expose more active centers to the gaseous reactants (He et al., 2015).

The doped La can endow the catalyst with moderate basicity and improve the $\mathrm{CO}_{2}$ adsorption capacity of the catalyst (Garbarino et al., 2019). As a result, the low-temperature catalytic activity and catalytic stability can be greatly improved owing to the enhancement in surface basicity and the dispersion of the $\mathrm{Ni}$ active centers (Wierzbicki et al., 2016; Liang et al., 2019c). In addition, La can have a positive effect on modifying the electronic environment around the metallic Ni active centers $(\mathrm{Hu}$ and Urakawa, 2018; Branco et al., 2020). Zhang et al. (2018a) prepared a La-doped $\mathrm{Ni} / \mathrm{Mg}$-Al used as the catalyst toward $\mathrm{CO}_{2}$ methanation. As shown in Figure 13, the obtained catalyst was provided with enhanced catalytic activity after doping an appropriate amount of La, especially under low temperature conditions. This phenomenon could be ascribed to the formation of surface free hydrogen promoted by La, which played the critical role in the process of removing nickel carbonyl on the surface. Besides, it could be observed in Figure 14 that the dispersion of $\mathrm{Ni}$ over the reduced catalyst became better with the increase of La loading amount. In addition, Quindimil et al. (2018) also found that an appropriate amount of La could obviously improve the reducibility and dispersion of Ni species. As a result, the number of accessible basic sites and active centers over the catalyst surface also increased owing to the enhancement of the dispersion of $\mathrm{Ni}$.

As regards $\mathrm{Ce}$, it has been considered as an important additive of $\mathrm{Ni}$ based catalyst toward $\mathrm{CO}_{2}$ methanation because it is beneficial to the improvement of various properties of the catalysts, such as the redox and dielectric properties, the stability of the catalyst, the activation of $\mathrm{CO}_{2}$ (Bian et al., 2015; Zhou G. et al., 2016; Movasati et al., 2017). For example, Liu H. et al. (2012) studied the effect of $\mathrm{CeO}_{2}$ on $\mathrm{Ni}-\mathrm{Al}_{2} \mathrm{O}_{3}$ catalyst toward $\mathrm{CO}_{2}$ methanation process. They found that the addition of $\mathrm{CeO}_{2}$ could improve the thermal stability of alumina support. Specifically, the improvement of the catalytic performance of Ce-doped catalysts was mainly related to the significant improvement of $\mathrm{Ni}$ dispensability and the increase of the oxygen vacancy on the catalyst surface (Guilera et al., 2019). Besides, the addition of Ce could improve the catalytic activity of the catalyst by promoting the dispersion of the metallic $\mathrm{Ni}$ on the support. Bacariza et al. (2018b) reported that the $\mathrm{CO}_{2}$ conversion and $\mathrm{CH}_{4}$ selectivity over the $\mathrm{Ni}-\mathrm{Ce} /$ Zeolite catalyst were significantly enhanced and it remained active at low temperature after the addition of $\mathrm{Ce}$, which was mainly attributed to the effect of Ce on the reducibility of $\mathrm{Ni}$ species and the high permittivity of $\mathrm{Ce}$.

In the case of $Y$ dopant, it was reported that oxygen vacancies would be generated after its introduction (Qin et al., 2019). Besides, the strong interaction between the oxygen vacancies and the oxygen in the $\mathrm{CO}_{2}$ could weaken the strength of the $\mathrm{C}=\mathrm{O}$ bond in $\mathrm{CO}_{2}$ molecule, which finally would inhibit the production of carbon deposits and promote the conversion of $\mathrm{CO}_{2}$ to methane at low temperature (Liang et al., 2019b). Therefore, Y displays an important role in improving catalytic activity. In addition, the $\mathrm{Y}$ incorporated catalysts usually exhibit excellent structural properties, such as large specific surface area, big pore volume, and narrow average pore size (Hwang et al., 2012). Takano et al. (2016) reported that the activity of the Ydoped $\mathrm{Ni} / \mathrm{ZrO}_{2}$ catalyst was higher than that of the $\mathrm{Ni} / \mathrm{ZrO}_{2}$ catalyst at all the doping concentration.

\section{Noble metals}

Noble metals, such as $\mathrm{Ru}, \mathrm{Pd}$, and $\mathrm{Pt}$, can evidently promote the dispersion and stabilization of $\mathrm{Ni}$ nanoparticles in the catalyst, which can contribute to the enhancement of the catalytic activity at low temperature. Besides, the precious metal can not only change the $\mathrm{H}_{2}$ adsorption capacity of the catalyst, but also provide more active centers for adsorbing and activating hydrogen (Kim et al., 2015). Mihet and Lazar (2018) carefully studied the catalytic effects of $\mathrm{Rh}, \mathrm{Pd}$, and Pt. Figure 15 demonstrated catalytic activity of catalysts. As shown, the $\mathrm{CO}_{2}$ conversion and $\mathrm{CH}_{4}$ selectivity over the $\mathrm{Ni} / \mathrm{Al}_{2} \mathrm{O}_{3}$ catalysts doped with Pt or Pd were significantly higher than those without modification. Meanwhile, the doping of noble metal could also 

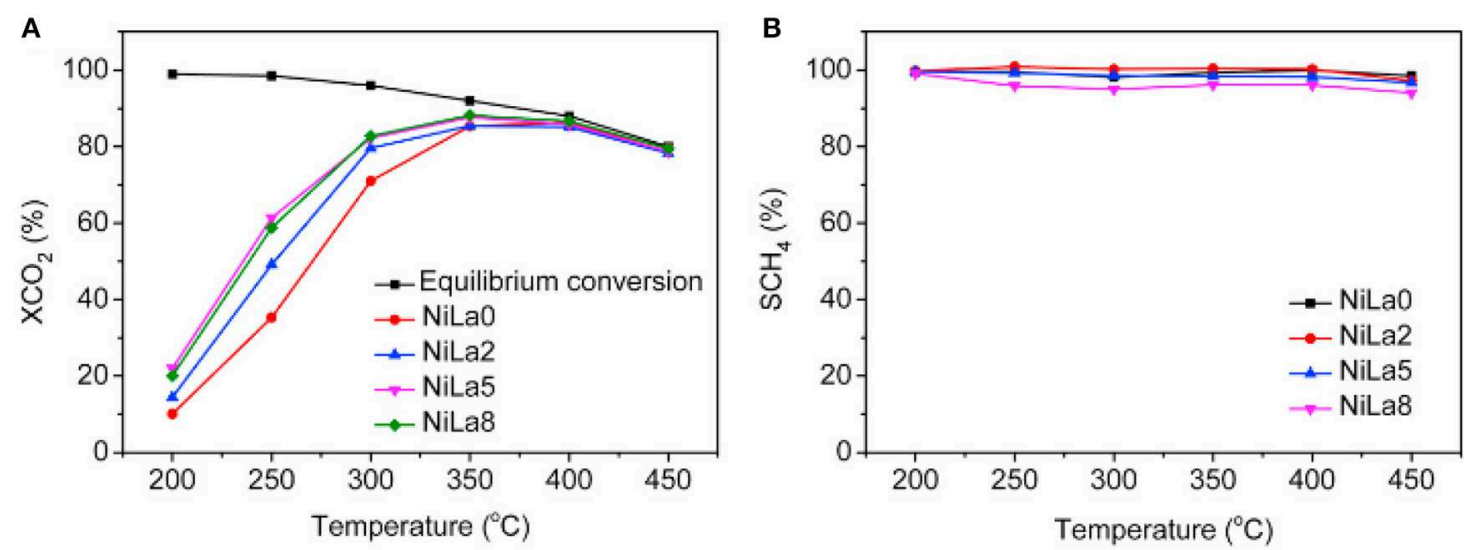

FIGURE 13 | (A) $\mathrm{CO}_{2}$ conversion and (B) $\mathrm{CH}_{4}$ selectivity vs. temperature for the NiLax (x= 0, 2, 5, 8) catalysts. Reproduced from Zhang G. et al. (2018) with permission from Elsevier and Copyright Clearance Center.

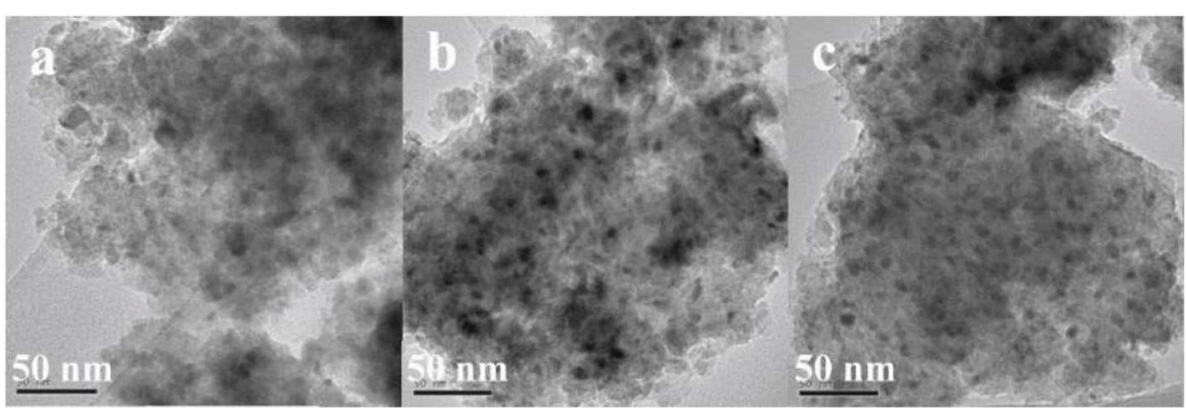

FIGURE 14 | TEM images of the reduced catalysts: (a) NiLaO, (b) NiLa2, (c) NiLa5. Reproduced from Zhang G. et al. (2018) with permission from Elsevier and Copyright Clearance Center.

increase the interface between the metal and support, further enhancing the $\mathrm{H}_{2}$ chemisorption capacity. In addition, Zamani et al. (2015) reported that the addition of noble metals could further increase the reducibility of the catalyst and enhance the activation of $\mathrm{CO}_{2}$. Therefore, the doping of the precious metal is a significance method of enhance the catalytic performance (Ocampo et al., 2011).

In the case of $\mathrm{Ru}$, the impregnation of its generally helps to reduce the particle size of the $\mathrm{Ni}$ active centers and thereby increase the surface area of the metallic Ni (Polanski et al., 2017). The high dispersion and narrow distribution of $\mathrm{Ni}-\mathrm{Ru}$ nanoparticles over the support are beneficial to increasing the activity and stability of the catalysts toward $\mathrm{CO}_{2}$ methanation (Shang et al., 2018; Navarro-Jaén et al., 2019). Sharma et al. (2011) found that $\mathrm{Ru}$ could accelerate the decomposition rate of carbonate reaction intermediate and inhibit the formation of sintering of the catalyst. Besides, the synergistic effect of the bimetallic $\mathrm{Ni}-\mathrm{Ru}$ can improve the chemisorption capacity of the catalyst for $\mathrm{H}_{2}$, but $\mathrm{Ru}$ has no significantly promoting effect on the adsorption capacity of $\mathrm{CO}_{2}$ (Liu et al., 2018a).

For the single metal catalysts, Pd based catalyst often displays much higher catalytic activity but lower $\mathrm{CH}_{4}$ selectivity than the Ni-based catalyst (Beaumont et al., 2014). Therefore, it was believed that the bimetallic Ni-Pd catalyst could achieve better catalytic performance due to the synergistic effect between Pd and Ni (Oemar et al., 2015). Li B. et al. (2019) found that the catalytic performance of the bimetallic Ni-Pd/SBA-15 catalyst was better than that of the corresponding monometallic $\mathrm{Ni}$ and $\mathrm{Pd}$ counterparts. The strong interaction between $\mathrm{Ni}$ and $\mathrm{Pd}$ existed on the catalyst by forming bimetallic $\mathrm{Ni}-\mathrm{Pd}$ alloy and the charge transfer from $\mathrm{Pd}$ to $\mathrm{Ni}$ atoms caused surface $\mathrm{Ni}$ atoms to receive more negative charge. Specifically, the charge transference from $\mathrm{Pd}$ to $\mathrm{Ni}$ atoms caused the surface $\mathrm{Ni}$ atoms to accumulate lots of negative electrons, which can promote the adsorption and dissociation of $\mathrm{CO}_{2}$ (Steinhauer et al., 2009).

\section{Composite Additives}

Recently, the composite additives have been gradually attracted more and more attention due to their outstanding catalytic performances because the composite additives can combine the advantages of different additives together to achieve enhanced catalytic performance toward $\mathrm{CO}_{2}$ methanation (Toemen et al., 2016). Generally, the catalysts doped with composite additives usually exhibit higher thermal sintering resistance and better stability than the counterpart with single 


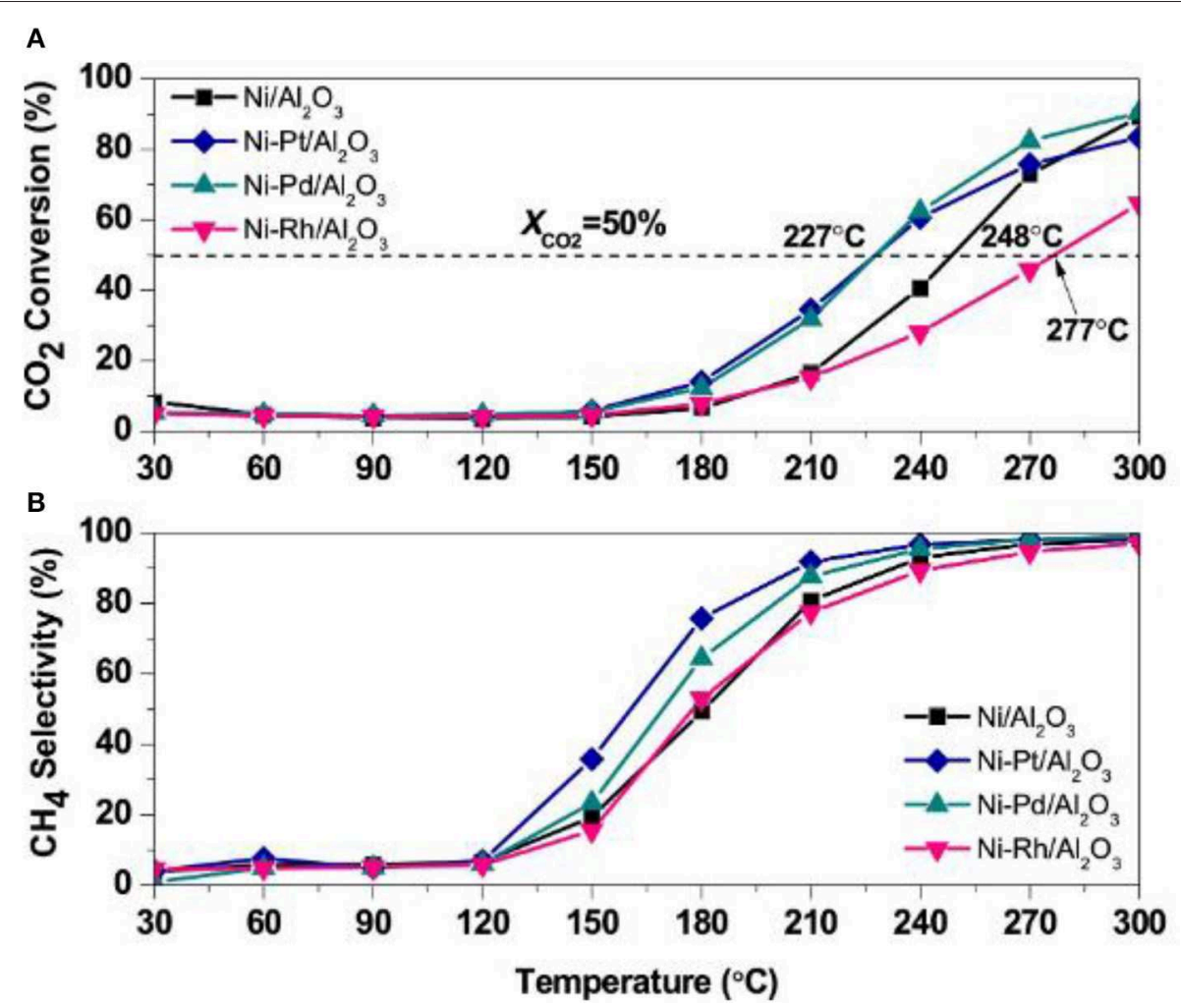

FIGURE 15 | (A) $\mathrm{CO}_{2}$ conversion, and (B) $\mathrm{CH}_{4}$ selectivity profiles obtained during TPRea runs on Ni/ $\gamma-\mathrm{Al}_{2} \mathrm{O}_{3}, \mathrm{Ni}-\mathrm{Pt} / \gamma-\mathrm{Al}_{2} \mathrm{O}_{3}, \mathrm{Ni}-\mathrm{Pd} / \gamma-\mathrm{Al} \mathrm{O}_{3}$, and $\mathrm{Ni}-\mathrm{Rh} / \gamma-\mathrm{Al}_{2} \mathrm{O}_{3}$ $\left(\mathrm{CO}_{2}: \mathrm{H}_{2}=1: 4, \mathrm{GHSV}=5,700 \mathrm{~h}^{-1}\right)$. Reproduced from Mihet and Lazar (2018) with permission from Elsevier and Copyright Clearance Center.

additive due to the synergistic effect between different additives (Frontera et al., 2018).

It was reported that the combination of the electronic additive $\mathrm{Mn}$ and the lattice-defective additive $\mathrm{Mg}$ could greatly promote the dispersion of the active component, hinder the thermal sintering of the active component, and enhance the strong interaction between the support and metallic $\mathrm{Ni}$, thereby promoting the $\mathrm{CO}_{2}$ methanation reaction (Rahmani et al., 2014; Tan et al., 2019). Meanwhile, the electron transference between the composite additives has a positive effect on the activation and dissociation of $\mathrm{CO}_{2}$ on the catalyst surface (Ramezani et al., 2018). Besides, Zhou et al. (2018) found that the $\mathrm{Ni}$ particle size of the catalyst doped with $\mathrm{Mn}$ and $\mathrm{Mg}$ was significantly reduced compared to the catalysts with single additives. As shown in Figure 16, large $\mathrm{Ni}$ particles were presented with severely agglomerated on the Mn doped $\mathrm{Ni} / \mathrm{Al}_{2} \mathrm{O}_{3}$ and $\mathrm{Mg}$ doped $\mathrm{Ni} / \alpha-\mathrm{Al}_{2} \mathrm{O}_{3}$. However, the surface of dual promoter doped catalysts were homogeneously covered with $\mathrm{Ni}$ particles, which would facilitate the activation of $\mathrm{H}_{2}$ and $\mathrm{CO}_{2}$ conversion. Thus, adding $\mathrm{Mg}$ and $\mathrm{Mn}$ additives was considered as an effective method to improve catalytic performance of $\mathrm{Ni}$ based catalysts.

$\mathrm{Ru}$ and $\mathrm{Mn}$ composite additives can decrease the coke formation and then improve the stability of the catalyst during the $\mathrm{CO}_{2}$ methanation reaction (Kim et al., 2015). Besides, Ru and $\mathrm{Mn}$ promotes the adsorption and dissociation of $\mathrm{CO}_{2}$ because they can increase the surface active centers of the catalyst (Zamani et al., 2019). Wan Abu Bakar et al. (2015) compared the effects of $\mathrm{Mn}$ single additive and $\mathrm{Ru}-\mathrm{Mn}$ composite additive on the catalyst, respectively. They found that $\mathrm{Ru} / \mathrm{Mn} / \mathrm{Ni} / \mathrm{Al}_{2} \mathrm{O}_{3}$ exhibited better catalytic activity than $\mathrm{Mn} / \mathrm{Ni} / \mathrm{Al}_{2} \mathrm{O}_{3}$. The $\mathrm{CO}_{2}$ conversion of the $\mathrm{Ru} / \mathrm{Mn} / \mathrm{Ni} / \mathrm{Al}_{2} \mathrm{O}_{3}$ catalyst could be as high as $99.7 \%$ at $300^{\circ} \mathrm{C}$. Specifically, the high $\mathrm{CO}_{2}$ conversion was probably due to the $\mathrm{Mn}$ species which caused the removal of $\mathrm{Cl}$ ions from $\mathrm{RuCl}_{3}$ precursor and increased the density of active $\mathrm{Ru}$ oxide species on the catalyst which resulted in the high catalytic activity.

$\mathrm{Mn}-\mathrm{Fe}$ has been described as efficient composite additives because both $\mathrm{Mn}$ and $\mathrm{Fe}$ could promote the adsorption and activation of $\mathrm{CO}_{2}$, which is considered as an important part of $\mathrm{CO}_{2}$ methanation (Rahmani et al., 2014; Li et al., 2018d). In addition, the modification of $\mathrm{Mn}$ can increase the density of the basic sites on the catalyst, further enhancing the low-temperature catalytic activity (Burger et al., 2018). The thermal stability of the catalyst can be intensified by doping Fe because the Ni-Fe alloy forming during the catalytic process allows $\mathrm{Ni}$ to be uniformly dispersed on the catalyst surface (Zagaynov et al., 2019). Furthermore, it was reported that the reduced $\mathrm{Fe}$ and $\mathrm{Mn}$ would interact with the metallic $\mathrm{Ni}$ phase, thereby affecting the equilibrium state between the $\mathrm{Ni}$ atoms and causing an alleviated reducibility of the active Ni phase. 


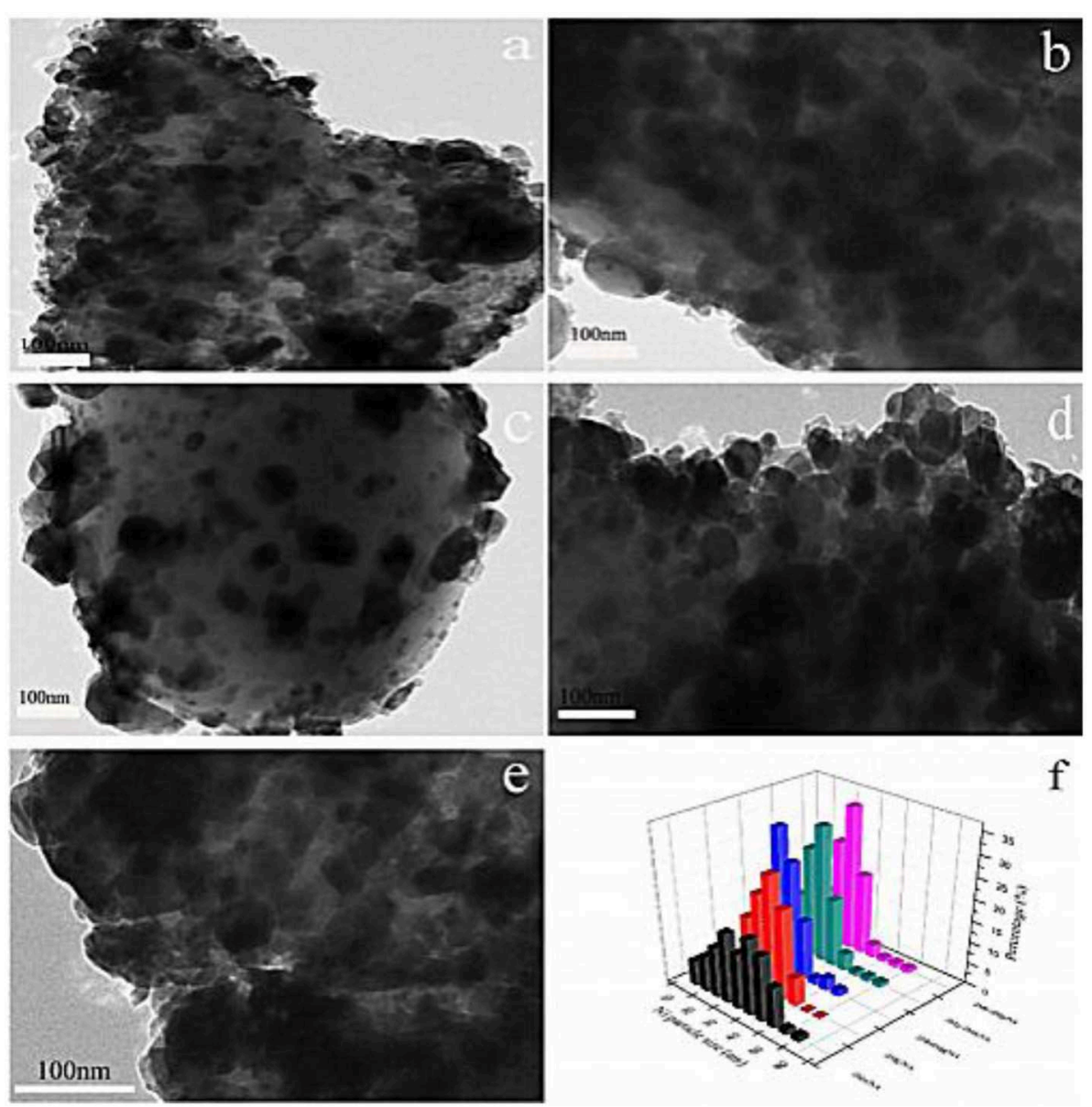

FIGURE 16 | HRTEM images of (a) $2 \mathrm{Mn}$, (b) $2 \mathrm{Mg}$, (c) 2Mn2Mg, (d) $2 \mathrm{Mg}-2 \mathrm{Mn}$, (e) $2 \mathrm{Mn}-2 \mathrm{Mg}$, and (f) particle distribution of reduced catalysts. Reproduced from Zhou et al. (2018) with permission from Elsevier and Copyright Clearance Center.

\section{Summary}

In general, the alteration of the supports and the addition of the additives have been the main research line of Ni-based catalysts. The researches on supports were mainly carried out from multiple perspectives such as increasing the surface area, changing the channel structure, and adjusting the pore diameter, which could benefit the dispersion of the metallic Ni active sites. The research of catalytic additives mainly included the above four parts, including the alkaline earth metal oxides, transition metals, rare earth metal oxides, and noble metals, which contributed to the activation of the $\mathrm{CO}_{2}$ at low temperature. The development of Ni-based catalysts with low-temperature catalytic activity should focus on the interaction of additives and supports in catalytic reactions in the future.

\section{PREPARATION CONDITIONS OF NI-BASED CATALYST}

Generally, the physicochemical properties of the Ni based catalyst and its catalytic activity are greatly affected by the preparation conditions, such as the preparation method and calcination conditions (Bacariza et al., 2015). Specifically, calcination is considered as a decisive step in changing the performance of the catalyst. An increase in the calcination temperature can change the position as well as type of metallic Ni active centers on the support and decrease the porosity of the catalyst (Zhang et al., 2011). Besides, the preparation method also has significant effects on the properties of the catalysts, such as surface alkalinity, reducibility of the Ni species. It was reported that the reducibility of Ni species could be improved over the catalyst prepared by hydrothermal method (Guo et al., 2018). In addition, the $\mathrm{Ni}$ loading over the catalyst also greatly influences the catalytic performances. Specifically, only the moderate loading amount of $\mathrm{Ni}$ can significantly increase the catalytic activity and the thermal sintering of Ni particles will cause blockage of the pores of the support (Lechkar et al., 2018).

\section{Preparation Method}

The dispersion of $\mathrm{Ni}$ active components and the metal-support interaction are closely related to the catalyst activity, which was strongly influenced by the preparation method. Therefore, preparation method of catalyst is an importantly influential 
TABLE 2 | Specific advantages and disadvantages of the preparation methods.

\begin{tabular}{|c|c|c|}
\hline Preparation method & Advantages & Disadvantages \\
\hline Impregnation method & It is easy to operate. & $\begin{array}{l}\text { The metal particles of the catalyst are unevenly distributed } \\
\text { in the pores of the porous material. }\end{array}$ \\
\hline Precipitation method & $\begin{array}{l}\text { (1) It is easy to operate. } \\
\text { (2) The size and distribution of the metal particles are } \\
\text { relatively uniform. }\end{array}$ & $\begin{array}{l}\mathrm{PH} \text { value and temperature have greatly impacts on the } \\
\text { catalyst. }\end{array}$ \\
\hline Sol-gel method & $\begin{array}{l}\text { (1) Outstanding stability. } \\
\text { (2) Good catalytic performance. } \\
\text { (3) High Ni dispersion. }\end{array}$ & Long response time. \\
\hline Plasma method & $\begin{array}{l}\text { (1) Reduce the particle size of the catalyst. } \\
\text { (2) Improve the dispersion of } \mathrm{Ni} \text {. } \\
\text { (3) Enhance the interaction between the } \mathrm{Ni} \text { and the support. }\end{array}$ & $\begin{array}{l}\text { (1) Immature technology. } \\
\text { (2) High requirements for operation parameters. }\end{array}$ \\
\hline Urea hydrolysis method & Not affected by $\mathrm{pH}$. & - \\
\hline Ammonia evaporation method & Enhanced metal-support effect of the catalyst. & - \\
\hline Microwave assisted method & $\begin{array}{l}\text { (1) Short reaction time. } \\
\text { (2) Uniform heating for the substances with same microwave } \\
\text { absorbing properties. }\end{array}$ & - \\
\hline
\end{tabular}

factor to improve catalytic performance (Guilera et al., 2019). The specific advantages and disadvantages of the preparation methods are summarized in Table 2. Each method has its own unique advantage. The impregnation method has been considered as a cheap and efficient method, which mainly employs the capillary pressure to push the active components into the pore channels of the support (Romero-Sáez et al., 2018). Besides, the catalyst prepared by coprecipitation usually has a large specific surface area (Beierlein et al., 2019). The sol-gel method can promote the high dispersion of active components on the support (Moghaddam et al., 2018). Solution combustion is a simple and easy technique for the operation, where the oxidant is the metal nitrate and the reducing agent is the fuel. The fuel not only provides energy for the reaction, but also mixes with metal cations. Thus, the catalyst prepared by solution combustion method usually has good catalytic activity (Zhao et al., 2012; Jiang et al., 2018; Xanthopoulou et al., 2018).

Beierlein et al. (2019) prepared Ni-based catalysts by dry impregnation (DI), wet impregnation (WI), sedimentation precipitation (DP), and coprecipitation (CP) methods. For catalysts prepared with $\mathrm{CP}$ and $\mathrm{DI}$, it was found that the pore size distribution was related to the mass fraction of $\mathrm{Ni}$. As the comparison, the pore size distribution of the catalyst prepared by DP and WI was not affected by the Ni loading. The saturation concentration of $\mathrm{Ni}$ loading existed during the wet impregnation due to the limitation of solubility. The saturation concentration hindered the maximum Ni loading amount over the support. Therefore, the structure of the catalyst prepared by WI was not affected as the Ni loading increased. During the drying process of the impregnated catalyst, $\mathrm{Ni}$ species gradually entered the mesopores of the supports with the increase of the Ni loading. In the DP catalyst, nickel hydroxide did not form a precipitate in the solution. The increase in the Ni loading could greatly result in a significant increase in the $\mathrm{Ni}$ surface area, which in turn affected the catalytic activity in the form of $\mathrm{CO}_{2}$ conversion. In addition, if it is aimed to improve the dispersion of $\mathrm{Ni}$ species on the surface of the catalyst, the deposition precipitation method and the coprecipitation method will be considered as better candidates because the surface area of the catalyst the surface area of Ni nanoparticles prepared by the precipitation method are usually large, which is an important factor for promoting the $\mathrm{CO}_{2}$ conversion. Besides, Jiang et al. (2018) prepared $\mathrm{Ni}$ /bentonite catalyst by solution combustion method (SCS). Compared with the catalyst prepared by the impregnation method (IMP), Ni species were provided with higher dispersion, narrower particle size distribution, and larger specific surface area, thereby promising outstanding catalytic activity. As shown in Figure 17, the activity of the catalyst prepared by the SCS method was better than that of IMP catalyst.

In recent years, the researchers have also investigated and developed new preparing methods by employing new technologies, such as microwave assisted method, plasma method, and urea hydrolysis method. Compared with the coprecipitation method, the catalyst prepared by the ultrasonic assisted coprecipitation method has a larger surface area and pore volume, and more uniform $\mathrm{Ni}$ nanoparticle distribution (Daroughegi et al., 2017). Daroughegi et al. (2019) found that the use of ultrasonic irradiation during precipitation could inhibit the agglomeration of $\mathrm{Ni}$ particles. Besides, the catalyst prepared by the oxalate method and the ammonia evaporation method also has excellent catalytic performance at a relatively low reaction temperature owing to the outstanding stability of the catalyst (Lo Faro et al., 2015; Ashok et al., 2017). The citric acid complication is superior to traditional impregnation because it can effectively reduce the particle size and promote the dispersion of Ni species, which is beneficial to the intrinsic activity of the catalyst (Tan et al., 2019). The plasma is composed of ionized ions, which is featured as high efficiency, less pollution, and simple operation, and high reactivity. A synergistic effect between the plasma and the catalyst allows the $\mathrm{CO}_{2}$ methanation reaction to proceed at a lower temperature (Biset-Peiró et al., 2019; Wierzbicki et al., 2019). Specifically, the textural properties, such as surface area 


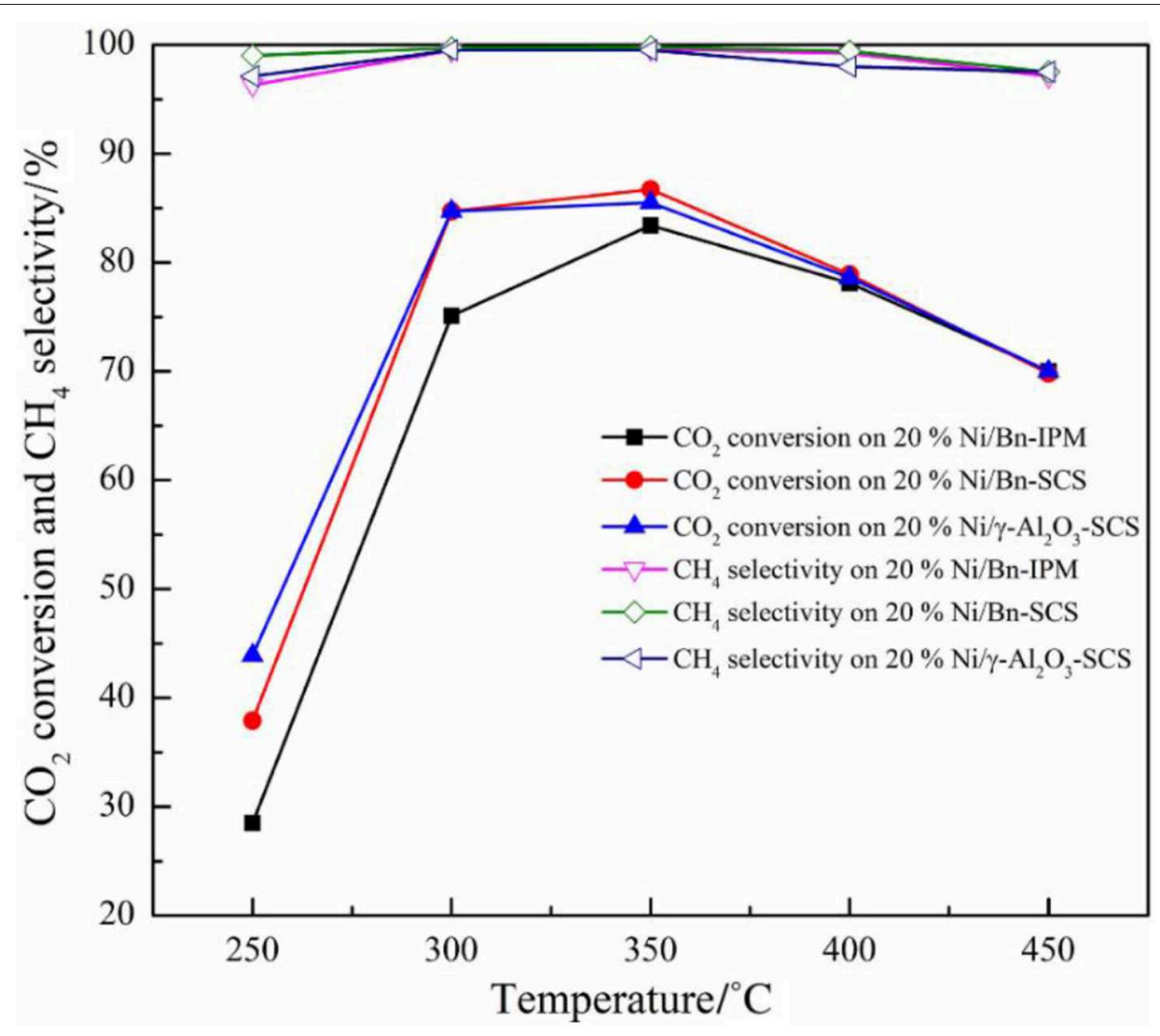

FIGURE 17 | The catalytic activity of Ni/Bn-IPM, Ni/Bn-SCS, and Ni/ $\gamma-\mathrm{Al}_{2} \mathrm{O}_{3}$ catalyst was for $\mathrm{CO}_{2}$ methanation. Reaction conditions: $\mathrm{V}\left(\mathrm{H}_{2}\right) / \mathrm{V}(\mathrm{CO} 2)=4: 1$, atmospheric pressure, GHSV $=3,600 \mathrm{ml} \cdot(\mathrm{g} \mathrm{cat})^{-1} \cdot \mathrm{h}^{-1}$. Reproduced from Jiang et al. (2018) with permission from Elsevier and Copyright Clearance Center.

and pore volume, of the Ni-based catalyst prepared by the plasma method will be better than those of traditional catalyst. Furthermore, it was reported that $\mathrm{Ni}$ based catalysts prepared by plasma have higher $\mathrm{Ni}$ dispersion and $\mathrm{CO}_{2}$ adsorption capacity (Xiong et al., 2019). Therefore, great efforts have been devoted to the study of plasma methods (Bian et al., 2015). Debek et al. (2019) used the low-pressure glow discharge plasma method to prepare a Ni-based catalyst, which could impede carbon deposition on the catalyst and enhance the stability of the catalyst under low pressure conditions. As regards the microwave assisted method, its main characteristic is that microwave is used as the heat source. As an energy-efficient technology, the microwave assisted method can shorten the reaction time because the microwave can simultaneously heat the bulk and surface parts of the catalyst from the molecular level (Jing et al., 2018). The microwave assisted method can also be combined with the coprecipitation method or sol-gel method, which can achieve better catalytic effects and performances (Dong et al., 2018). Song et al. (2017) investigated Ni based catalysts supported on $\mathrm{Al}_{2} \mathrm{O}_{3}$ prepared by impregnation (I) and microwave assisted methods $(\mathrm{M})$. The $\mathrm{CO}_{2}$ conversion rates of $\mathrm{NiAl}_{2} \mathrm{O}_{3}-\mathrm{M}$ were higher than that of $\mathrm{NiAl}_{2} \mathrm{O}_{3}$ - $\mathrm{I}$ at the equal amount of $\mathrm{Ni}$ loadings in Figure 18, which may be attributed to the high dispersion of $\mathrm{Ni}$ nanoparticles. As shown in Figure 19, the metallic $\mathrm{Ni}$ diffraction peaks could not be observed over $\mathrm{Ni}_{2} \mathrm{OAl}_{2} \mathrm{O}_{3}-\mathrm{M}$ catalyst, indicating that the Ni particles were highly dispersed in nano size state, lower than the XRD detection limit $(3.0 \mathrm{~nm})$. As

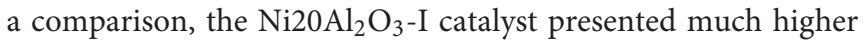
metallic Ni diffraction peaks, suggesting the worse dispersion of metallic Ni particles. Therefore, the microwave method could facilitate the uniform distribution of $\mathrm{Ni}$ on the support. In addition, microwave assisted method contributes to greater catalytic stability and sintering resistance of the catalyst (Dong et al., 2018). As for the urea hydrolysis method, it uses urea as a precipitant and can react with metal precursors controllably at relatively low temperatures. As a result, the $\mathrm{CO}_{2}$ adsorption capacity of the catalyst prepared by the urea hydrolysis method is stronger than that of the catalyst prepared by the coprecipitation method (Zhang et al., 2018a). Layered double hydroxides (LDHs) materials are mixed hydroxides of di- and tri-valent metals, present in the brucite like layers with anions present between the layers (Wierzbicki et al., 2019). Ni based catalysts prepared by synthesizing $\mathrm{LDH}$ as precursor have attracted considerable interests for $\mathrm{CO}_{2}$ methanation because the catalytic activity of the catalyst was improved compared to Ni-based catalysts prepared by conventional methods like impregnation (Li et al., 2016). Specifically, the high sorption capacity for $\mathrm{CO}_{2}$ in the layered space was crucial for the methanation of $\mathrm{CO}_{2}$ reaction (Guo et al., 2016). In addition, it was reported that DLHs formed nano-oxides after appropriate thermal 

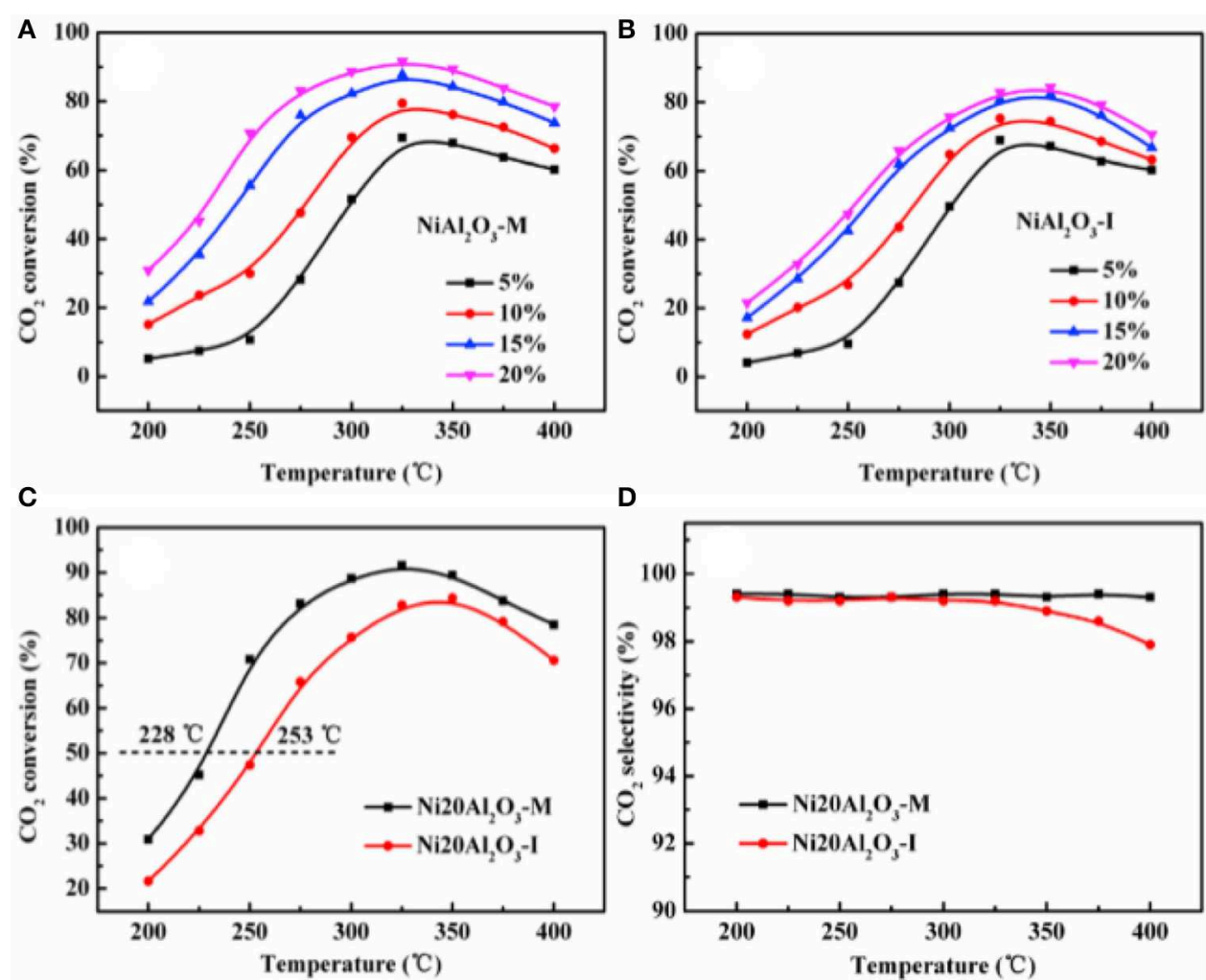

FIGURE 18 | The $\mathrm{CO}_{2}$ conversion over the catalysts (A-C): (A) NiAl $\mathrm{O}_{3}-\mathrm{M}$ with different $\mathrm{Ni}$ loadings; (B) $\mathrm{NiAl}_{2} \mathrm{O}_{3}-\mathrm{I}$ with different $\mathrm{Ni}$ loadings; (C) $\mathrm{Ni2OAl} \mathrm{O}_{3}-\mathrm{M}$ and $\mathrm{Ni}_{2} \mathrm{Al}_{2} \mathrm{O}_{3}$-I; (D) the $\mathrm{CH}_{4}$ selectivity over $\mathrm{Ni}_{2} \mathrm{OAl}_{2} \mathrm{O}_{3}-\mathrm{M}$ and $\mathrm{Ni}_{2} \mathrm{OAl}_{2} \mathrm{O}_{3}-$ I. Reproduced from Song et al. (2017) with permission from Elsevier and Copyright Clearance Center.

treatment whose strong interaction hindered $\mathrm{Ni}$ from sintering (Liu J. et al., 2015).

\section{Nickel Loading}

Recently, the influence of the metallic Ni loading content on the catalytic performance of different catalysts has been widely reported (Su et al., 2016). Within a certain range, the activity of the catalyst can increase with the increase of the $\mathrm{Ni}$ loading amount due to providing sufficient active centers. Besides, the metal loading amount also can affect the reduction property of the catalyst (Wierzbicki et al., 2017). Zhang Z. et al. (2019) found that the reverse water gas shift (RWGS) side reaction had a competitive relationship with the $\mathrm{CO}_{2}$ methanation reaction in the case of low nickel loading amount and the high nickel loading (around 25\%) was beneficial to the enhancement of the $\mathrm{CO}_{2}$ methanation reaction. As shown in Figure 20, the $\mathrm{CO}_{2}$ methanation reaction gradually dominated with the increase of the Ni loading amount. They found that the catalyst could achieve the best activity for methanation and low yield of CO when the Ni loading was $20 \mathrm{wt} \%$. Therefore, it could be concluded that the increase of active sites $\left(\mathrm{Ni}^{0}\right)$ was beneficial to the achievement of high $\mathrm{CO}_{2}$ conversion. However, when the nickel loading amount exceeded a certain range, further increasing the loading amount would cause seriously thermal agglomeration of the metallic nickel active centers, thereby destroying the structure of the catalyst (Quindimil et al., 2019). Ocampo et al. (2011) found that the charge of nickel cation and its coordination state in the crystal lattice affected its solubility in the $\mathrm{CeO}_{2}-\mathrm{ZrO}_{2}$ structure. In the $\mathrm{CZ}$ bimetal architecture, it would compete with $\mathrm{Zr}^{4+}$, resulting in a decrease in $\mathrm{NiO}$ concentration on the catalyst surface when the concentration of $\mathrm{Ni}^{2+}$ increased. Furthermore, they found that high $\mathrm{Ni}$ species loading would result in the formation of abundant $\mathrm{Ni}$ active centers and improved low temperature $\mathrm{CO}_{2}$ methanation performance (Lin et al., 2019). Therefore, the reactivity of the catalyst varied with the loading of the active component.

It was reported that the loading amount of $\mathrm{Ni}$ supported on the catalyst has a significant effects on both the dispersion of $\mathrm{Ni}$ on the catalyst surface and metal-support interaction, which in turn affects the catalytic behavior. Overall, the dispersion of the metallic $\mathrm{Ni}$ active centers decreases as the loading increases (Quindimil et al., 2019). Ali Lechkar et al. (2018) preliminarily found that at least two different $\mathrm{CO}_{2}$ methanation reaction sites existed in a Ni-based catalyst, which was identified as $\mathrm{Ni}$ crystals from $\mathrm{NiO}$ reduction and the $\mathrm{Ni}$ atoms surrounded by oxygen atoms in the alumina crystal lattice. More reactive sites can be associated with readily reducible $\alpha$ and $\beta \mathrm{NiO}$ species, while less reducible $\mathrm{x}-\mathrm{NiO}$ species may be associated with less reactive sites. They also found that lots of $\mathrm{r}$-type 
$\mathrm{NiO}$ species with less reducibility existed on the catalyst when the Ni loading was low. However, $\beta$-type materials with more reducibility and reactivity are dominant under conditions of high nickel loading. $\beta$-type $\mathrm{NiO}$ species play a pivotal role as the main active centers for the methanation reaction (Alihosseinzadeh et al., 2015). Therefore, the effect of metallic Ni loading amount on the catalytic performance of the catalyst can be attributed to the increase in the number of active centers over the catalyst surface.

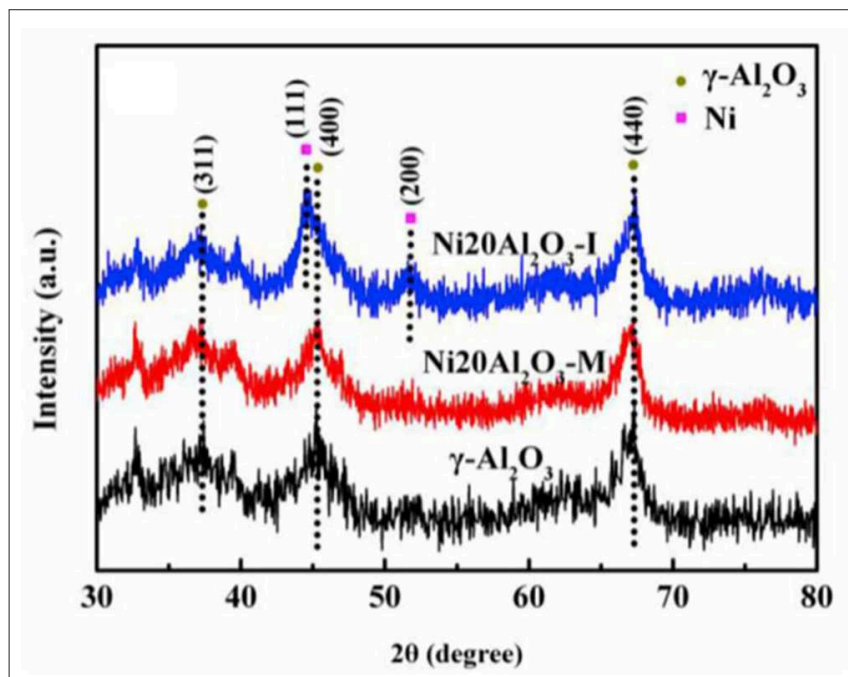

FIGURE $19 \mid X R D$ patterns of $\mathrm{Al}_{2} \mathrm{O}_{3}, \mathrm{Ni}_{2} \mathrm{OAl}_{2} \mathrm{O}_{3}-\mathrm{M}$ and $\mathrm{Ni}_{2} \mathrm{OAl}_{2} \mathrm{O}_{3}-\mathrm{I}$. Reproduced from Song et al. (2017) with permission from Elsevier and Copyright Clearance Center.

\section{Calcination Temperature}

It was well-known that the activity of Ni-based catalysts could largely depend on the calcination temperature because it could change the dispersion of active metal particles and influence the activation of the catalytic center of the catalyst, thereby affecting the activity of the catalyst (Al-Fatesh and Fakeeha, 2012; Özdemir et al., 2014; Al-Fatesh et al., 2019).

The local structure of the catalyst framework would be destroyed during calcination process, especially at high temperature. Therefore, the pore size of the catalyst decreases with the calcination temperature increasing due to the thermal shrinkage of the framework (Zamani et al., 2019). Commonly, the lower calcination temperature is beneficial to preventing the agglomeration of $\mathrm{Ni}$ species. Sun et al. (2007) found that increasing the calcination temperature would cause a sharp decrease in the surface area of the structure, resulting in the collapse of the porous structure. In addition, the $\mathrm{Ni}$ particles could migrate from the outer surface to internal positions with the increase of the calcination temperature, which is usually considered as the main reason for the improvement in the catalytic activity. However, the increase in the calcination temperature can also reduce the dispersion of the Ni species, resulting in a lower catalytic activity (Bacariza et al., 2015). Zhang C. et al. (2018) studied the reducibility of $\mathrm{Ni} / \mathrm{Al}_{2} \mathrm{O}_{3}$ catalysts at different calcination temperatures. As shown in Figure 21 with the increase of the calcination temperature, the main reduction peak of the catalyst shifted to high temperature. When the calcination temperature was higher than $650^{\circ} \mathrm{C}$, the reduction degree of the catalyst gradually decreased. This indicated that the increase of calcination temperature intensified the strong metalsupport interaction between the nickel and the alumina support,

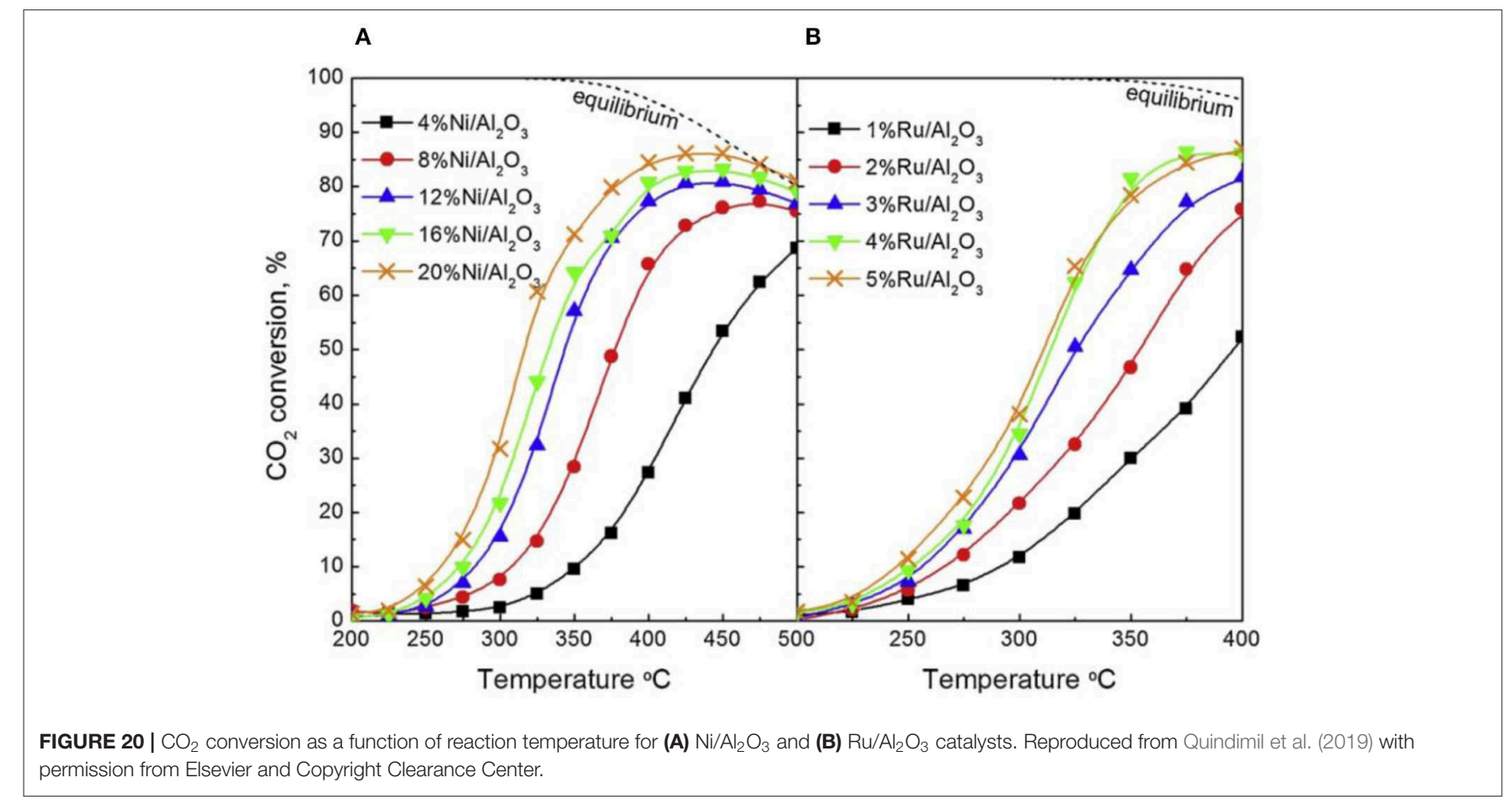



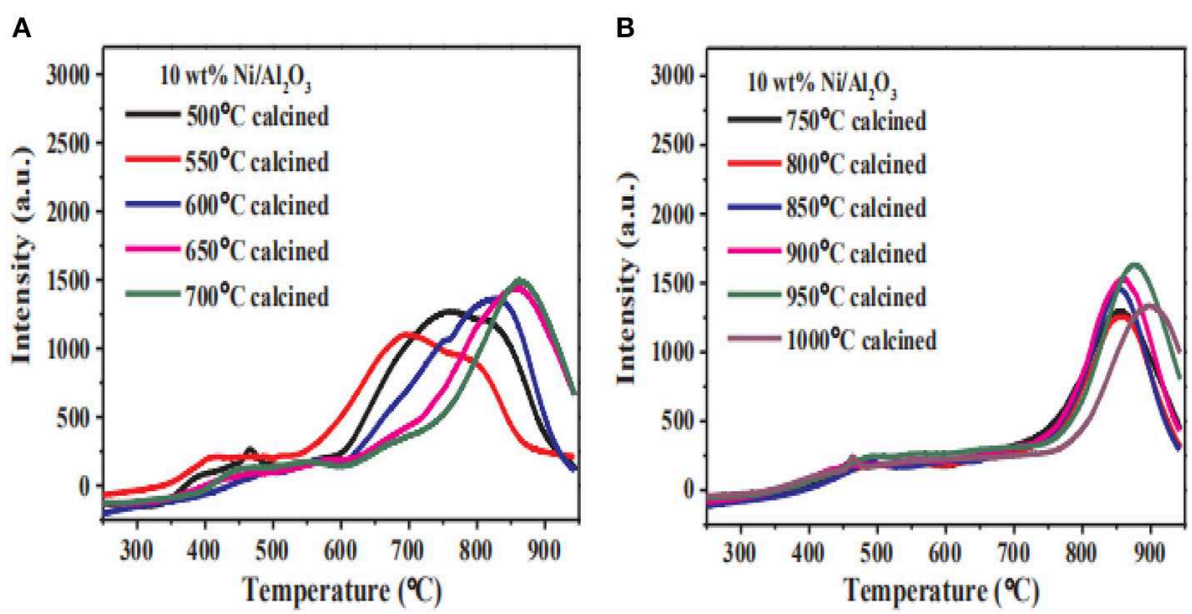

FIGURE 21 | $\mathrm{H}_{2}$-TPR and reduction degree for the $\mathrm{Ni} / \mathrm{Al}_{2} \mathrm{O}_{3}$ catalysts with different calcination temperature (T). (A) $\mathrm{T}=500,550,600,650,700^{\circ} \mathrm{C}$ and (B) $\mathrm{T}=700$, 750, 800, 850, 900, 950, $1000^{\circ} \mathrm{C}$. Reproduced from Zhang C. et al. (2018) with permission from Elsevier and Copyright Clearance Center.
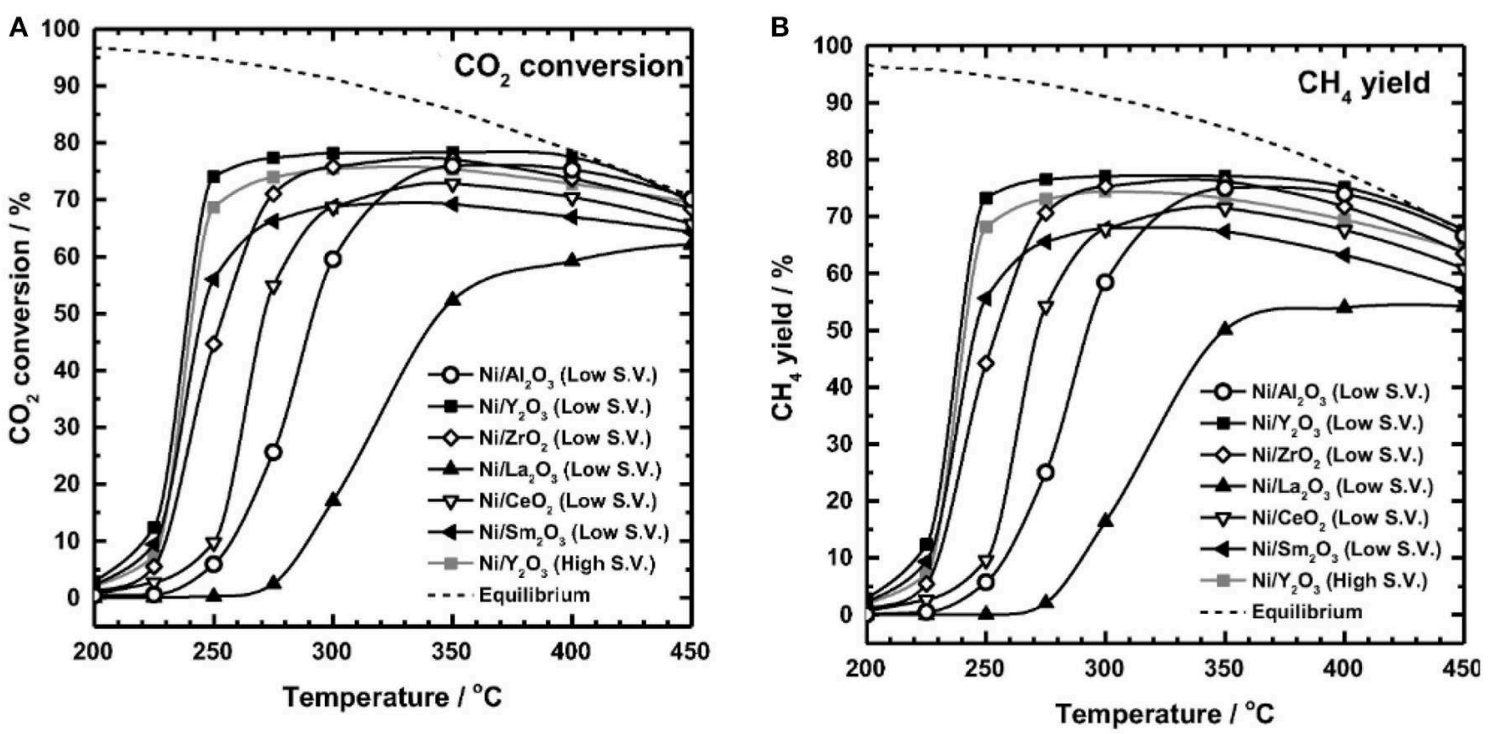

FIGURE 22 | (A) $\mathrm{CO}_{2}$ conversion, and (B) $\mathrm{CH}_{4}$ yields in $\mathrm{CO}_{2}$ methanation over 10 wt.\% Ni/metal oxide catalysts $\left(\mathrm{Al}_{2} \mathrm{O}_{3}, \mathrm{Y}_{2} \mathrm{O}_{3}, \mathrm{ZrO}_{2}, \mathrm{La}_{2} \mathrm{O}_{3}, \mathrm{CeO}_{2}, \mathrm{Sm}_{2} \mathrm{O}_{3}\right)$. Reaction gas: $10 \% \mathrm{CO}_{2}-40 \% \mathrm{H}_{2}-50 \% \mathrm{~N}_{2}$. Low S.V.: $20,000 \mathrm{~kg}^{-1} \mathrm{~h}^{-1}$. High S.V.: $30,000 \mathrm{I} \mathrm{kg}^{-1} \mathrm{~h}^{-1}$. Reproduced from Muroyama et al. (2016) with permission from Elsevier and Copyright Clearance Center.

which could make the reduction of the $\mathrm{Ni}$ species in $\mathrm{H}_{2}$ stream very difficult.

\section{Summary}

Overall, the preparation strategies and conditions can directly affect the catalytic performance of the catalyst by influencing the morphology and promoting the dispersion of metallic $\mathrm{Ni}$ active components. Besides, the calcination temperature and the metallic Ni loading amount are commonly used to improve catalyst performance. Therefore, great efforts will still be devoted to promote the low-temperature activity of the catalysts by employing different preparation methods.

\section{THE INFLUENCES OF REACTION CONDITIONS FOR NI-BASED CATALYST TOWARD $\mathrm{CO}_{2}$ METHANATION}

The reaction conditions of the Ni-based catalyst, such as reaction temperature, gas hourly space velocity, etc., have important influences on the $\mathrm{CO}_{2}$ methanation process. Younas et al. (2018) used a quadratic model to correlate variable parameters such as methanation temperature, humidity, and catalyst mass with the effect of $\mathrm{CO}_{2}$ concentration. Their studies showed that the reaction temperature and humidity had an important impact on $\mathrm{CO}_{2}$ methanation. 
The reaction temperature is considered as the dominant factor in the activity of Ni-based catalysts (Stangeland et al., 2017b). Ni-based catalysts usually have low $\mathrm{CO}_{2}$ conversion at low temperatures because the dissociation of $\mathrm{CO}_{2}$ chemical bonds requires higher activation energy. With the increase of the temperature, the $\mathrm{CO}_{2}$ molecule can acquire the desired activation energy and achieve the improvement in reactivity. However, the metallic $\mathrm{Ni}$ active centers easily suffer thermal sintering at high reaction temperature (Ma et al., 2011; Stangeland et al., 2017a; Tada et al., 2017). Muroyama et al. (2016) studied the effect of temperature on the catalytic performances over different catalysts. As shown in Figure 22, most of the investigated catalysts performed their respective maximum $\mathrm{CO}_{2}$ conversion and $\mathrm{CH}_{4}$ selectivity at $300-350^{\circ} \mathrm{C}$. However, further increasing the reaction temperature would cause the decrease of the catalytic activity and $\mathrm{CH}_{4}$ selectivity. From the viewpoint of thermodynamics, the high temperature and exothermic feature of $\mathrm{CO}_{2}$ methanation process can affect the thermodynamic equilibrium and deactivation of the catalyst. The high temperature facilitates the reverse water gas shift reaction and hinders the $\mathrm{CO}_{2}$ methanation reaction (Mutz et al., 2015; Pastor-Pérez et al., 2019).

In addition to the reaction temperature, the pressure and humidity are also considered as important ways to optimize the $\mathrm{CO}_{2}$ methanation process. Mutz et al. (2017) found that the $\mathrm{CO}_{2}$ conversion experienced significant increase in the temperature range of $250-450^{\circ} \mathrm{C}$ when the pressure increased from 1 bar to 10 bar. The phenomenon could be ascribed to deposited carbon amounts affected by the pressure. Carbon deposition is a significant factor affecting catalyst performance. Thus, the catalytic reactor should be operated at elevated pressure to avoid carbon formation (Jurgensen et al., 2015). Besides, it was found that increasing the humidity could increase the $\mathrm{CH}_{4}$ selectivity of the catalyst because the presence of water vapor had the positive effect of inhibiting the reverse water gas shift (RWGS) reaction and thereby promoting the conversion of $\mathrm{CO}_{2}$ to $\mathrm{CH}_{4}$ (Jiménez et al., 2010). However, the $\mathrm{CO}_{2}$ conversion rate and the $\mathrm{CH}_{4}$ selectivity are lowered with excessive humidity because the affluent water molecules can cover the metallic $\mathrm{Ni}$ active center of the catalyst (Zhang et al., 2018b). For example, Aziz et al. (2015) reported that the presence of water vapor had a negative effect on the catalytic of $5 \mathrm{Ni} / \mathrm{MSN}$ and alsocaused the structure collapse of MSN. Specifically, the structure collapse may be ascribed to the mechanochemical reaction through the hydrolysis of $\mathrm{Si}-\mathrm{O}-\mathrm{Si}$ bond in the presence of adsorbed water due to its hydrophilicity (Batista et al., 2005). The negative effect was possibly due to the formation of $\mathrm{CO}_{2}$ through the water gas shift (WGS) reaction between intermediate $\mathrm{CO}$ and the excess of water. In addition, water vapor may cause dilution of the gaseous reactants, inhibiting the interaction of $\mathrm{H}_{2}$ with $\mathrm{CO}_{2}$ (Younas et al., 2018).

Various methanation reactors have also been developed to avoid the thermal sintering of the $\mathrm{Ni}$-based catalysts and improve the catalytic performance. Common reactors include fixed-bed reactors and fluidized-bed reactors (Zimmermann et al., 2019). Fixed-bed reactors are widely used in industrial applications. The main concern of fixed-bed reactor research for $\mathrm{CO}_{2}$ methanation is the control of reactor temperature (Rönsch et al., 2016). Structured reactors are under development to overcome this drawback, which has better heat transfer capacities and lower pressure drops than traditional fixed bed reactors (Kreitz et al., 2019). Compared with fixed-bed reactors, fluidized-bed reactors have a higher $\mathrm{CO}_{2}$ conversion rate, which are closer to the point of thermodynamic equilibrium. Nevertheless, the fluidized-bed reactor also possesses its own disadvantages. Specifically, the fluidization of catalyst particles requires high mechanical stress of the particles and reactor walls, which will cause the loss of the catalyst and shorter reactor life Liu J. et al. (2015).

Generally, the development trend of catalysts should focus on the improvement of the low-temperature catalytic activity and the maintenance of the high catalytic stability in the future based on the previously investigated reaction.

\section{CATALYTIC APPLICATION OF NI-BASED CATALYSTS IN INDUSTRIALIZATION OF $\mathrm{CO}_{2}$ METHANATION}

With the continuous improvement of the awareness of environmental protection and the increasingly urgent task of reducing greenhouse gas emissions, the research on industrialization of $\mathrm{CO}_{2}$ methanation has been vigorously launched in the $21^{\text {st }}$ century. The catalysts of the industrial $\mathrm{CO}_{2}$ methanation is summarized in Table 3 (Golosman and Efremov, 2012). The Ni-based catalysts are generally selected for industrial methanation technology (Kopyscinski et al., 2009). However, various challenges still exists in industrial applications of Ni-based catalysts. Specifically, $\mathrm{CO}_{2}$ mathanation is a strongly exothermic reaction, which would cause thermal sintering of the metallic Ni-based catalyst (Kopyscinski et al., 2009). In addition, the stress by long-term operation and impurities in the feed could deactivate the catalyst (Wolf et al., 2019). Therefore, many

TABLE 3 | Summary of the Ni-based Catalysts for industrial $\mathrm{CO}_{2}$ methanation.

\begin{tabular}{|c|c|c|c|c|c|}
\hline Catalyst brand & Main active component & Operating temperature $/{ }^{\circ} \mathrm{C}$ & Pressure/Mpa & Lifetime & Conversion \\
\hline CRG-LH & $\mathrm{Ni}$ & $250-700$ & $1-6$ & $2-3$ years & $\geq 98 \%$ \\
\hline RANG-19 & $\mathrm{Ni}$ & $200-450$ & up to 4 & - & - \\
\hline MCR-2X & $\mathrm{Ni}$ & $250-700$ & up to 8 & $2-3$ years & $\geq 98 \%$ \\
\hline $\mathrm{Cl}-85$ & $\mathrm{Ni}$ & 260 & $1-6$ & 3-4 years & $\geq 98 \%$ \\
\hline
\end{tabular}


scholars have made great efforts to address these issues. Burger et al. (2018) synthesized Fe- and Mn- promoted co-precipitated $\mathrm{Ni}$-Al catalysts. The focus on this work was placed on NiAl-based catalysts due to their advantages in metal costs and excellent catalytic performance. Besides, it was reported that the core-shell structure could make Ni nanoparticles dispersed in the porous silicon shell and the surface would not be easy to generate carbon deposition, thus promising a long lifespan of several months (Le et al., 2019b). In addition, Wolf et al. conducted a systematic study of co-precipitated $\mathrm{Ni}-\mathrm{Al}$ catalysts in order to investigate sulfur poisoning (Wolf et al., 2019). It was found that sulfur poisoning was ascribed to site blockage rather than electronic effects. Overall, the development of Ni-based catalysts in the application of industrial $\mathrm{CO}_{2}$ methanation is still immatureand the related researches are not enough, which demand further investigation, such as sulfur poisoning.

\section{THE MECHANISM OF $\mathrm{CO}_{2}$ METHANATION OVER NI BASED CATALYSTS}

$\mathrm{CO}_{2}$ methanation has great potential to break through the bottleneck of $\mathrm{CO}_{2}$ immobilization and resource utilization. Therefore, this reaction has recently received more and more attention due to its important strategic significance. The rational design of the Ni-based catalyst used in this reaction mainly depends on the determination of the metallic active centers and surface reaction intermediates (Zhou et al., 2017; Liang et al., 2019a).

Generally, the performance of $\mathrm{CO}_{2}$ in methanation reaction can be divided into two steps. Specifically, the first step is that $\mathrm{CO}_{2}$ reacts with the catalyst to form the carbonaceous intermediates and the following step is that the carbonaceous intermediates on the catalyst surface reacts with hydrogen species to form methane. However, the intermediates produced by the $\mathrm{CO}_{2}$ methanation reaction is currently no uniform consensus of the interpretation (Yang Lim et al., 2016). Some researchers believe that $\mathrm{CO}$ is the most likely intermediate for methanation (Westermann et al., 2015). $\mathrm{CO}_{2}$ absorbs on the surface of the catalyst dissociates to form $\mathrm{CO}$, then $\mathrm{CO}$ dissociates into $\mathrm{C}$ and $\mathrm{O}$ species and then $\mathrm{C}$ hydrogenates to generate $\mathrm{CH}_{4}$ (Miguel et al., 2018; Li Y. et al., 2019). In the first stage of the reaction, the stability of the adsorption of CO on the surface of the catalyst is the key step to determining whether $\mathrm{CO}$ is desorbed or further reduced. The equilibrium between the formation of adsorbed carbon and its removal from surface hydrogen reactions affects the conversion of $\mathrm{CO}_{2}$ (Jalama, 2017). Therefore, co-dissociation is a decisive factor affecting the rate of residual reduction steps (Li Y. et al., 2019).

Another viewpoint that $\mathrm{CO}$ is not the $\mathrm{CO}_{2}$ methanation reaction intermediate also has been put forward. Some researchers believe that $\mathrm{CO}_{2}$ is converted to methane by the formation of carbonates, formates, etc. (Aldana et al., 2013; Ilsemann et al., 2019). Wang W. et al. (2016) studied the mechanism of $\mathrm{CO}_{2}$ methanation over $\mathrm{Ni}-\mathrm{Ce} / \mathrm{CNT}$ catalyst through the diffuse reflaxions infrared fourier transformations spectroscopy (DRIFTS) analysis. As observed in Figure 23,

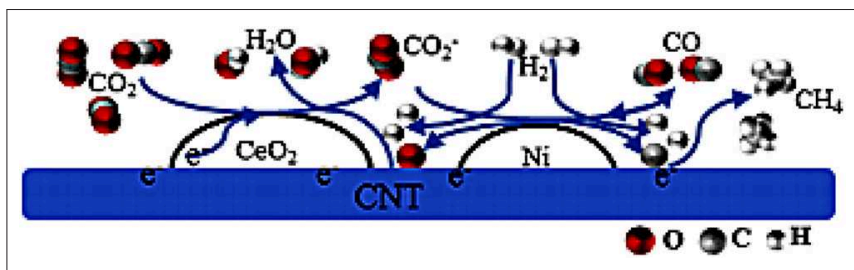

FIGURE 23 | Reaction mechanism on the cerium promoted nickel catalyst supported on CNTs for $\mathrm{CO}_{2}$ methanation. Reproduced from Wang W. et al. (2016) with permission from Elsevier and Copyright Clearance Center.

electrons were provided by the doped ruthenium and carbon nanotubes. With the help of the doped agent, the electrons were transferred to the $\mathrm{CO}_{2}$ molecules during the process of its activation. The activated $\mathrm{CO}_{2}$ dissociated on the surface of $\mathrm{Ni}$, forming carbonate intermediate species. Finally, the atomic hydrogen reacted with the carbonate intermediate to form methane. Takano et al. (2016) also found that many types of carbonates on the Y-doped $\mathrm{Ni} / \mathrm{ZrO}_{2}$ catalyst were observed and the carbonate was the main adsorbate in the reaction during the process of the DRIFTS analysis. Thus, carbonates were the reaction intermediate for the formation of $\mathrm{CH}_{4}$ on the $\mathrm{Ni} / \mathrm{ZrO}_{2}$ catalyst. They found that the bidentate carbonates were probably the most important intermediates adsorbed on these highly active $\mathrm{Y}$ doped catalysts. The combination of $\mathrm{Y}^{3+}$ and $\mathrm{Ni}^{2+}$ with $\mathrm{ZrO}_{2}$ created oxygen vacancies in the oxide, which would help to form a stable bidentate carbonate adsorbate on the catalyst.

It was reported that different supports also could cause different reaction intermediates during the $\mathrm{CO}_{2}$ methanation processes (Solis-Garcia and Fierro-Gonzalez, 2019). Muroyama et al. (2016) compared the $\mathrm{CO}_{2}$ methanation reaction over Nibased catalysts supported on different metal oxides. Although almost no $\mathrm{CO}_{2}$ methanation reaction occurred over $\mathrm{Ni} / \mathrm{La}_{2} \mathrm{O}_{3}$ catalyst at $250^{\circ} \mathrm{C}$, the chemisorption of $\mathrm{CO}_{2}$ by $\mathrm{Ni} / \mathrm{La}_{2} \mathrm{O}_{3}$ was more obvious than other samples. In contrast, the strong chemisorption of $\mathrm{CO}_{2}$ was not observed over the $\mathrm{Ni} / \mathrm{Y}_{2} \mathrm{O}_{3}$ and $\mathrm{Ni} / \mathrm{Sm}_{2} \mathrm{O}_{3}$ catalysts. For $\mathrm{Ni} / \mathrm{Y}_{2} \mathrm{O}_{3}$ catalysts, the main reaction intermediates of the $\mathrm{CO}_{2}$ methanation reaction were carbonate and formate species. The carbonate species was the initial reaction intermediates and then it was gradually converted into monodentate formate and bidentate formate through hydrogenation process. The main reaction pathway for $\mathrm{CH}_{4}$ production was hydrogenation of monodentate formate because the reaction rate of monodentate was faster than that of bidentate. $\mathrm{CO}_{2}$ methanation process over the $\mathrm{Ni} / \mathrm{La}_{2} \mathrm{O}_{3}$ catalyst did not experience bicarbonate and formate intermediates because of the high desorption temperature of $\mathrm{CO}_{2} \cdot \mathrm{CH}_{4}$ was formed by experiencing the formate intermediate rather than the $\mathrm{CO}$ pathway over the $\mathrm{Ni} / \mathrm{ZrO}_{2}$ catalyst. Furthermore, Pan et al. (2014) also found that the methanation reaction mechanisms over $\mathrm{Ni} / \mathrm{Al}_{2} \mathrm{O}_{3}$ and $\mathrm{Ni} / \mathrm{Y}_{2} \mathrm{O}_{3}$ were similar. As regard the $\mathrm{Ni} / \mathrm{Al}_{2} \mathrm{O}_{3}, \mathrm{CO}_{2}$ reacted directly with surface hydroxyl groups and surface oxygen to form bicarbonate and monodentate carbonate intermediates. The reaction between $\mathrm{CO}_{2}$ and the surface hydroxyl group could be attributed to the nucleophilic attack of 

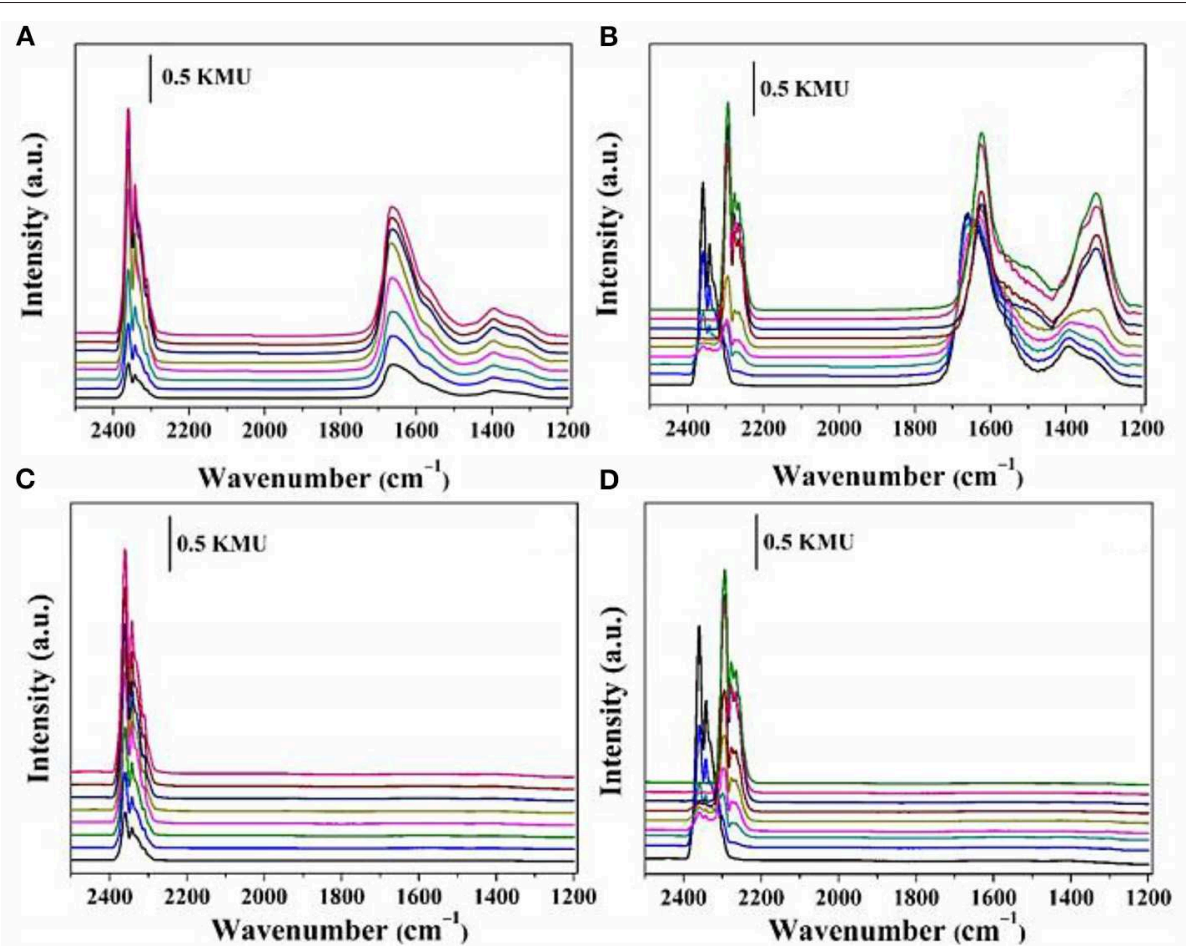

FIGURE 24 | DRIFT spectra recorded at $170{ }^{\circ} \mathrm{C}$ during 60 min with ${ }^{12} \mathrm{CO}_{2}$ as reaction gas and subsequent 60 min reaction by introducing ${ }^{13} \mathrm{CO}_{2}$ over: (A,B) Ni/MgAl-MMO and (C,D) Ni/CNT. From bottom to top: (A,C) 0.5, 1.5, 3, 5, 10, 20, 40, 60 min; (B,D) 0, 0.5, 1.5, 3, 5, 10, 20, 40, 60 min. Reproduced from Liu J. et al. (2016) with permission from Royal Society of Chemistry.

the oxygen atom of the hydroxyl group on the $\mathrm{CO}_{2}$ carbon atom (Solis-Garcia and Fierro-Gonzalez, 2019). Similarly, the bidentate formate appeared at $225^{\circ} \mathrm{C}$ could be owing to the reaction between the bicarbonate (and/or monodentate) carbonate and $\mathrm{H}_{2}$. As the temperature increased, methane characteristic peaks began to form and the intensity of formate slowly decreased. According to previous reports (Guilera et al., 2019), the $\mathrm{CO}_{2}$ methanation catalysts commonly possess weak basicity site, medium basicity site, and strong basicity site. The weak basicity sites are usually derived from surface hydroxyl groups and the moderate and strong basicity sites are derived from surface oxygen. Moderate basicity sites promote the decomposition of formate salts. Strong alkaline sites have a negative effect on the activation of carbonates, thereby inhibiting the generation of $\mathrm{CH}_{4}$. Therefore, the hydrogenation of monodentate carbonates was hindered by the strong basicity sites of surface oxygen in $\mathrm{Ni} / \mathrm{Al}_{2} \mathrm{O}_{3}$. The hydrogenation of bidentate carbonates was the main reaction pathway for $\mathrm{CH}_{4}$ formation. The methanation reaction of $\mathrm{Ni} / \mathrm{CeO}_{2}-\mathrm{ZrO}_{2}$ was different with that of $\mathrm{Ni} / \mathrm{Y}_{2} \mathrm{O}_{3}$. The hydrogen carbonate, bidentate carbonate and monodentate carbonate intermediates appeared over $\mathrm{Ni} / \mathrm{CeO}_{2}-\mathrm{ZrO}_{2}$ during the methanation reaction. As the temperature increased, the number of carbonate species gradually decreased and the number of bidendate species gradually increased. This indicated that the bidentate species were main intermediates in the reaction (Pan et al., 2014). According to the report by Wang F. et al.
(2016), $\mathrm{CO}_{2}$ was mainly converted to $\mathrm{CO}_{2}^{\delta-}$ on $\mathrm{Ru} / \mathrm{CeO}_{2}$ catalyst while $\mathrm{CO}_{2}$ was converted to bicarbonate on $\mathrm{Ru} / \alpha-\mathrm{Al}_{2} \mathrm{O}_{3}$ catalyst. Besides, Wei et al. (Liu J. et al., 2016) found that the doped additive affected the dominant reaction pathway during the process of $\mathrm{CO}_{2}$ methanation. As shown in Figure 24, carbonate and hydrocarbonate were identified immediately over the $\mathrm{Mg}$ assisted $\mathrm{Ni}$ catalyst. However, the formation of any relevant intermediates was hardly observed in the case of $\mathrm{Ni} /$ carbon nanotube (CNT) catalyst because $\mathrm{MgO}$ base sites promoted the activation of $\mathrm{CO}_{2}$ molecule to carbonate/hydrocarbonate species and $\mathrm{Ni} / \mathrm{CNT}$ lacked base sites. Further, $\mathrm{CO}_{2}$ was mainly converted into methane via the formate intermediate over the Ni-based catalyst prepared by the ammonia evaporation method. However, the formate intermediate could not be formed over the $\mathrm{Ni} / \mathrm{CeO}_{2}-\mathrm{ZrO}_{2}$ catalyst prepared by wet impregnation method (Ashok et al., 2017). In general, the nature of the catalytic support, additive and preparation strategy of the catalyst could affect the dominant reaction pathway and intermediates during the process of the methanation of $\mathrm{CO}_{2}$.

As for the activation site of $\mathrm{CO}_{2}$, some scholars believe that the activation of $\mathrm{CO}_{2}$ occurs over the metallic $\mathrm{Ni}$ active site (Aziz et al., 2014b). Solis-Garcia and Fierro-Gonzalez (2019) reported the mechanistic path of $\mathrm{CO}_{2}$ methanation on Ni/MSN. Specifically, $\mathrm{CO}_{2}$ and $\mathrm{H}_{2}$ molecules were firstlyadsorbed on $\mathrm{Ni}$ active sites, followed by dissociation to form $\mathrm{CO}, \mathrm{O}$, and $\mathrm{H}$ atoms, and migrated onto the MSN surface. The $\mathrm{CO}$ then interacted with 
oxide surfaces of the MSN and bidentate formate was also formed through the interaction with atomic hydrogen. Meanwhile, the $\mathrm{O}$ atom spilt over onto the surface of the MSN and was stabilized in the oxygen vacancy site near the Ni sites. However, the viewpoint of Jangam et al. (2019) was opposite. They found that carbonate was generated by the reaction of $\mathrm{CO}_{2}$ with a surface basic oxyanion on the metal oxide. Therefore, the activation of $\mathrm{CO}_{2}$ occurred on the support. Besides, Aldana et al. (2013) also found that $\mathrm{CO}_{2}$ was activated on the $\mathrm{CeO}_{2}-\mathrm{ZrO}_{2}$. Therefore, up to now, the real activation site of the $\mathrm{CO}_{2}$ molecule has still been the controversy of the $\mathrm{CO}_{2}$ methanation reaction.

\section{CONCLUSIONS AND PERSPECTIVE}

Nowadays, $\mathrm{CO}_{2}$ emissions are increasing, resulting in a series of global environmental problems. Therefore, it is of greatly practical significance to study $\mathrm{CO}_{2}$ methanation technology in order to solve the problem of energy shortage and reduce the concentration of $\mathrm{CO}_{2}$ in the atmosphere. Besides, it is of great urgency to develop highly efficient $\mathrm{Ni}$ based catalyst to accelerate this process because of the kinetic limitations of $\mathrm{CO}_{2}$ methanation.

In recent years, Ni-based catalysts have been widely used due to their good catalytic performance and low price. In order to develop Ni-based catalysts with good low-temperature activity, the global scientists have made great efforts to investigate different influencing factors, such as catalytic support, dopant, preparation method. This review generally summarizes different ways to improve catalyst performance. From the perspective of preparation methods, the traditional preparation methods of $\mathrm{Ni}$ based catalysts, such as impregnation and coprecipitation, have become basically mature technologies. Therefore, the researchers have begun to develop new methods and strategies, such as microwave assisted method and plasma method. The catalytic performance of the catalyst prepared by these methods is usually superior to that by the conventional preparation method. In the viewpoint of dopants, their addition can adjust the acidityalkalinity and electronic/redox property of the catalyst, further improving the dispersion and coordination environment of the

\section{REFERENCES}

Abate, S., Mebrahtu, C., Giglio, E., Deorsola, F., Bensaid, S., Perathoner, S., et al. (2016). Catalytic performance of $\gamma-\mathrm{Al}_{2} \mathrm{O}_{3}-\mathrm{ZrO}_{2}-\mathrm{TiO}_{2}-\mathrm{CeO}_{2}$ composite oxide supported ni-based catalysts for $\mathrm{CO}_{2}$ methanation. IND Eng. Chem. Res. 55, 4451-4460. doi: 10.1021/acs.iecr.6b00134

Ahn, J. Y., Chang, S. W., Lee, S. M., Kim, S. S., Chung, W. J., Lee, J. C., et al. (2019). Developing Ni-based honeycomb-type catalysts using different binary oxidesupported species for synergistically enhanced $\mathrm{CO}_{2}$ methanation activity. Fuel 250, 277-284. doi: 10.1016/j.fuel.2019.03.123

Akbari, E., Alavi, S. M., Rezaei, M. (2018). $\mathrm{CeO}_{2}$ promoted Ni-MgO- $\mathrm{Al}_{2} \mathrm{O} 3$ nanocatalysts for carbon dioxide reforming of methane. J. $\mathrm{CO}_{2}$ Util. 24, 128-138. doi: 10.1016/j.jcou.2017.12.015

Alarcón, A., Guilera, J., Díaz, J. A., and Andreu, T. (2019). Optimization of nickel and ceria catalyst content for synthetic natural gas production through $\mathrm{CO}_{2}$ methanation. Fuel Process. Technol. 193, 114-122. doi: 10.1016/j.fuproc.2019.05.008 metallic active sites. As a result, the additive-modified Ni-based catalyst has the advantages of good reactivity and long lifespan. In this review, the additives are divided into four categories, namely rare earth metals, alkaline earth metals, transition metals and precious metals, and their effects on the catalyst are described and summarized in detail. As for the catalytic supports, they can obviously influence the textural property of the catalyst, thereby affecting the catalytic performances toward $\mathrm{CO}_{2}$ methanation process. In terms of reaction conditions, such as temperature, pressure, humidity, etc., they are also considered as important factors affecting the catalytic behavior of the catalyst, which have been carefully summarized in this review. In addition, the reaction mechanism of $\mathrm{Ni}$ based catalysts toward $\mathrm{CO}_{2}$ methanation are also carefully reviewed. It was believed that the nature of the catalytic support, additive and preparation strategy of the catalyst could affect the dominant reaction pathway and intermediates during the process of the methanation of $\mathrm{CO}_{2}$.

In future research, the hot spots of research on Ni-based catalysts toward $\mathrm{CO}_{2}$ methanation should still be placed on the improvement of both low-temperature catalytic performance and anti-sintering property of the metallic Ni active site. The development of new supports ought to be the main research line. Besides, the investigation of $\mathrm{CO}_{2}$ methanation mechanism on the Ni-based catalyst is beneficial to finding routes to improve the activity of catalysts. Meanwhile, it is of great significance to optimize the preparation method in order to scale up the synthesis of the catalysts in the future industrialization process. Finally, taking the cost of preparing catalysts into consideration is necessary in order to achieve green catalysis and catalysts should be applied to industrial $\mathrm{CO}_{2}$ methanation by improving reactors and other methods.

\section{AUTHOR CONTRIBUTIONS}

MC, LX, and CL: conceptualization. YC and XH: software. MC, $\mathrm{LX}$, and CW: validation. XW, YL, and BY: investigation. MC, $\mathrm{XH}$, and QS: resources. ZM, BY, and CW: data curation. CL: writing-original draft preparation. CL, LX, and MC: writingreview and editing. MC and LX: supervision, methodology, and project administration.
Aldana, P. A. U., Ocampo, F., Kobl, K., Louis, B., Thibault-Starzyk, F., Daturi, M., et al. (2013). Catalytic $\mathrm{CO}_{2}$ valorization into $\mathrm{CH} 4$ on Ni-based ceria-zirconia. Reaction mechanism by operando IR spectroscopy. Catal. Today 215, 201-207. doi: 10.1016/j.cattod.2013.02.019

Al-Fatesh, A. S., Abu-Dahrieh, J. K., Atia, H., Armbruster, U., Ibrahim, A. A., Khan, W. U., et al. (2019). Effect of pre-treatment and calcination temperature on $\mathrm{Al}_{2} \mathrm{O}_{3}-\mathrm{ZrO}_{2}$ supported Ni-Co catalysts for dry reforming of methane. Int. J. Hydrogen Energy 44, 21546-21558. doi: 10.1016/j.ijhydene.2019.06.085

Al-Fatesh, A. S., Arafat, Y., Atia, H., Ibrahim, A. A., Ha, Q. L. M., Schneider, M., et al. (2017). $\mathrm{CO}_{2}$-reforming of methane to produce syngas over $\mathrm{Co}-\mathrm{Ni} / \mathrm{SBA}-15$ catalyst: effect of support modifiers $\left(\mathrm{Mg}, \mathrm{La}\right.$ and $\mathrm{Sc}$ ) on catalytic stability. J. $\mathrm{CO}_{2}$ Util. 21, 395-404. doi: 10.1016/j.jcou.2017.08.001

Al-Fatesh, A. S. A., and Fakeeha, A. H. (2012). Effects of calcination and activation temperature on dry reforming catalysts. J. Saudi. Chem. Soc. 16, 55-61. doi: $10.1016 /$ j.jscs.2010.10.020

Alihosseinzadeh, A., Nematollahi, B., Rezaei, M., and Lay, E. N. (2015). CO methanation over $\mathrm{Ni}$ catalysts supported on high surface area mesoporous 
nanocrystalline $\gamma-\mathrm{Al}_{2} \mathrm{O}_{3}$ for $\mathrm{CO}$ removal in $\mathrm{H}_{2}$-rich stream. Int. J. Hydrogen Energy 40, 1809-1819. doi: 10.1016/j.ijhydene.2014.11.138

Aljishi, A., Veilleux, G., Lalinde, J. A. H., and Kopyscinski, J. (2018). The effect of synthesis parameters on ordered mesoporous nickel alumina catalyst for $\mathrm{CO}_{2}$ methanation. Appl. Catal. A Gen. 549, 263-272. doi: 10.1016/j.apcata.2017.10.012

Alrafei, B., Polaert, I., Ledoux, A., and Azzolina-Jury, F. (2019). Remarkably stable and efficient $\mathrm{Ni}$ and Ni-Co catalysts for $\mathrm{CO}_{2}$ methanation. Catal. Today doi: 10.1016/j.cattod.2019.03.026. [Epub ahead of Print].

Andersen, N. I., Serov, A., and Atanassov, P. (2015). Metal oxides/CNT nanocomposite catalysts for oxygen reduction/oxygen evolution in alkaline media. Appl. Catal. B Environ. 163, 623-627. doi: 10.1016/j.apcatb.2014.08.033

Ashok, J., Ang, M. L., and Kawi, S. (2017). Enhanced activity of $\mathrm{CO}_{2}$ methanation over $\mathrm{Ni} / \mathrm{CeO}_{2}-\mathrm{ZrO}_{2}$ catalysts: influence of preparation methods. Catal. Today 281, 304-311. doi: 10.1016/j.cattod.2016.07.020

Atzori, L., Rombi, E., Meloni, D., Monaci, R., Sini, M. F., and Cutrufello, M. G. (2019). Nanostructured $\mathrm{Ni} / \mathrm{CeO}_{2}-\mathrm{ZrO}_{2}$ catalysts for $\mathrm{CO}_{2}$ conversion into synthetic natural gas. J. Nanosci. Nanotechnol. 19, 3269-3276. doi: 10.1166/jnn.2019.16612

Aziz, M. A. A., and Jalil, A. A. (2015). $\mathrm{CO}_{2}$ methanation over heterogeneous catalysts:recent progress and future prospects. RSC 17, 2647-2663. doi: 10.1039/C5GC00119F

Aziz, M. A. A., Jalil, A. A., Triwahyono, S., Mukti, R. R., Taufiq-Yap, Y. H., and Sazegar, M. R. (2014a). Highly active Ni-promoted mesostructured silica nanoparticles for $\mathrm{CO}_{2}$ methanation. Appl. Catal. B Environ. 147, 359-368. doi: 10.1016/j.apcatb.2013.09.015

Aziz, M. A. A., Jalil, A. A., Triwahyono, S., and Saad, M. W. A. (2015). $\mathrm{CO}_{2}$ methanation over Ni-promoted mesostructured silica nanoparticles: influence of Ni loading and water vapor on activity and response surface methodology studies. Chem. Eng. J. 260, 757-764. doi: 10.1016/j.cej.2014.09.031

Aziz, M. A. A., Jalil, A. A., Triwahyono, S., and Sidik, S. M. (2014b). Methanation of carbon dioxide on metal-promoted mesostructured silica nanoparticles. Appl. Catal. A Gen. 486, 115-122. doi: 10.1016/j.apcata.2014.08.022

Bacani, R., Toscani, L. M., Martins, T. S., Fantini, M. C. A., Lamas, D. G., and Larrondo, S. A. (2017). Synthesis and characterization of mesoporous $\mathrm{NiO} / \mathrm{ZrO}_{2}-\mathrm{CeO}_{2}$ catalysts for total methane conversion. Ceram. Int. 43, 7851-7860. doi: 10.1016/j.ceramint.2017.03.101

Bacariza, M. C., Biset-Peiró, M., Graça, I., Guilera, J., Morante, J., Lopes, J. M., et al. (2018b). DBD plasma-assisted $\mathrm{CO}_{2}$ methanation using zeolite-based catalysts: structure composition-reactivity approach and effect of Ce as promoter. J. $\mathrm{CO}_{2}$ Util. 26, 202-211. doi: 10.1016/j.jcou.2018.05.013

Bacariza, M. C., Graça, I., Bebiano, S. S., Lopes, J. M., and Henriques, C. (2018a). Micro- and mesoporous supports for $\mathrm{CO}_{2}$ methanation catalysts: a comparison between SBA-15, MCM-41 and USY zeolite. Chem. Eng. Sci. 175, 72-83. doi: 10.1016/j.ces.2017.09.027

Bacariza, M. C., Graça, I., Westermann, A., Ribeiro, M. F., Lopes, J. M., and Henriques, C. (2015). $\mathrm{CO}_{2}$ hydrogenation over Ni-based zeolites: effect of catalysts preparation and pre-reduction conditions on methanation performance. Top. Catal. 59, 314-325. doi: 10.1007/s11244-015-0435-4

Batista, M. S., Santiago, E. I., Assaf, E. M., and Ticianelli, E. A. (2005). Evaluation of the water-gas shift and $\mathrm{CO}$ methanation processes for purification of reformate gases and the coupling to a PEM fuel cell system. J. Power Sources 145, 50-54. doi: 10.1016/j.jpowsour.2004.12.032

Beaumont, S. K., Alayoglu, S., Specht, C., Michalak, W. D., Pushkarev, V. V., Guo, J., et al. (2014). Combining in situ NEXAFS spectroscopy and $\mathrm{CO}_{2}$ methanation kinetics to study Pt and Co nanoparticle catalysts reveals key insights into the role of platinum in promoted cobalt catalysis. J. Am. Chem. Soc. 136, 9898-9901. doi: 10.1021/ja505286j

Beierlein, D., Häussermann, D., Pfeifer, M., Schwarz, T., Stöwe, K., Traa, Y., et al. (2019). Is the $\mathrm{CO}_{2}$ methanation on highly loaded Ni-Al2O3 catalysts really structure-sensitive. Appl. Catal. B Environ. 247, 200-219. doi: 10.1016/j.apcatb.2018.12.064

Bian, L., Zhang, L., Xia, R., and Li, Z. (2015). Enhanced low-temperature $\mathrm{CO}_{2}$ methanation activity on plasma-prepared Ni-based catalyst. J. Nat. Gas Sci. Eng. 27, 1189-1194. doi: 10.1016/j.jngse.2015.09.066

Bian, Z., Chan, Y. M., Yu, Y., and Kawi, S. (2018). Morphology dependence of catalytic properties of $\mathrm{Ni} / \mathrm{CeO}_{2}$ for $\mathrm{CO}_{2}$ methanation: a kinetic and mechanism study. Catal. Today. doi: 10.1016/j.cattod.2018.04.067. [Epub ahead of Print].
Bian, Z., and Kawi, S. (2017). Highly carbon-resistant $\mathrm{Ni}-\mathrm{Co} / \mathrm{SiO}_{2}$ catalysts derived from phyllosilicates for dry reforming of methane. J. $\mathrm{CO}_{2}$ Util. 18, 345-352. doi: 10.1016/j.jcou.2016.12.014

Biset-Peiró, M., Guilera, J., Zhang, T., Arbiol, J., and Andreu, T. (2019). On the role of ceria in $\mathrm{Ni}-\mathrm{Al}_{2} \mathrm{O}_{3}$ catalyst for $\mathrm{CO}_{2}$ plasma methanation. Appl. Catal. A Gen. 575, 223-229. doi: 10.1016/j.apcata.2019.02.028

Branco, J. B., Brito, P. E., and Ferreira, A. C. (2020). Methanation of $\mathrm{CO}_{2}$ over nickel-lanthanide bimetallic oxides supported on silica. Chem. Eng. J. 380:122465. doi: 10.1016/j.cej.2019.122465

Bukhari, S. N., Chong, C. C., and Setiabudi, H. D. (2019). Optimal $\mathrm{Ni}$ loading towards efficient $\mathrm{CH}_{4}$ production from $\mathrm{H}_{2}$ and $\mathrm{CO}_{2}$ over $\mathrm{Ni}$ supported ontofibrous SBA-15. Int. J. Hydr. Energy 44, 7228-7240. doi: 10.1016/j.ijhydene.2019.01.259

Burger, T., Koschany, F., Thomys, O., Köhler, K., and Hinrichsen, O. (2018). $\mathrm{CO}_{2}$ methanation over $\mathrm{Fe}$ - and $\mathrm{Mn}$-promoted co-precipitated $\mathrm{Ni}$-Al catalysts: synthesis, characterization and catalysis study. Appl. Catal. A Gen. 558, 44-54. doi: 10.1016/j.apcata.2018.03.021

Cai, M., Wen, J., Chu, W., Cheng, X., and Li, Z. (2011). Methanation of carbon dioxide on $\mathrm{Ni} / \mathrm{ZrO}_{2}-\mathrm{Al}_{2} \mathrm{O}_{3}$ catalysts: effects of $\mathrm{ZrO}_{2}$ promoter and preparation method of novel $\mathrm{ZrO}_{2}-\mathrm{Al}_{2} \mathrm{O}_{3}$ carrier. J. Nat. Gas. Chem. 20, 318-324. doi: 10.1016/S1003-9953(10)60187-9

Cai, W., Ye, L., Zhang, L., Ren, Y., Yue, B., Chen, X., et al. (2014). Highly dispersed nickel-containing mesoporous silica with superior stability in carbon dioxide reforming of methane: the effect of anchoring. Materials 7, 2340-2355. doi: $10.3390 / \mathrm{ma7} 032340$

Chai, S., Men, Y., Wang, J., Liu, S., Song, Q., An, W., et al. (2019). Boosting $\mathrm{CO}_{2}$ methanation activity on $\mathrm{Ru} / \mathrm{TiO}_{2}$ catalysts by exposing $(001)$ facets of anatase $\mathrm{TiO}_{2}$. J. $\mathrm{CO}_{2}$ Util. 33, 242-252. doi: 10.1016/j.jcou.2019.05.031

Champon, I., Bengaouer, A., Chaise, A., Thomas, S., and Roger, A. C. (2019). Carbon dioxide methanation kinetic model on a commercial $\mathrm{Ni} / \mathrm{Al}_{2} \mathrm{O}_{3}$ catalyst. J. $\mathrm{CO}_{2}$ Util. 34, 256-265. doi: 10.1016/j.jcou.2019.05.030

Charisiou, N. D., Douvartzides, S. L., Siakavelas, G. I., Tzounis, L., Sebastian, V., Stolojan, V., et al. (2019). The relationship between reaction temperature and carbon deposition on nickel catalysts based on $\mathrm{Al}_{2} \mathrm{O}_{3}, \mathrm{ZrO}_{2}$ or $\mathrm{SiO}_{2}$ supports during the biogas dry reforming reaction. Catal 9:676. doi: $10.3390 /$ catal9080676

Daroughegi, R., Meshkani, F., and Rezaei, M. (2017). Enhanced activity of $\mathrm{CO}_{2}$ methanation over mesoporous nanocrystalline $\mathrm{Ni}_{-} \mathrm{Al}_{2} \mathrm{O}_{3}$ catalysts prepared by ultrasound-assisted co-precipitation method. Int. J. Hydrogen Energy 42, 15115-15125. doi: 10.1016/j.ijhydene.2017.04.244

Daroughegi, R., Meshkani, F., and Rezaei, M. (2019). Characterization and evaluation of mesoporous high surface area promoted $\mathrm{Ni}-\mathrm{Al}_{2} \mathrm{O}_{3}$ catalysts in CO2 methanation. J. Energy Inst. 93, 482-495. doi: 10.1016/j.joei.2019.07.003

Debek, R., Azzolina-Jury, F., Travert, A., Maugé, F., and Thibault-Starzyk, F. (2019). Low-pressure glow discharge plasma-assisted catalytic $\mathrm{CO}_{2}$ hydrogenation-The effect of metal oxide support on the performance of the Ni-based catalyst. Catal. Today 337, 182-194. doi: 10.1016/j.cattod.2019.03.039

Dong, X., Jin, B., Sun, Y., Shi, K., and Yu, L. (2018). Re-promoted Ni-Mn bifunctional catalysts prepared by microwave heating for partial methanation coupling with water gas shift under low $\mathrm{H}_{2} / \mathrm{CO}$ conditions. Appl. Catal. A Gen. 552, 105-116. doi: 10.1016/j.apcata.2017.12.026

Fang, X., Zhang, J., Liu, J., Wang, C., Huang, Q., Xu, X., et al. (2018). Methane dry reforming over $\mathrm{Ni} / \mathrm{Mg}-\mathrm{Al}-\mathrm{O}$ : on the significant promotional effects of rare earth $\mathrm{Ce}$ and $\mathrm{Nd}$ metal oxides. J. $\mathrm{CO}_{2}$ Util 25, 242-253. doi: 10.1016/j.jcou.2018.04.011

Feng, X., Feng, J., and Li, W. (2018). Insight into $\mathrm{MgO}$ promoter with low concentration for the carbon-deposition resistance of $\mathrm{Ni}$-based catalysts in the $\mathrm{CO}_{2}$ reforming of $\mathrm{CH}_{4}$. Chinese J Catal 39, 88-98. doi: 10.1016/S1872-2067(17)62928-0

Feng, Y., Yang, W., and Chu, W. (2016). Effect of Ca modification on the catalytic performance of $\mathrm{Ni} / \mathrm{AC}$ for $\mathrm{CO}_{2}$ methanation. Integr. Ferroelectr. 172, 40-48. doi: 10.1080/10584587.2016.1175333

Ferreira, A. C., and Branco, J. B. (2019). Methanation of $\mathrm{CO}_{2}$ over nanostructured nickel-4f block element bimetallic oxides. Int. J. Hydrogen Energy 44, 6505-6513. doi: 10.1016/j.ijhydene.2019.01.160

Frontera, P., Macario, A., Malara, A., Santangelo, S., Triolo, C., Crea, F., et al. (2018). Trimetallic Ni-based catalysts over gadolinia-doped ceria for green fuel production. Catal 8:435. doi: 10.3390/catal8100435 
Gac, W., Zawadzki, W., Rotko, M., Greluk, M., Słowik, G., and Kolb, G. (2019). Effects of support composition on the performance of nickel catalysts in $\mathrm{CO}_{2}$ methanation reaction. Catal. Today. doi: 10.1016/j.cattod.2019.07.026. [Epub ahead of print].

Gac, W., Zawadzki, W., Słowik, G., Sienkiewicz, A., and Kierys, A. (2018). Nickel catalysts supported on silica microspheres for $\mathrm{CO}_{2}$ methanation. Microporous Mesoporous Mater. 272, 79-91. doi: 10.1016/j.micromeso.2018.06.022

Garbarino, G., Wang, C., Cavattoni, T., Finocchio, E., Riani, P., FlytzaniStephanopoulos, M., et al. (2019). A study of $\mathrm{Ni} / \mathrm{La}-\mathrm{Al}_{2} \mathrm{O}_{3}$ catalysts: a competitive system for $\mathrm{CO}_{2}$ methanation. Appl. Catal. B Environ. 248, 286-297. doi: 10.1016/j.apcatb.2018.12.063

Ghanbari, T., Abnisa, F., and Wan Daud, W. M. A. (2019). A review on production of metal organic frameworks (MOF) for $\mathrm{CO}_{2}$ adsorption. Sci. Total Environ. 707:135090. doi: 10.1016/j.scitotenv.2019.135090

Gnanakumar, E. S., Chandran, N., Kozhevnikov, I. V., Grau-Atienza, A., Ramos Fernández, E. V., Sepulveda-Escribano, A., et al. (2019). Highly efficient nickelniobia composite catalysts for hydrogenation of $\mathrm{CO}_{2}$ to methane. Chem. Eng. Sci. 194, 2-9. doi: 10.1016/j.ces.2018.08.038

Golosman, E. Z., and Efremov, V. N. (2012). Industrial catalysts for the hydrogenation of carbon oxides. Catal. Industry 4, 267-283. doi: 10.1134/S2070050412040071

Guilera, J., del Valle, J., Alarcón, A., Díaz, J. A., and Andreu, T. (2019). Metal-oxide promoted $\mathrm{Ni} / \mathrm{Al}_{2} \mathrm{O}_{3}$ as $\mathrm{CO}_{2}$ methanation micro-size catalysts. J. $\mathrm{CO}_{2}$ Util 30, 11-17. doi: 10.1016/j.jcou.2019.01.003

Guo, C., Wu, Y., Qin, H., and Zhang, J. (2014). CO methanation over $\mathrm{ZrO}_{2} / \mathrm{Al}_{2} \mathrm{O}_{3}$ supported $\mathrm{Ni}$ catalysts: a comprehensive study. fuel process. Technol. 124, 61-69. doi: 10.1016/j.fuproc.2014.02.017

Guo, M., and Lu, G. (2014). The effect of impregnation strategy on structural characters and $\mathrm{CO}_{2}$ methanation properties over $\mathrm{MgO}$ modified $\mathrm{Ni} / \mathrm{SiO}_{2}$ catalysts. Catal. Commun. 54, 55-60. doi: 10.1016/j.catcom.2014.05.022

Guo, Q., Zhang, Q., Wang, H., Liu, Z., and Zhao, Z. (2016). Coreshell structured $\mathrm{ZnO} @ \mathrm{Cu}-\mathrm{Zn}-\mathrm{Al}$ layered double hydroxides with enhanced photocatalytic efficiency for $\mathrm{CO}_{2}$ reduction. Catal. Commun. 77, 118-122. doi: 10.1016/j.catcom.2016.01.019

Guo, X., Peng, Z., Hu, M., Zuo, C., Traitangwong, A., Meeyoo, V., et al. (2018). Highly active Ni-based catalyst derived from double hydroxides precursor for low temperature $\mathrm{CO}_{2}$ methanation. Ind. Eng. Chem. Res. 57, 9102-9111. doi: 10.1021/acs.iecr.8b01619

Haynes, D. J., Shekhawat, D., Berry, D., Roy, A., and Spivey, J. J. (2019). Effect of calcination temperature on steam reforming activity of Ni-based pyrochlore catalysts. J. Rare Earth. doi: 10.1016/j.jre.2019.07.015. [Epub ahead of print].

He, H., Sekoulopoulos, S., and Zygmunt, S. (2016). Single-electron activation of $\mathrm{CO}_{2}$ on graphene-supported $\mathrm{ZnO}$ nanoclusters: effects of doping in the support. J. Phys. Chem. C 120, 16732-16740. doi: 10.1021/acs.jpcc.6b04526

He, L., BotaoTeng, Zhang, Y., and Fan, M. (2015). Development of composited rare-earth promoted cobalt-based Fischer-Tropsch synthesis catalysts with high activity and selectivity. Appl. Catal. A Gen. 505, 276-283. doi: 10.1016/j.apcata.2015.07.041

Hu, F., Tong, S., Lu, K., Chen, C. M., Su, F. Y., Zhou, J., et al. (2019). Reduced graphene oxide supported $\mathrm{Ni}$-Ce catalysts for $\mathrm{CO}_{2}$ methanation: the support and ceria promotion effects. J. $\mathrm{CO}_{2}$ Util. 34, 676-687. doi: 10.1016/j.jcou.2019.08.020

$\mathrm{Hu}, \mathrm{L}$., and Urakawa, A. (2018). Continuous $\mathrm{CO}_{2}$ capture and reduction in one process: $\mathrm{CO}_{2}$ methanation over unpromoted and promoted $\mathrm{Ni} / \mathrm{ZrO}_{2}$. J. $\mathrm{CO}_{2}$ Util 25, 323-329. doi: 10.1016/j.jcou.2018.03.013

Hwang, S., Hong, U. G., Lee, J., Baik, J. H., Koh, D. J., Lim, H., et al. (2012). Methanation of carbon dioxide over mesoporous nickel-M-alumina ( $\mathrm{M}=\mathrm{Fe}$, $\mathrm{Zr}, \mathrm{Ni}, \mathrm{Y}$, and $\mathrm{Mg}$ ) xerogel catalysts: effect of second metal. Catal. Lett. 142, 860-868. doi: 10.1007/s10562-012-0842-0

Iglesias, I., Quindimil, A., Mariño, F., De-La-Torre, U., and GonzálezVelasco, J. R. (2019). $\mathrm{Zr}$ promotion effect in $\mathrm{CO}_{2}$ methanation over ceria supported nickel catalysts. Int. J. Hydrogen Energy 44, 1710-1719. doi: 10.1016/j.ijhydene.2018.11.059

Ilsemann, J., Sonström, A., Gesing, T. M., Anwander, R., and Bäumer, M. (2019). Highly active $\mathrm{Sm}_{2} \mathrm{O}_{3}-\mathrm{Ni}$ xerogel catalysts for $\mathrm{CO}_{2}$ methanation. Chem. Cat. Chem. 11, 1732-1741. doi: 10.1002/cctc.201802049

Jalama, K. (2017). Carbon dioxide hydrogenation over nickel-, ruthenium-, and copper-based catalysts: review of kinetics and mechanism. Catal. Rev. 59, 95-164. doi: 10.1080/01614940.2017.13 16172

Jangam, A., Das, S., Dewangan, N., Hongmanorom, P., Hui, W. M., and Kawi, S. (2019). Conversion of CO2 to C1 chemicals: Catalyst design, kinetics and mechanism aspects of the reactions. Catal. Today. doi: 10.1016/j.cattod.2019.08.049

Jia, X., Zhang, X., Rui, N., Hu, X., Liu, C.-J. (2019). Structural effect of Ni/ZrO $\mathrm{rO}_{2}$ catalyst on $\mathrm{CO}_{2}$ methanation with enhanced activity. Appl. Catal. B. Environ. 244, 159-169. doi: 10.1016/j.apcatb.2018.11.024

Jiang, H., Gao, Q., Wang, S., Chen, Y., and Zhang, M. (2019). The synergistic effect of Pd NPs and UiO-66 for enhanced activity of carbon dioxide methanation. J. $\mathrm{CO}_{2}$ Util 31, 167-172. doi: 10.1016/j.jcou.2019.03.011

Jiang, Y., Huang, T., Dong, L., Qin, Z., and Ji, H. (2018). Ni/bentonite catalysts prepared by solution combustion method for $\mathrm{CO}_{2}$ methanation. Chin. J. Chem. Eng. 26, 2361-2367. doi: 10.1016/j.cjche.2018. 03.029

Jiménez, V., Sánchez, P., Panagiotopoulou, P., Valverde, J. L., and Romero, A. (2010). Methanation of $\mathrm{CO}, \mathrm{CO} 2$ and selective methanation of $\mathrm{CO}$, in mixtures of $\mathrm{CO}$ and $\mathrm{CO}_{2}$, over ruthenium carbon nanofibers catalysts. Appl. Catal. A Gen. 390, 35-44. doi: 10.1016/j.apcata.2010.09.026

Jing, J., Li, L., Chu, W., Wei, Y., and Jiang, C. (2018). Microwave-assisted synthesis of high performance copper-based catalysts for hydrogen production from methanol decomposition. Int. J. Hydrogen Energy 43, 12059-12068. doi: 10.1016/j.ijhydene.2018.04.104

Jurgensen, L., Ehimen, E. A., Born, J., and Holm-Nielsen, J. B. (2015) Dynamic biogas upgrading based on the Sabatier process: thermodynamic and dynamic process simulation. Bioresour. Technol. 178, 323-329. doi: 10.1016/j.biortech.2014.10.069

Kim, W., Koo, K. Y., Lee, H-j., Shul, Y. G., and Yoon, W. L. (2015). Highly dispersed nickel catalyst promoted by precious metals for CO selective methanation. Int. J. Hydr. Energy 40, 10033-10040. doi: 10.1016/j.ijhydene.2015.06.033

Kirchner, J., Anolleck, J. K., Lösch, H., and Kureti, S. (2018). Methanation of $\mathrm{CO}_{2}$ on iron based catalysts. Appl. Catal. B Environ. 223, 47-59. doi: 10.1016/j.apcatb.2017.06.025

Kopyscinski, J., Schildhauer, T. J., and Biollaz, S. M. A. (2009). Production of synthetic natural gas (SNG) from coal and dry biomass - A technology review from 1950 to 2010. Fuel 89, 1763-1783. doi: 10.1016/j.fuel.2010.01.027

Kreitz, B., Wehinger, G. D., and Turek, T. (2019). Dynamic simulation of the $\mathrm{CO}_{2}$ methanation in a micro-structured fixed-bed reactor. Chem. Eng. Sci. 195, 541-552. doi: 10.1016/j.ces.2018.09.053

László, B., Baán, K., Varga, E., Oszk,ó, A., Erdohelyi, A., Kónya, Z., et al. (2016). Photo-induced reactions in the $\mathrm{CO}_{2}$-methane system on titanate nanotubes modified with Au and Rh nanoparticles. Appl. Catal. B Environ. 199, 473-484. doi: 10.1016/j.apcatb.2016.06.057

Le, T. A., Kim, J., Kang, J. K., and Park, E. D. (2019a). CO and CO2 methanation over M (M Mn, Ce, Zr, Mg, K, Zn, or V)-promoted Ni/Al@ $\mathrm{Al}_{2} \mathrm{O}_{3}$ catalysts. Catal. Today 9:599. doi: 10.3390/catal9070599

Le, T. A., Kim, J., Kang, J. K., and Park, E. D. (2019b). CO and CO methanation over Ni/Al@Al2O3 core-shell catalyst. Catal. Today. 9:599. doi: 10.1016/j.cattod.2019.09.028

Lechkar, A., Barroso Bogeat, A., Blanco, G., Pintado, J. M., and Soussi el Begrani, M. (2018). Methanation of carbon dioxide over ceria-praseodymia promoted $\mathrm{Ni}$-alumina catalysts. Influence of metal loading, promoter composition and alumina modifier. Fuel 234, 1401-1413. doi: 10.1016/j.fuel.2018.07.157

Li, B., Luo, Y., Li, B., Yuan, X., and Wang, X. (2019). Catalytic performance of iron-promoted nickel-based ordered mesoporous alumina FeNiAl catalysts in dry reforming of methane. Fuel Process. Technol. 193, 348-360. doi: 10.1016/j.fuproc.2019.05.033

Li, B., Xu, Z., Jing, F., Luo, S., Wang, N., and Chu, W. (2016). Improvement of catalytic stability for $\mathrm{CO}_{2}$ reforming of methane by copper promoted Ni-based catalyst derived from layered-double hydroxides. J. Nat. Gas Chem. 25, 1078-1085. doi: 10.1016/j.jechem.2016. 11.001

Li, J., Zhou, Y., Xiao, X., Wang, W., Wang, N., Qian, W., et al. (2018). Regulation of Ni-CNT interaction on Mn-promoted nickel nanocatalysts supported on oxygenated CNTs for $\mathrm{CO}_{2}$ selective hydrogenation. ACS Appl. Mater. Interfaces 10, 41224-41236. doi: 10.1021/acsami.8b04220 
Li, S., Liu, G., Zhang, S., An, K., Ma, Z., Wang, L., et al. (2020). Cerium-modified $\mathrm{Ni}-\mathrm{La} 2 \mathrm{O} 3 / \mathrm{ZrO} 2$ for $\mathrm{CO} 2$ methanation. J. Nat. Gas Chem. 43, 155-164. doi: 10.1016/j.jechem.2019.08.024

Li, W., Liu, Y., Mu, M., Ding, F., Liu, Z., Guo, X., et al. (2019). Organic acid-assisted preparation of highly dispersed $\mathrm{Co} / \mathrm{ZrO}_{2}$ catalysts with superior activity for $\mathrm{CO}_{2}$ methanation. Appl. Catal. B Environ. 254, 531-540. doi: 10.1016/j.apcatb.2019.05.028

Li, W., Nie, X., Jiang, X., Zhang, A., Ding, F., Liu, M., et al. (2018a). $\mathrm{ZrO}_{2}$ support imparts superior activity and stability of Co catalysts for $\mathrm{CO}_{2}$ methanation. Appl. Catal. B Environ. 220, 397-408. doi: 10.1016/j.apcatb.2017.08.048

Li, W., Wang, H., Jiang, X., Zhu, J., Liu, Z., Guo, X., et al. (2018b). A short review of recent advances in $\mathrm{CO}_{2}$ hydrogenation to hydrocarbons over heterogeneous catalysts. RSC Adv. 8, 7651-7669. doi: 10.1039/C7RA13546G

Li, X., Wang, Y., Zhang, G., Sun, W., Bai, Y., Zheng, L., et al. (2019). Influence of Mg-promoted Ni-based catalyst supported on coconut shell carbon for $\mathrm{CO}_{2}$ methanation. Chem. Select 4, 838-845. doi: 10.1002/slct.201803369

$\mathrm{Li}, \mathrm{Y}$., Lu, G., and Ma, J. (2014). Highly active and stable nano NiO-MgO catalyst encapsulated by silica with a core-shell structure for $\mathrm{CO}_{2}$ methanation. RSC Adv. 4, 17420-17428. doi: 10.1039/C3RA46569A

Li, Y., Zhang, H., Zhang, L., and Zhang, H. (2019). Bimetallic Ni Pd/SBA-15 alloy as an effective catalyst for selective hydrogenation of $\mathrm{CO} 2$ to methane. Int. J. Hydr. Energy 44, 13354-13363. doi: 10.1016/j.ijhydene.2019.03.276

Li, Z., Das, S., Hongmanorom, P., Dewangan, N., Wai, M. H., and Kawi, S. (2018c). Silica-based micro- and mesoporous catalysts for dry reforming of methane. Catal. Sci. Technol. 8, 2763-2778. doi: 10.1039/C8CY00622A

Li, Z., Zhao, T., and Zhang, L. (2018d). Promotion effect of additive Fe on $\mathrm{Al}_{2} \mathrm{O}_{3}$ supported $\mathrm{Ni}$ catalyst for $\mathrm{CO}_{2}$ methanation. Appl. Organomet. Chem. 32:e4328. doi: $10.1002 /$ aoc. 4328

Liang, C., Hu, X., Wei, T., Jia, P., Zhang, Z., Dong, D., et al. (2019b). Methanation of $\mathrm{CO}_{2}$ over $\mathrm{Ni} / \mathrm{Al}_{2} \mathrm{O}_{3}$ modified with alkaline earth metals: Impacts of oxygen vacancies on catalytic activity. Int. J. Hydrogen Energy 44, 8197-8213. doi: 10.1016/j.ijhydene.2019.02.014

Liang, C., Wei, T., Wang, H., Yu, Z., Dong, D., Zhang, S., et al. (2019c). Impacts of $\mathrm{La}$ addition on formation of the reaction intermediates over alumina and silica supported nickel catalysts in methanation of CO2. J. Energy Inst. 93, 723-738. doi: 10.1016/j.joei.2019.05.009

Liang, C., Ye, Z., Dong, D., Zhang, S., Liu, Q., Chen, G., et al. (2019a). Methanation of $\mathrm{CO}_{2}$ : impacts of modifying nickel catalysts with variable-valence additives on reaction mechanism. Fuel 254:115864. doi: 10.1016/j.fuel.2019.115654

Lin, J., Ma, C., Wang, Q., Xu, Y., Ma, G., Wang, J., et al. (2019). Enhanced low-temperature performance of $\mathrm{CO}_{2}$ methanation over mesoporous $\mathrm{Ni} / \mathrm{Al}_{2} \mathrm{O}_{3}-\mathrm{ZrO}_{2}$ catalysts. Appl. Catal. B Environ. 243, 262-272. doi: 10.1016/j.apcatb.2018.10.059

Liu, H., Xu, S., Zhou, G., Xiong, K., Jiao, Z., and Wang, S. (2018). $\mathrm{CO}_{2}$ hydrogenation to methane over Co/KIT-6 catalysts: effect of Co content. Fuel 217, 570-576. doi: 10.1016/j.fuel.2017.12.112

Liu, H., Zou, X., Wang, X., Lu, X., and Ding, W. (2012). Effect of $\mathrm{CeO}_{2}$ addition on $\mathrm{Ni} / \mathrm{Al}_{2} \mathrm{O}_{3}$ catalysts for methanation of carbon dioxide with hydrogen. J. Nat. Gas Chem. 21, 703-707. doi: 10.1016/S1003-9953(11)60422-2

Liu, J., Bing, W., Xue, X., Wang, F., Wang, B., He, S., et al. (2016). Alkaline-assisted $\mathrm{Ni}$ nanocatalysts with largely enhanced low-temperature activity toward $\mathrm{CO}_{2}$ methanation. Catal. Sci. Technol. 6, 3976-3983. doi: 10.1039/C5CY02026C

Liu, J., Cui, D., Yu, J., Su, F., and Xu, G. (2015). Performance characteristics of flfluidized bed syngas methanation over $\mathrm{Ni}-\mathrm{Mg} / \mathrm{Al}_{2} \mathrm{O}_{3}$ catalyst. Chin. J. Chem. Eng. 23, 86-92. doi: 10.1016/j.cjche.2014.09.038

Liu, J., Li, C., Wang, F., He, S., Chen, H., Zhao, Y., et al. (2013). Enhanced low-temperature activity of $\mathrm{CO} 2$ methanation over highly-dispersed Ni/TiO2 catalyst. Catal. Sci. Technol. 3, 2627-2633. doi: 10.1039/c3cy00355h

Liu, Q., Bian, B., Fan, J., and Yang, J. (2018b). Cobalt doped Ni based ordered mesoporous catalysts for $\mathrm{CO}_{2}$ methanation with enhanced catalytic performance. Int. J. Hydro. Ener. 43, 4893-4901. doi: 10.1016/j.ijhydene.2018.01.132

Liu, Q., Gao, J., Gu, F., Lu, X., Liu, Y., Li, H., et al. (2015). One-pot synthesis of ordered mesoporous Ni-V-Al catalysts for CO methanation. J. Catal. 326, 127-138. doi: 10.1016/j.jcat.2015.04.003

Liu, Q., Gu, F., Gao, J., Li, H., Xu, G., and Su, F. (2014). Coking-resistant Ni$\mathrm{ZrO}_{2} / \mathrm{Al}_{2} \mathrm{O}_{3}$ catalyst for $\mathrm{CO}$ methanation. J. Nat. Gas. Chem. 23, 761-770. doi: 10.1016/S2095-4956(14)60210-2
Liu, Q., Wang, S., Zhao, G., Yang, H., Yuan, M., An, X., et al. (2018a). $\mathrm{CO}_{2}$ methanation over ordered mesoporous NiRu-doped $\mathrm{CaO}-\mathrm{Al}_{2} \mathrm{O}_{3}$ nanocomposites with enhanced catalytic performance. Int. J. Hydro. Ener. 43, 239-250. doi: 10.1016/j.ijhydene.2017.11.052

Liu, Q., Zhong, Z., Gu, F., Wang, X., Lu, X., Li, H., et al. (2016). CO methanation on ordered mesoporous Ni-Cr-Al catalysts: effects of the catalyst structure and $\mathrm{Cr}$ promoter on the catalytic properties. J. Catal. 337, 221-232. doi: 10.1016/j.jcat.2016.01.023

Liu, W., Li, L., Zhang, X., Wang, Z., Wang, X., and Peng, H. (2018). Design of $\mathrm{Ni}-\mathrm{ZrO}_{2} @ \mathrm{SiO}_{2}$ catalyst with ultra-high sintering and coking resistance for dry reforming of methane to prepare syngas. J. CO2 Util. 27, 297-307. doi: 10.1016/j.jcou.2018.08.003

Liu, X., Wang, D., and Li, Y. (2012). Synthesis and catalytic properties of bimetallic nanomaterials with various architectures. Nanotoday 7, 448-466. doi: 10.1016/j.nantod.2012.08.003

Lo Faro, M., Frontera, P., Antonucci, P., and Aric,ò, A. S. (2015). Ni$\mathrm{Cu}$ based catalysts prepared by two different methods and their catalytic activity toward the ATR of methane. Chem. Eng. Res. Des. 93, 269-277. doi: 10.1016/j.cherd.2014.05.014

Löfberg, A., Guerrero-Caballero, J., Kane, T., Rubbens, A., and JalowieckiDuhamel, L. (2017). Ni/ $\mathrm{CeO}_{2}$ based catalysts as oxygen vectors for the chemical looping dry reforming of methane for syngas production. Appl. Catal. B Environ. 212, 159-174. doi: 10.1016/j.apcatb.2017.04.048

Long, X., Qiu, W., Wang, Z., Wang, Y., and Yang, S. (2019). Recent advances in transition metal-based catalysts with heterointerfaces for energy conversion and storage. Mater. Today Chem. 11, 16-28. doi: 10.1016/j.mtchem.2018.09.003 Luengnaruemitchai, A., and Kaengsilalai, A. (2008). Activity of different zeolitesupported Ni catalysts for methane reforming with carbon dioxide. Chem. Eng. J. 144, 96-102. doi: 10.1016/j.cej.2008.05.023

Ma, H., Ma, K., Ji, J., Tang, S., Liu, C., Jiang, W., et al. (2019). Graphene intercalated $\mathrm{Ni}-\mathrm{SiO}_{2} / \mathrm{GO}$-Ni-foam catalyst with enhanced reactivity and heat-transfer for $\mathrm{CO}_{2}$ methanation. Chem. Eng. Sci. 194, 10-21. doi: 10.1016/j.ces.2018.05.019

Ma, S., Tan, Y., and Han, Y. (2011). Methanation of syngas over coral reef-like $\mathrm{Ni} / \mathrm{Al}_{2} \mathrm{O}_{3}$ catalysts. J. Nat. Gas. Chem. 20, 435-440. doi: 10.1016/S1003-9953(10)60192-2

Martínez, J., Hernández, E., Alfaro, S., López Medina, R., Valverde Aguilar, G., Albiter, E., et al. (2018). High selectivity and stability of nickel catalysts for $\mathrm{Co} 2$ methanation: support effects. Catalysts 9:24. doi: 10.3390/catal9010024

Miguel, C. V., Mendes, A., and Madeira, L. M. (2018). Intrinsic kinetics of $\mathrm{CO}_{2}$ methanation over an industrial nickel-based catalyst. J. CO2 Util. 25, 128-136. doi: $10.1016 /$ j.jcou.2018.03.011

Mihet, M., and Lazar, M. D. (2018). Methanation of $\mathrm{CO}_{2}$ on $\mathrm{Ni} / \gamma-\mathrm{Al}_{2} \mathrm{O}_{3}$ : influence of $\mathrm{Pt}, \mathrm{Pd}$ or $\mathrm{Rh}$ promotion. Catal. Today 306, 294-299. doi: 10.1016/j.cattod.2016.12.001

Moghaddam, S. V., Rezaei, M., Meshkani, F., and Daroughegi, R. (2018). Synthesis of nanocrystalline mesoporous $\mathrm{Ni} / \mathrm{Al}_{2} \mathrm{O}_{3} \mathrm{SiO}_{2}$ catalysts for $\mathrm{CO}_{2}$ methanation reaction. Int. J. Hydro. Ener. 43, 19038-19046. doi: 10.1016/j.ijhydene.2018.08.163

Movasati, A., Alavi, S. M., and Mazloom, G. (2017). $\mathrm{CO}_{2}$ reforming of methane over $\mathrm{Ni} / \mathrm{ZnAl}_{2} \mathrm{O}_{4}$ catalysts: influence of $\mathrm{Ce}$ addition on activity and stability. Int. J. Hydro. Ener. 42, 16436-16448. doi: 10.1016/j.ijhydene.2017. 05.199

Muroyama, H., Tsuda, Y., Asakoshi, T., Masitah, H., Okanishi, T., Matsui, T., et al. (2016). Carbon dioxide methanation over Ni catalysts supported on various metal oxides. J. Catal. 343, 178-184. doi: 10.1016/j.jcat.2016.07.018

Mutz, B., Belimov, M., Wang, W., Sprenger, P., Serrer, M.-A., Wang, D., et al. (2017). Potential of an alumina-supported Ni3Fe catalyst in the methanation of $\mathrm{CO}_{2}$ : impact of alloy formation on activity and stability. ACS Catal. 7, 6802-6814. doi: 10.1021/acscatal.7b01896

Mutz, B., Carvalho, H. W. P., Mangold, S., Kleist, W., and Grunwaldt, J. D. (2015). Methanation of $\mathrm{CO}_{2}$ : structural response of a Ni-based catalyst under fluctuating reaction conditions unraveled by operando spectroscopy. J. Catal. 327, 48-53. doi: 10.1016/j.jcat.2015.04.006

Mutz, B., Sprenger, P., Wang, W., Wang, D., Kleist, W., and Grunwaldt, J. D. (2018). Operando raman spectroscopy on $\mathrm{CO}_{2}$ methanation over alumina-supported $\mathrm{Ni}, \mathrm{Ni3} F e$ and NiRh0.1 catalysts: role of carbon formation as possible deactivation pathway. Appl. Catal. A Gen. 556, 160-171. doi: 10.1016/j.apcata.2018.01.026 
Navarro-Jaén, S., Navarro, J. C., Bobadilla, L. F., Centeno, M. A., Laguna, O. H., and Odriozola, J. A. (2019). Size-tailored Ru nanoparticles deposited over $\gamma-\mathrm{Al}_{2} \mathrm{O}_{3}$ for the $\mathrm{CO}_{2}$ methanation reaction. Appl. Surf. Sci. 483, 750-761. doi: 10.1016/j.apsusc.2019.03.248

Ocampo, F., Louis, B., Kiwi-Minsker, L., and Roger, A.-C. (2011). Effect of $\mathrm{Ce} / \mathrm{Zr}$ composition and noble metal promotion on nickel based $\mathrm{Ce}_{\mathrm{x}} \mathrm{Zr}_{1-\mathrm{x}} \mathrm{O}_{2}$ catalysts for carbon dioxide methanation. Appl. Catal. A Gen. 392, 36-44. doi: 10.1016/j.apcata.2010.10.025

Oemar, U., Hidajat, K., and Kawi, S. (2015). Pd-Ni catalyst over spherical nanostructured $\mathrm{Y}_{2} \mathrm{O}_{3}$ support for oxy- $\mathrm{CO}_{2}$ reforming of methane: role of surface oxygen mobility. Int. J. Hydro. Ener. 40, 12227-12238. doi: 10.1016/j.ijhydene.2015.07.076

Ou, Z., Qin, C., Niu, J., Zhang, L., and Ran, J. (2019). A comprehensive DFT study of $\mathrm{CO}_{2}$ catalytic conversion by $\mathrm{H} 2$ over Pt-doped $\mathrm{Ni}$ catalysts. Int. J. Hydro. Ener. 44, 819-834. doi: 10.1016/j.ijhydene.2018.11.008

Özdemir, H., Öksüzömer, M. A. F., and Gürkaynak, M.A. (2014). Effect of the calcination temperature on $\mathrm{Ni} / \mathrm{MgAl}_{2} \mathrm{O}_{4}$ catalyst structure and catalytic properties for partial oxidation of methane. Fuel 116, 63-70. doi: 10.1016/j.fuel.2013.07.095

Pan, Q., Peng, J., Sun, T., Wang, S., and Wang, S. (2014). Insight into the reaction route of $\mathrm{CO}_{2}$ methanation: promotion effect of medium basic sites. Catal. Commun. 45, 74-78. doi: 10.1016/j.catcom.2013.10.034

Panagiotopoulou, P. (2017). Hydrogenation of $\mathrm{CO}_{2}$ over supported noble metal catalysts. Appl. Catal. A Gen. 542, 63-70. doi: 10.1016/j.apcata.2017.05.026

Pastor-Pérez, L., Patel, V., Le Sach,é, E., and Reina, T. R. (2019). CO2 methanation in the presence of methane: catalysts design and effect of methane concentration in the reaction mixture. J. Ener. Inst. 93, 415-424. doi: 10.1016/j.joei.2019.01.015

Pastor-Pérez, L., Sach,é, E. L., Jones, C., Gu, S., Arellano-Garcia, H., and Reina, T. R. (2018). Synthetic natural gas production from $\mathrm{CO}_{2}$ over $\mathrm{Ni}-\mathrm{x} / \mathrm{CeO}_{2}-\mathrm{ZrO}_{2}$ $(\mathrm{x}=\mathrm{Fe}, \mathrm{Co})$ catalysts: influence of promoters and space velocity. Catal. Today 317, 108-113. doi: 10.1016/j.cattod.2017.11.035

Peymani, M., Alavi, S. M., and Rezaei, M. (2017). Synthesis gas production by catalytic partial oxidation of propane on mesoporous nanocrystalline $\mathrm{Ni} / \mathrm{Al}_{2} \mathrm{O}_{3}$ catalysts. Appl. Catal. A Gen. 529, 1-9. doi: 10.1016/j.apcata.2016.10.012

Pizzolitto, C., Pupulin, E., Menegazzo, F., Ghedini, E., Di Michele, A., Mattarelli, M., et al. (2019). Nickel based catalysts for methane dry reforming: effect of supports on catalytic activity and stability. Int. J. Hydro. Ener. 44, 28065-28076. doi: 10.1016/j.ijhydene.2019.09.050

Polanski, J., Siudyga, T., Bartczak, P., Kapkowski, M., Ambrozkiewicz, W., Nobis, A., et al. (2017). Oxide passivated Ni-supported $\mathrm{Ru}$ nanoparticles in silica: a new catalyst for low-temperature carbon dioxide methanation. Appl. Catal. B Environ. 206, 16-23. doi: 10.1016/j.apcatb.2017.01.017

Qin, Z., Wang, X., Dong, L., Su, T., Li, B., Zhou, Y., et al. (2019). $\mathrm{CO}_{2}$ methanation on $\mathrm{Co} / \mathrm{TiO} 2$ catalyst: effects of $\mathrm{Y}$ on the support. Chem. Eng. Sci. 210:115245. doi: 10.1016/j.ces.2019.115245

Quindimil, A., De-La-Torre, U., Pereda-Ayo, B., Davó-Quiñonero, A., BailónGarcía, E., Lozano-Castelló, D., et al. (2019). Effect of metal loading on the $\mathrm{CO}_{2}$ methanation: a comparison between alumina supported $\mathrm{Ni}$ and $\mathrm{Ru}$ catalysts. Catal. Today. doi: 10.1016/j.cattod.2019.06.027. [Epub ahead of print].

Quindimil, A., De-La-Torre, U., Pereda-Ayo, B., González-Marcos, J. A., and González-Velasco, J. R. (2018). Ni catalysts with La as promoter supported over Y- and BETA- zeolites for $\mathrm{CO}_{2}$ methanation. Appl. Catal. B Environ. 238, 393-403. doi: 10.1016/j.apcatb.2018.07.034

Rahmani, S., Rezaei, M., and Meshkani, F. (2014). Preparation of promoted nickel catalysts supported on mesoporous nanocrystalline gamma alumina for carbon dioxide methanation reaction. J. Ind. Eng. Chem. 20, 4176-4182. doi: 10.1016/j.jiec.2014.01.017

Ramezani, Y., Meshkani, F., and Rezaei, M. (2018). Promotional effect of $\mathrm{Mg}$ in trimetallic nickel-manganese-magnesium nanocrystalline catalysts in $\mathrm{CO}_{2}$ reforming of methane. Int. J. Hydro. Ener. 43, 22347-22356. doi: 10.1016/j.ijhydene.2018.09.222

Ratchahat, S., Sudoh, M., Suzuki, Y., Kawasaki, W., Watanabe, R., and Fukuhara, C. (2018). Development of a powerful $\mathrm{CO}_{2}$ methanation process using a structured $\mathrm{Ni} / \mathrm{CeO} 2$ catalyst. J. CO2 Util. 24, 210-219. doi: 10.1016/j.jcou.2018.01.004

Ray, K., Bhardwaj, R., Singh, B., and Deo, G. (2018). Developing descriptors for $\mathrm{CO}_{2}$ methanation and $\mathrm{CO}_{2}$ reforming of $\mathrm{CH}_{4}$ over $\mathrm{Al}_{2} \mathrm{O}_{3}$ supported $\mathrm{Ni}$ and low-cost Ni based alloy catalysts. Phys. Chem. Chem. Phys. 20, 15939-15950. doi: 10.1039/C8CP01859F

Ren, J., Qin, X., Yang, J.-Z., Qin, Z.-F., Guo, H.-L., Lin, J. Y., et al. (2015). Methanation of carbon dioxide over $\mathrm{Ni}-\mathrm{M} / \mathrm{ZrO}_{2}(\mathrm{M}=\mathrm{Fe}, \mathrm{Co}, \mathrm{Cu})$ catalysts: effect of addition of a second metal. Fuel Process. Technol. 137, 204-211. doi: 10.1016/j.fuproc.2015.04.022

Rezaei, M., and Alavi, S. M. (2019). Dry reforming over mesoporous nanocrystalline $5 \% \mathrm{Ni} / \mathrm{M}-\mathrm{MgAl}_{2} \mathrm{O}_{4}\left(\mathrm{M}: \mathrm{CeO}_{2}, \mathrm{ZrO}_{2}, \mathrm{La}_{2} \mathrm{O}_{3}\right)$ catalysts. Int. J. Hydro. Ener. 44, 16516-16525. doi: 10.1016/j.ijhydene.2019.04.213

Romero-Sáez, M., Dongil, A. B., Benito, N., Espinoza-González, R., Escalona, N., and Gracia, F. (2018). $\mathrm{CO}_{2}$ methanation over nickel- $\mathrm{ZrO}_{2}$ catalyst supported on carbon nanotubes: a comparison between two impregnation strategies. Appl. Catal. B Environ. 237, 817-825. doi: 10.1016/j.apcatb.2018.06.045

Rönsch, S., Schneider, J., Matthischke, S., Schlüter, M., Götz, M., Lefebvre, J., et al. (2016). Review on methanation-from fundamentals to current projects. Fuel 166, 276-296. doi: 10.1016/j.fuel.2015.10.111

Shadravan, V., Kennedy, E., and Stockenhuber, M. (2018). An experimental investigation on the effects of adding a transition metal to $\mathrm{Ni} / \mathrm{Al}_{2} \mathrm{O}_{3}$ for catalytic hydrogenation of $\mathrm{CO}$ and $\mathrm{CO}_{2}$ in presence of light alkanes and alkenes. Catal. Today 307, 277-285. doi: 10.1016/j.cattod.2017.05.036

Shang, X., Deng, D., Wang, X., Xuan, W., Zou, X., Ding, W., et al. (2018). Enhanced low-temperature activity for $\mathrm{CO}_{2}$ methanation over $\mathrm{Ru}$ doped the $\mathrm{Ni} / \mathrm{Ce}_{\mathrm{x}} \mathrm{Zr}_{1-\mathrm{x}} \mathrm{O}_{2}$ catalysts prepared by one-pot hydrolysis method. Int. J. Hydro. Ener. 43, 7179-7189. doi: 10.1016/j.ijhydene.2018.02.059

Sharma, S., Hu, Z., Zhang, P., McFarland, E. W., and Metiu, H. (2011). $\mathrm{CO}_{2}$ methanation on Ru-doped ceria. J. Catal. 278, 297-309. doi: $10.1016 /$ j.jcat.2010.12.015

Shen, W., Momoi, H., Komatsubara, K., Saito, T., Yoshida, A., and Naito, S. (2011). Marked role of mesopores for the prevention of sintering and carbon deposition in dry reforming of methane over ordered mesoporous $\mathrm{Ni}-\mathrm{Mg}$-Al oxides. Catal. Today 171, 150-155. doi: 10.1016/j.cattod.2011.04.003

Siang, T. J., Singh, S., Omoregbe, O., Bach, L. G., Phuc, N. H. H., and Vo, D. V. N. (2018). Hydrogen production from $\mathrm{CH} 4$ dry reforming over bimetallic $\mathrm{Ni}-\mathrm{Co} / \mathrm{Al}_{2} \mathrm{O}_{3}$ catalyst. J. Ener. Inst. 91, 683-694. doi: 10.1016/j.joei.2017.06.001

Solis-Garcia, A., and Fierro-Gonzalez, J. C. (2019). Mechanistic insights into the $\mathrm{CO}_{2}$ methanation catalyzed by supported metals: a review. J. Nanosci. Nanotechnol. 19, 3110-3123. doi: 10.1166/jnn.2019.16606

Solis-Garcia, A., Louvier-Hernandez, J. F., Almendarez-Camarillo, A., and Fierro-Gonzalez, J. C. (2017). Participation of surface bicarbonate, formate and methoxy species in the carbon dioxide methanation catalyzed by $\mathrm{ZrO}_{2}$-supported Ni. Appl. Catal. B Environ. 218, 611-620. doi: 10.1016/j.apcatb.2017.06.063

Song, F., Zhong, Q., Yu, Y., Shi, M., Wu, Y., Hu, J., and Song, Y. (2017). Obtaining well-dispersed $\mathrm{Ni} / \mathrm{Al}_{2} \mathrm{O}_{3}$ catalyst for $\mathrm{CO}_{2}$ methanation with a microwave-assisted method. Int. J. Hydro. Ener. 42, 4174-4183. doi: 10.1016/j.ijhydene.2016.10.141

Stangeland, K., Kalai, D., Li, H., and Yu, Z. (2017a). $\mathrm{CO}_{2}$ methanation: the effect of catalysts and reaction conditions. Ener. Proce. 105, 2022-2027. doi: 10.1016/j.egypro.2017.03.577

Stangeland, K., Kalai, D., Li, H., and Yu, Z. (2017b). The effect of temperature and initial methane concentration on carbon dioxide methanation on $\mathrm{Ni}$ based catalysts. Ener. Proce. 105, 2016-2021. doi: 10.1016/j.egypro.2017.03.576

Steinhauer, B., Kasireddy, M. R., Radnik, J., and Martin, A. (2009). Development of Ni-Pd bimetallic catalysts for the utilization of carbon dioxide and methane by dry reforming. Appl. Catal. A Gen. 366, 333-341. doi: 10.1016/j.apcata.2009.07.021

Su, X., Xu, J., Liang, B., Duan, H., Hou, B., and Huang, Y. (2016). Catalytic carbon dioxide hydrogenation to methane: a review of recent studies. J. Nat. Gas. Chem. 25, 553-565. doi: 10.1016/j.jechem.2016.03.009

Sun, H., Wang, H., and Zhang, J. (2007). Preparation and characterization of nickel-titanium composite xerogel catalyst for $\mathrm{CO}_{2}$ reforming of CH4. Appl. Catal. B Environ. 73, 158-165. doi: 10.1016/j.apcatb.2006.07.019

Tada, S., Ikeda, S., Shimoda, N., Honma, T., Takahashi, M., Nariyuki, A., et al. (2017). Sponge Ni catalyst with high activity in $\mathrm{CO}_{2}$ methanation. Int. J. Hydro. Ener. 42, 30126-30134. doi: 10.1016/j.ijhydene.2017. 10.138

Tada, S., Shimizu, T., Kameyama, H., Haneda, T., and Kikuchi, R. (2012). $\mathrm{Ni} / \mathrm{CeO}_{2}$ catalysts with high $\mathrm{CO}_{2}$ methanation activity and high $\mathrm{CH}_{4}$ 
selectivity at low temperatures. Int. J. Hydro. Ener. 37, 5527-5531. doi: 10.1016/j.ijhydene.2011.12.122

Takano, H., Kirihata, Y., Izumiya, K., Kumagai, N., Habazaki, H., and Hashimoto, K. (2016). Highly active $\mathrm{Ni} / \mathrm{Y}$-doped $\mathrm{ZrO}_{2}$ catalysts for $\mathrm{CO}_{2}$ methanation. Appl. Surf. Sci. 388, 653-663. doi: 10.1016/j.apsusc.2015.11.187

Tan, J., Wang, J., Zhang, Z., Ma, Z., Wang, L., and Liu, Y. (2019). Highly dispersed and stable Ni nanoparticles confined by $\mathrm{MgO}$ on $\mathrm{ZrO}_{2}$ for $\mathrm{CO}_{2}$ methanation. Appl. Surf. Sci. 481, 1538-1548. doi: 10.1016/j.apsusc.2019.03.217

Toemen, S., Abu Bakar, W. A. W., and Ali, R. (2016). Effect of ceria and strontia over $\mathrm{Ru} / \mathrm{Mn} / \mathrm{Al}_{2} \mathrm{O}_{3}$ catalyst: catalytic methanation, physicochemical and mechanistic studies. J. CO2 Util. 13, 38-49. doi: 10.1016/j.jcou.2015.11.005

Valinejad Moghaddam, S., Rezaei, M., Meshkani, F., and Daroughegi, R. (2018). Carbon dioxide methanation over Ni-M/Al2O3 (M: Fe, CO, Zr, La and $\mathrm{Cu}$ ) catalysts synthesized using the one-pot sol-gel synthesis method. Int. J. Hydro. Ener. 43, 16522-16533. doi: 10.1016/j.ijhydene.2018.07.013

Veselovskaya, J. V., Parunin, P. D., Netskina, O. V., Kibis, L. S., Lysikov, A. I., and Okunev, A. G. (2018). Catalytic methanation of carbon dioxide captured from ambient air. Energy 159, 766-773. doi: 10.1016/j.energy.2018.06.180

Vidal Vázquez, F., Kihlman, J., Mylvaganam, A., Simell, P., Koskinen-Soivi, M. L., and Alopaeus, V. (2018). Modeling of nickel-based hydrotalcite catalyst coated on heat exchanger reactors for $\mathrm{CO}_{2}$ methanation. Chem. Eng. J. 349, 694-707. doi: 10.1016/j.cej.2018.05.119

Wan Abu Bakar, W. A., Ali, R., and Mohammad, N. S. (2015). The effect of noble metals on catalytic methanation reaction over supported $\mathrm{Mn} / \mathrm{Ni}$ oxide based catalysts. Arab. J. Chem. 8, 632-643. doi: 10.1016/j.arabjc.2013.06.009

Wang, A., Hsieh, Y., Chen, Y., and Mou, C. (2006). Au-Ag alloy nanoparticle as catalyst for $\mathrm{CO}$ oxidation: effect of $\mathrm{Si} / \mathrm{Al}$ ratio of mesoporous support. J. Catal. 237, 197-206. doi: 10.1016/j.jcat.2005. 10.030

Wang, F., Han, B., Zhang, L., Xu, L., Yu, H., and Shi, W. (2018). $\mathrm{CO}_{2}$

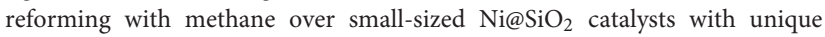
features of sintering-free and low carbon. Appl. Catal. B Environ. 235, 26-35. doi: 10.1016/j.apcatb.2018.04.069

Wang, F., He, S., Chen, H., Wang, B., Zheng, L., Wei, M., et al. (2016). Active site dependent reaction mechanism over $\mathrm{Ru} / \mathrm{CeO}_{2}$ catalyst toward $\mathrm{CO}_{2}$ methanation. J. Am. Chem. Soc. 138, 6298-6305. doi: 10.1021/jacs.6b02762

Wang, W., Chu, W., Wang, N., Yang, W., and Jiang, C. (2016). Mesoporous nickel catalyst supported on multi-walled carbon nanotubes for carbon dioxide methanation. Int. J. Hydro. Ener. 41, 967-975. doi: 10.1016/j.ijhydene.2015.11.133

Wang, X., Zhu, L., Liu, Y., and Wang, S. (2018). $\mathrm{CO}_{2}$ methanation on the catalyst of Ni/MCM-41 promoted with $\mathrm{CeO}_{2}$. Sci. Total Environ. 625, 686-695. doi: 10.1016/j.scitotenv.2017.12.308

Wang, Y., Yao, L., Wang, S., Mao, D., and Hu, C. (2018). Low-temperature catalytic $\mathrm{CO}_{2}$ dry reforming of methane on Ni-based catalysts: a review. Fuel Process. Technol. 169, 199-206. doi: 10.1016/j.fuproc.2017.10.007

Westermann, A., Azambre, B., Bacariza, M. C., Graça, I., Ribeiro, M. F., Lopes, J. M., et al. (2015). Insight into $\mathrm{CO}_{2}$ methanation mechanism over NiUSY zeolites: an operando IR study. Appl. Catal. B Environ. 174-175, 120-125. doi: 10.1016/j.apcatb.2015.02.026

Wierzbicki, D., Baran, R., Debek, R., Motak, M., Grzybek, T., Gálvez, M. E., et al. (2017). The influence of nickel content on the performance of hydrotalcitederived catalysts in $\mathrm{CO}_{2}$ methanation reaction. Int. J. Hydro. Ener. 42, 23548-23555. doi: 10.1016/j.ijhydene.2017.02.148

Wierzbicki, D., Debek, R., Motak, M., Grzybek, T., Gálvez, M. E., and Da Costa, P. (2016). Novel Ni-La-hydrotalcite derived catalysts for $\mathrm{CO}_{2}$ methanation. Catal. Commun. 83, 5-8. doi: 10.1016/j.catcom.2016.04.021

Wierzbicki, D., Moreno, M. V., Ognier, S., Motak, M., Grzybek, T., Da Costa, P., et al. (2019). Ni-Fe layered double hydroxide derived catalysts for nonplasma and DBD plasma-assisted CO2 methanation. Int. J. Hydro. Ener. 45, 10423-10432. doi: 10.1016/j.ijhydene.2019.06.095

Wolf, M., Schüler, C., and Hinrichsen, O. (2019). Sulfur poisoning of coprecipitated $\mathrm{Ni}-\mathrm{Al}$ catalysts for the methanation of $\mathrm{CO}_{2}$. J. CO2 Util. 32, 80-91. doi: 10.1016/j.jcou.2019.03.003

Xanthopoulou, G., Thoda, O., Roslyakov, S., Steinman, A., Kovalev, D., Levashov, E., et al. (2018). Solution combustion synthesis of nano-catalysts with a hierarchical structure. J. Catal. 364, 112-124. doi: 10.1016/j.jcat.2018. 04.003
Xiang, X., Zhao, H., Yang, J., Zhao, J., Yan, L., Song, H., et al. (2016). Nickel based mesoporous silica-ceria-zirconia composite for carbon dioxide reforming of methane. Appl. Catal. A Gen. 520, 140-150. doi: 10.1016/j.apcata.2016.04.020

Xiong, J., Dong, X., Song, Y., and Dong, Y. (2013). A high performance $\mathrm{Ru}-\mathrm{ZrO}_{2} /$ carbon nanotubes-Ni foam composite catalyst for selective $\mathrm{CO}$ methanation. J. Power Sour. 242, 132-136. doi: 10.1016/j.jpowsour.2013.05.084

Xiong, Y., Wang, B., Yan, J., Hong, J., Wang, L., Zhang, Y., et al. (2019). Plasma assisted preparation of nickel-based catalysts supported on $\mathrm{CeO}_{2}$ with different morphologies for hydrogen production by glycerol steam reforming. Powder Technol. 354, 324-332. doi: 10.1016/j.powtec.2019.06.003

Xu, L., Cui, Y., Chen, M., Lian, X., Yang, B., Wu, C., et al. (2019). Effects of the fabrication strategy on the catalytic performances of Co-Ni bimetal ordered mesoporous catalysts toward $\mathrm{CO}_{2}$ methanation. Sustain. Ener. Fuels 3, 3038-3049. doi: 10.1039/C9SE00336C

Xu, L., Lian, X., Chen, M., Cui, Y., Wang, F., Li, W., et al. (2018). $\mathrm{CO}_{2}$ methanation over Co Ni bimetal-doped ordered mesoporous $\mathrm{Al}_{2} \mathrm{O}_{3}$ catalysts with enhanced low-temperature activities. Int. J. Hydro. Ener. 43, 17172-17184. doi: 10.1016/j.ijhydene.2018.07.106

Xu, L., Wang, F., Chen, M., Nie, D., Lian, X., Lu, Z., et al. (2017c). $\mathrm{CO}_{2}$ methanation over rare earth doped $\mathrm{Ni}$ based mesoporous catalysts with intensified low-temperature activity. Int. J. Hydro. Ener. 42, 15523-15539. doi: 10.1016/j.ijhydene.2017.05.027

Xu, L., Wang, F., Chen, M., Yang, H., Nie, D., Qi, L., et al. (2017b). Alkaline-promoted $\mathrm{Ni}$ based ordered mesoporous catalysts with enhanced low-temperature catalytic activity toward $\mathrm{CO}_{2}$ methanation. RSC $A d v .7$, 18199-18210. doi: 10.1039/C7RA01673E

Xu, L., Wang, F., Chen, M., Zhang, J., Yuan, K., Wang, L., et al. (2016). $\mathrm{CO}_{2}$ methanation over a $\mathrm{Ni}$ based ordered mesoporous catalyst for the production of synthetic natural gas. RSC Adv .6, 28489-28499. doi: 10.1039/C6RA01139J

Xu, L., Yang, H., Chen, M., Wang, F., Nie, D., Qi, L., et al. (2017a). $\mathrm{CO}_{2}$ methanation over $\mathrm{Ca}$ doped ordered mesoporous $\mathrm{Ni}$ - $\mathrm{Al}$ composite oxide catalysts: the promoting effect of basic modifier. J. CO2 Util. 21, 200-210. doi: 10.1016/j.jcou.2017.07.014

Xu, L., Zhao, H., Song, H., and Chou, L. (2012). Ordered mesoporous alumina supported nickel based catalysts for carbon dioxide reforming of methane. Int. J. Hydro. Ener. 37, 7497-7511. doi: 10.1016/j.ijhydene.2012.01.105

Xu, Y., Du, X.-H., Li, J., Wang, P., Zhu, J., Ge, F. J., et al. (2019). A comparison of $\mathrm{Al}_{2} \mathrm{O}_{3}$ and $\mathrm{SiO}_{2}$ supported Ni-based catalysts in their performance for the dry reforming of methane. J.Fuel Chem. Technol. 47, 199-208. doi: 10.1016/S1872-5813(19)30010-6

Yan, X., Hu, T., Liu, P., Li, S., Zhao, B., Zhang, Q., et al. (2019). Highly efficient and stable $\mathrm{Ni} / \mathrm{CeO}_{2}-\mathrm{SiO}_{2}$ catalyst for dry reforming of methane: effect of interfacial structure of $\mathrm{Ni} / \mathrm{CeO}_{2}$ on $\mathrm{SiO}_{2}$. Appl. Catal. B Environ. 246, 221-231. doi: 10.1016/j.apcatb.2019.01.070

Yang Lim, J., McGregor, J., Sederman, A. J., and Dennis, J. S. (2016). Kinetic studies of $\mathrm{CO}_{2}$ methanation over a $\mathrm{Ni} / \gamma-\mathrm{Al}_{2} \mathrm{O}_{3}$ catalyst using a batch reactor. Chem. Eng. Sci. 141, 28-45. doi: 10.1016/j.ces.2015.10.026

Ye, R. P., Gong, W., Sun, Z., Sheng, Q., Shi, X., Wang, T., et al. (2019). Enhanced stability of $\mathrm{Ni} / \mathrm{SiO}_{2}$ catalyst for $\mathrm{CO}_{2}$ methanation: derived from nickel phyllosilicate with strong metal-support interactions. Energy 188:116059. doi: 10.1016/j.energy.2019.116059

Younas, M., Sethupathi, S., Kong, L. L., and Mohamed, A. R. (2018). $\mathrm{CO}_{2}$ methanation over $\mathrm{Ni}$ and $\mathrm{Rh}$ based catalysts: Process optimization at moderate temperature. Int. J. Ener. Res. 42, 3289-3302. doi: 10.1002/er.4082

Yuan, H., Zhu, X., Han, J., Wang, H., and Ge, Q. (2018). Rhenium-promoted selective $\mathrm{CO}_{2}$ methanation on Ni-based catalyst. J. CO2 Util. 26, 8-18. doi: 10.1016/j.jcou.2018.04.010

Zagaynov, I. V., Loktev, A. S., Mukhin, I. E., Konovalov, A. A., Dedov, A. G., and Moiseev, I. I. (2019). Trimetallic NiCoM catalysts $(\mathrm{M}=\mathrm{Mn}, \mathrm{Fe}$, $\mathrm{Cu}$ ) for methane conversion into synthesis gas. Men. Commun. 29, 22-24. doi: 10.1016/j.mencom.2019.01.006

Zamani, A. H., Ali, R., and Abu Bakar, W. A. W. (2015). Optimization of $\mathrm{CO}_{2}$ methanation reaction over $\mathrm{M}^{*} / \mathrm{Mn} / \mathrm{Cu}-\mathrm{Al}_{2} \mathrm{O}_{3}\left(\mathrm{M}^{*}: \mathrm{Pd}, \mathrm{Rh}\right.$ and $\left.\mathrm{Ru}\right)$ catalysts. J. Ind. Eng. Chem. 29, 238-248. doi: 10.1016/j.jiec.2015.02.028

Zamani, A. H., Shohaimi, N. A. M., Rosid, S. J. M., Abdullah, N. H., and Shukri, N. M. (2019). Enhanced low temperature reaction for the $\mathrm{CO}_{2}$ methanation over Ru promoted $\mathrm{Cu} / \mathrm{Mn}$ on alumina support catalyst using double reactor system. J. Taiwan Inst. Chem. Eng. 96, 400-408. doi: 10.1016/j.jtice.2018.12.009 
Zhan, Y., Wang, Y., Gu, D., Chen, C., Jiang, L., and Takehira, K. (2018). Ni/ $\mathrm{Al}_{2} \mathrm{O}_{3}$ $\mathrm{ZrO}_{2}$ catalyst for $\mathrm{CO}_{2}$ methanation: the role of $\gamma$-(Al, $\left.\mathrm{Zr}\right)_{2} \mathrm{O}_{3}$ formation. Appl. Surf. Sci. 459, 74-79. doi: 10.1016/j.apsusc.2018.07.206

Zhang, C., Hu, X., Zhang, Z., Zhang, L., Dong, D., Gao, G., et al. (2018). Steam reforming of acetic acid over $\mathrm{Ni} / \mathrm{Al} 2 \mathrm{O} 3$ catalyst: correlation of calcination temperature with the interaction of nickel and alumina. Fuel 227, 307-324. doi: 10.1016/j.fuel.2018.04.111

Zhang, G., Liu, J., Xu, Y., and Sun, Y. (2018). A review of $\mathrm{CH}_{4}-\mathrm{CO}_{2}$ reforming to synthesis gas over Ni-based catalysts in recent years (2010-2017). Int. J. Hydro. Ener. 43, 15030-15054. doi: 10.1016/j.ijhydene.2018.06.091

Zhang, G., Liu, J., Xu, Y., and Sun, Y. (2019). Ordered mesoporous Ni/Silicacarbon as an efficient and stable catalyst for $\mathrm{CO}_{2}$ reforming of methane. Int. J. Hydro. Ener. 44, 4809-4820. doi: 10.1016/j.ijhydene.2019.01.017

Zhang, L., Bian, L., Zhu, Z., and Li, Z. (2018a). La-promoted Ni/Mg-Al catalysts with highly enhanced low-temperature $\mathrm{CO}_{2}$ methanation performance. Int. J. Hydro. Ener. 43, 2197-2206. doi: 10.1016/j.ijhydene.2017.12.082

Zhang, L., Wang, F., Zhu, J., Han, B., Fan, W., Zhao, L., et al. (2019). CO 2 reforming

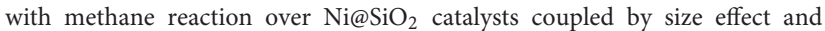
metal-support interaction. Fuel 256:115954. doi: 10.1016/j.fuel.2019.115954

Zhang, L., Xiao, M., Gao, Z., Ma, H., Bao, L., and Li, Z. (2018b). CO removal via selective methanation over the catalysts $\mathrm{Ni} / \mathrm{ZrO}_{2}$ prepared with reduction by the wet $\mathrm{H}_{2}$-rich gas. Int. J. Hydro. Ener. 43, 15985-15994. doi: 10.1016/j.ijhydene.2018.06.173

Zhang, Q., Qiu, K., Li, B., Jiang, T., Zhang, X., Ma, L., et al. (2011). Isoparaffin production by aqueous phase processing of sorbitol over the Ni/HZSM5 catalysts: effect of the calcination temperature of the catalyst. Fuel 90, 3468-3472. doi: 10.1016/j.fuel.2011.06.046

Zhang, X., Zhang, M., Zhang, J., Zhang, Q., Tsubaki, N., Tan, Y., et al. (2019). Methane decomposition and carbon deposition over $\mathrm{Ni} / \mathrm{ZrO}_{2}$ catalysts: Comparison of amorphous, tetragonal, and monoclinic zirconia phase. Int. J. Hydro. Ener. 44, 17887-17899. doi: 10.1016/j.ijhydene.2019.05.174

Zhang, Z., Tian, Y., Zhang, L., Hu, S., Xiang, J., Wang, Y., et al. (2019). Impacts of nickel loading on properties, catalytic behaviors of $\mathrm{Ni} / \gamma-\mathrm{Al}_{2} \mathrm{O}_{3}$ catalysts and the reaction intermediates formed in methanation of $\mathrm{CO}_{2}$. Int. J. Hydro. Ener. 44, 9291-9306. doi: 10.1016/j.ijhydene.2019.02.129

Zhao, A., Ying, W., Zhang, H., Ma, H., and Fang, D. (2012). Ni- $\mathrm{Al}_{2} \mathrm{O}_{3}$ catalysts prepared by solution combustion method for syngas methanation. Catal. Commun. 17, 34-38. doi: 10.1016/j.catcom.2011.10.010
Zhao, K., Li, Z., and Bian, L. (2016b). $\mathrm{CO}_{2}$ methanation and co-methanation of $\mathrm{CO}$ and $\mathrm{CO}_{2}$ over Mn-promoted $\mathrm{Ni} / \mathrm{Al}_{2} \mathrm{O}_{3}$ catalysts. Front. Chem. Sci. Eng. 10, 273-280. doi: 10.1007/s11705-016-1563-5

Zhao, K., Wang, W., and Li, Z. (2016a). Highly efficient $\mathrm{Ni} / \mathrm{ZrO}_{2}$ catalysts prepared via combustion method for $\mathrm{CO}_{2}$ methanation. J. CO2 Util. 16, 236-244. doi: $10.1016 /$ j.jcou.2016.07.010

Zhao, T., Hui, Y., and Niamatullah., Li, Z. (2019). Controllable preparation of ZIF-67 derived catalyst for $\mathrm{CO}_{2}$ methanation. Mol. Catal. 474:110421. doi: 10.1016/j.mcat.2019.110421

Zhou, G., Liu, H., Cui, K., Jia, A., Hu, G., Jiao, Z., et al. (2016). Role of surface Ni and $\mathrm{Ce}$ species of $\mathrm{Ni} / \mathrm{CeO}_{2}$ catalyst in $\mathrm{CO}_{2}$ methanation. Appl. Surf. Sci. 383, 248-252. doi: 10.1016/j.apsusc.2016.04.180

Zhou, G., Liu, H., Cui, K., Xie, H., Jiao, Z., Zhang, G., et al. (2017). Methanation of carbon dioxide over $\mathrm{Ni} / \mathrm{CeO}_{2}$ catalysts: effects of support $\mathrm{CeO}_{2}$ structure. Int. J. Hydro. Ener. 42, 16108-16117. doi: 10.1016/j.ijhydene.2017.05.154

Zhou, J., Ma, H., Jin, F., Zhang, H., and Ying, W. (2018). Mn and $\mathrm{Mg}$ dual promoters modified $\mathrm{Ni} / \alpha-\mathrm{Al}_{2} \mathrm{O}_{3}$ catalysts for high temperature syngas methanation. Fuel Process. Technol. 172, 225-232. doi: 10.1016/j.fuproc.2017.08.023

Zhou, R., Rui, N., Fan, Z., and Liu, C. J. (2016). Effect of the structure of $\mathrm{Ni} / \mathrm{TiO}_{2}$ catalyst on $\mathrm{CO}_{2}$ methanation. Int. J. Hydro. Ener. 41, 22017-22025. doi: 10.1016/j.ijhydene.2016.08.093

Zimmermann, R. T., Bremer, J., Sundmacher, K. (2019). Optimal catalyst particle design for flexible fixed-bed $\mathrm{CO}_{2}$ methanation reactors. Chem. Eng. J. 387:123704. doi: 10.1016/j.cej.2019.1 23704

Conflict of Interest: The authors declare that the research was conducted in the absence of any commercial or financial relationships that could be construed as a potential conflict of interest.

Copyright (c) $2020 \mathrm{Lv}, \mathrm{Xu}$, Chen, Cui, Wen, Li, Wu, Yang, Miao, Hu and Shou. This is an open-access article distributed under the terms of the Creative Commons Attribution License (CC BY). The use, distribution or reproduction in other forums is permitted, provided the original author(s) and the copyright owner(s) are credited and that the original publication in this journal is cited, in accordance with accepted academic practice. No use, distribution or reproduction is permitted which does not comply with these terms. 